\title{
Technical and Environmental Assessment of All-Electric 180-Passenger Commercial Aircraft
}

by

\section{Albert Reuben Gnadt}

B.S. Mechanical Engineering, University of Wisconsin-Madison, 2015

Submitted to the Department of Aeronautics and Astronautics

in partial fulfillment of the requirements for the degree of

Master of Science in Aeronautics and Astronautics

at the

MASSACHUSETTS INSTITUTE OF TECHNOLOGY

February 2018

(C) Massachusetts Institute of Technology 2018. All rights reserved.

Author

\section{Signature redacted}

Department of Aeronautics and Astronautics

February 1, 2018

\section{Signatûre redacted}

Certified by

- Steven R. H. Barrett

Associate Professor, Aeronautics and Astronautics

Thesis Supervisor

Accepted by

\section{Signature redacted}

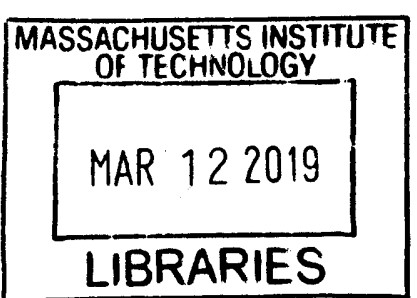

ARCHIVES
Hamsa Balakrishnan Associate Professor, Aeronautics and Astronautics Chair, Graduate Program Committee 


\title{
Technical and Environmental Assessment of All-Electric 180-Passenger Commercial Aircraft
}

by

\author{
Albert Reuben Gnadt \\ Submitted to the Department of Aeronautics and Astronautics \\ on February 1, 2018 in partial fulfillment of the \\ requirements for the degree of \\ Master of Science in Aeronautics and Astronautics
}

\section{Abstract}

Aviation emissions contribute to climate change, and all-electric aircraft offer an opportunity for zero in-flight emissions. Over the past decade, more than 50 all-electric conceptual, experimental, and commercial aircraft have been researched, with a particular focus on light aircraft. These designs are reviewed, along with progress in battery technology. An all-electric aircraft design and optimization program, TASOPTe, has been developed from an existing version for conventionally-powered aircraft, TASOPT. Both programs are largely based on first-principles, enabling the design of aircraft with unusually short design ranges. A series of optimized 180-passenger aircraft based on the Airbus A320neo configuration are designed and evaluated at 200-1600 $\mathrm{nmi}$ design ranges with 2-10 propulsors and $400-2000 \mathrm{Wh} / \mathrm{kg}$ batteries. The performance of these all-electric aircraft is compared to advanced conventionally-powered aircraft optimized for the same design ranges. Optimized all-electric aircraft are found to use two or four propulsors, depending on the design range and specific energy assumed. The design range limits for each specific energy are determined, which are restricted by aircraft weight and performance penalties. A factor of four increase in battery pack specific energy from current values of $200 \mathrm{Wh} / \mathrm{kg}$ to $800 \mathrm{Wh} / \mathrm{kg}$ enables $500 \mathrm{nmi}$ flights. However, a lower design range of $300 \mathrm{nmi}$ provides improved energy and environmental performance. The required grid power generation circumstances for commercial all-electric aircraft to become net environmentally beneficial is determined for each specific energy assumption. The entire energy conversion chain, including charging, transport, and discharging of electrical energy, is considered. Despite the higher total energy use, narrow-body all-electric aircraft have the potential for lower equivalent $\mathrm{CO}_{2}$ emissions if the electrical grid transitions toward renewable energy. This is largely enabled by the complete elimination of all highaltitude emissions, which would remove associated non- $\mathrm{CO}_{2}$ warming.

Thesis Supervisor: Steven R. H. Barrett

Title: Raymond L. Bisplinghoff Associate Professor of Aeronautics and Astronautics 


\section{Acknowledgements}

I would like to thank my advisor, Professor Steven Barrett, for accepting me into his lab midyear, allowing me to work on an interesting research project, and providing valuable guidance and support. Thank you Jayant Sabnis, Ray Speth, and Professor Mark Drela as well for many helpful discussions. To my lab mates and friends in LAE, especially Akshat, Tim, and Guillaume, thank you for your advice and friendship.

Thank you to my close friends both at MIT and across the country for your encouragement and confidence in me. I would like to give a shout out to the AeroAstro Ballers, Bows, $\mathrm{G}^{3}$, the 125ers, and the Esteemed Squad. A special thank you to Patrik for being my closest friend for over a decade. For your continuous supply of energy and inspiration, thank you Mr. Hyde and Mr. Shakur, respectively.

Finally, and most importantly, I am deeply grateful for the love and encouragement from my family. Thank you to my many cousins, aunts, and uncles, especially Aunt Char and Uncle Leroy, for your curiosity in my work and continued support. Mom and Katie, my successes would not have been possible without you. This thesis is dedicated to my father, whose last words to me have carried me through the darkest of times.

This material is based upon work supported by the National Science Foundation Graduate Research Fellowship Program under Grant No. 1122374. Any opinions, findings, and conclusions or recommendations expressed in this material are those of the authors and do not necessarily reflect the views of the National Science Foundation. 


\section{Contents}

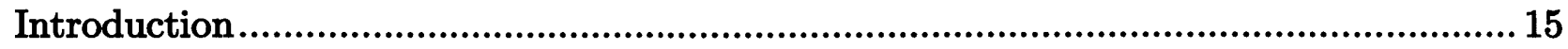

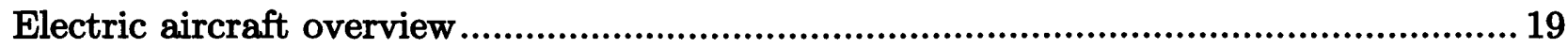

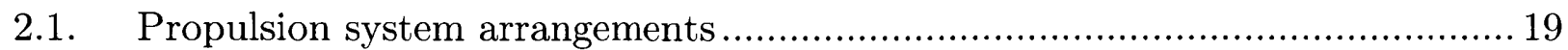

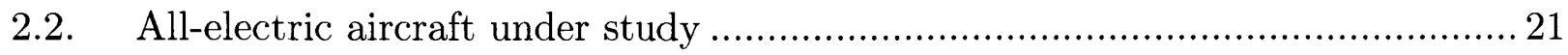

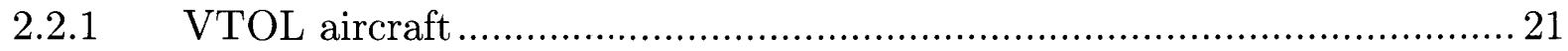

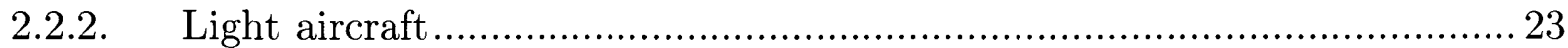

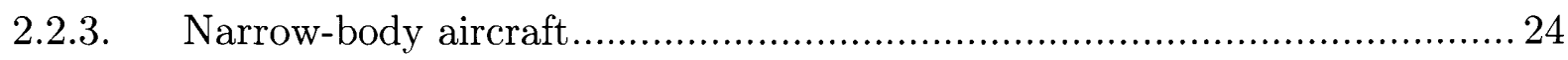

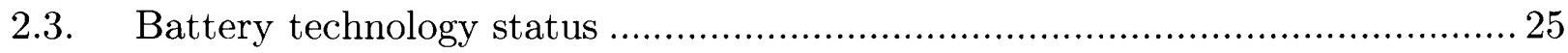

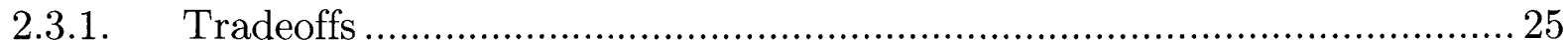

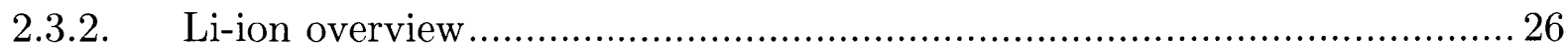

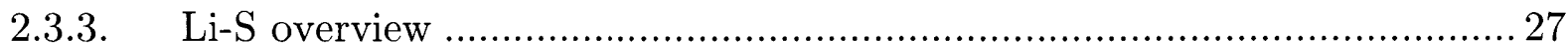

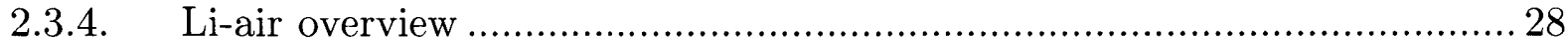

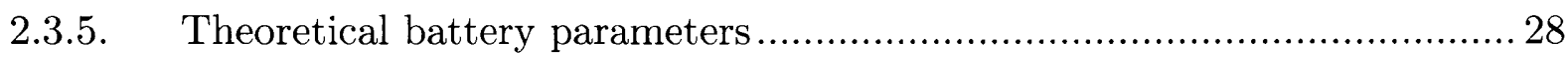

2.3.6. Theoretical all-electric aircraft range ................................................. 29

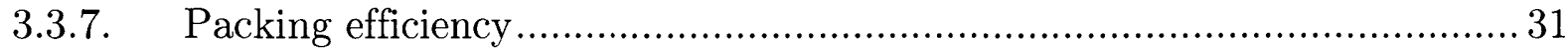

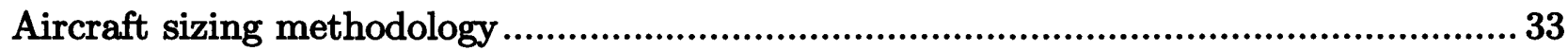

3.1. Common TASOPT and TASOPTe features .................................................. 33

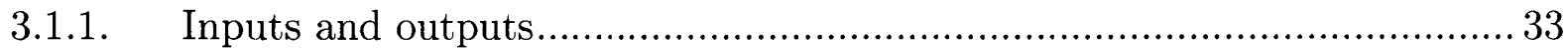

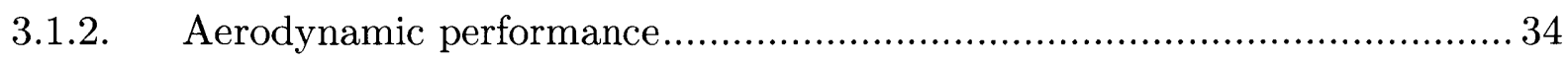

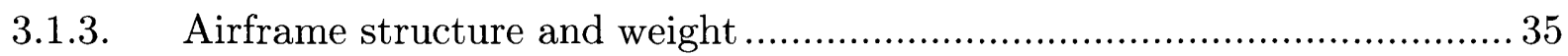

3.2. Electrical and propulsion system architecture.............................................. 35

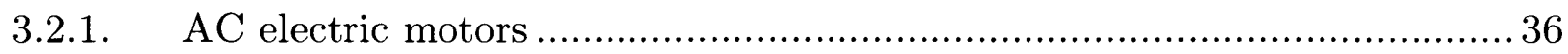

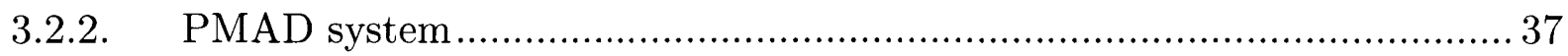

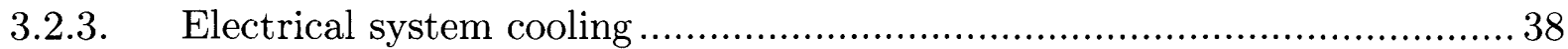

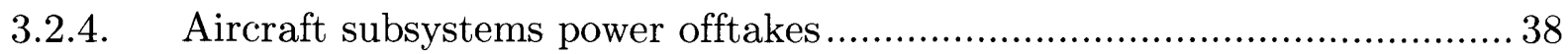

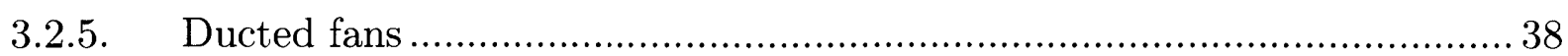

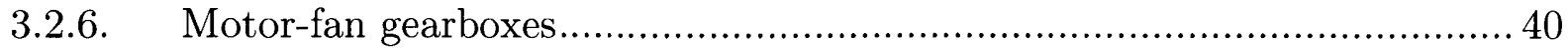

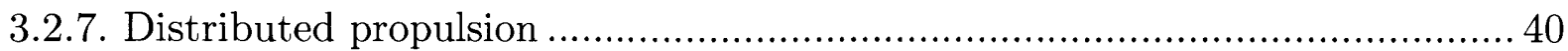

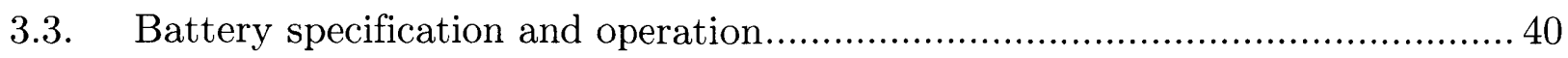




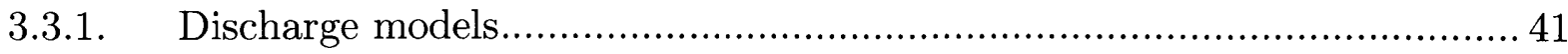

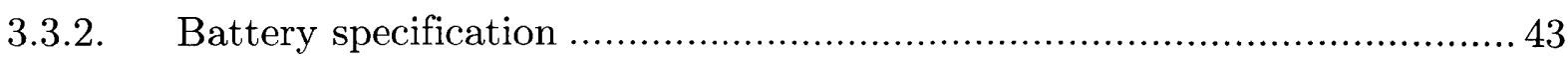

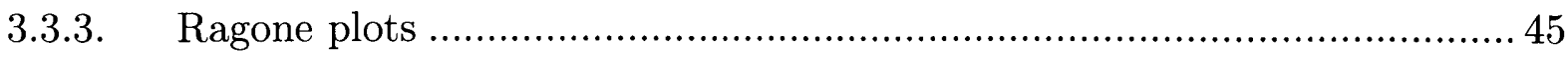

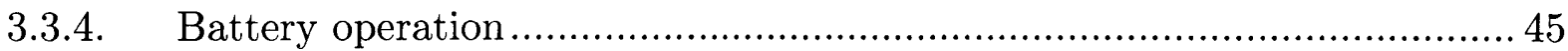

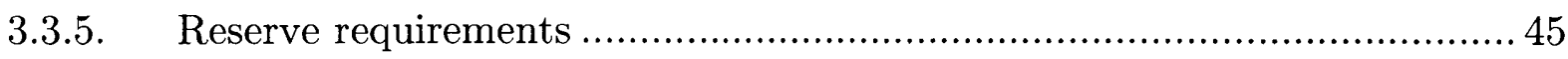

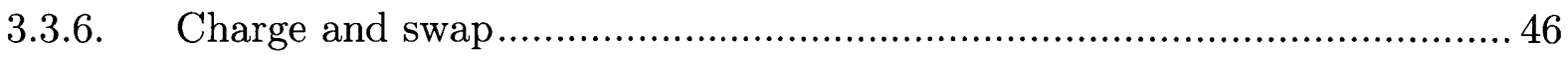

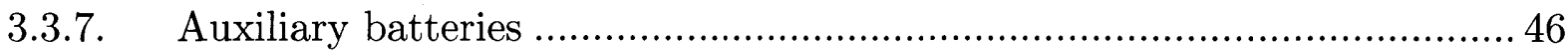

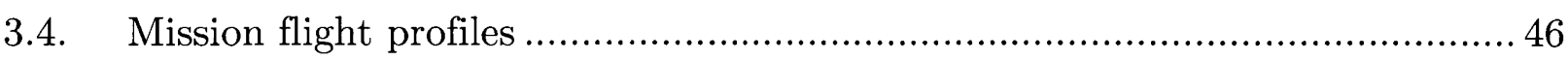

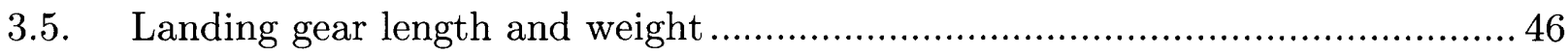

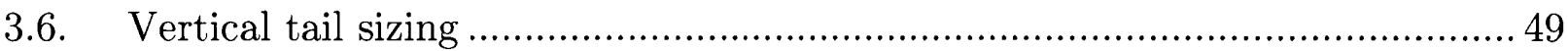

Aircraft configuration, mission, and technology assumptions .................................... 51

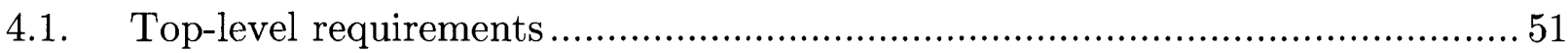

4.2. Electrical and propulsion system components ......................................... 52

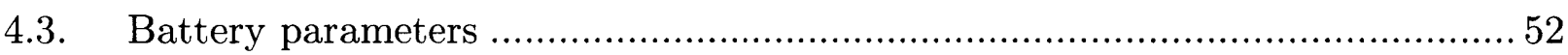

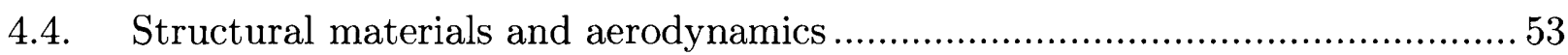

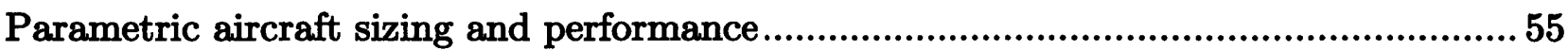

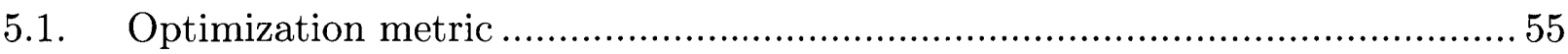

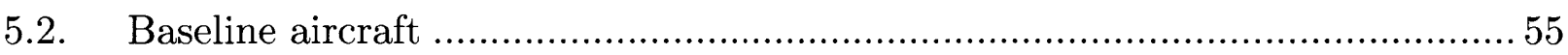

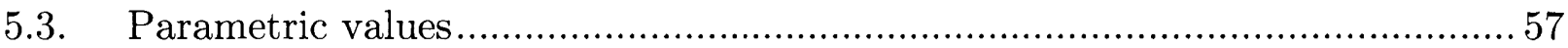

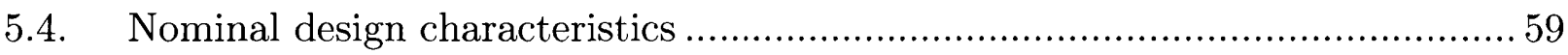

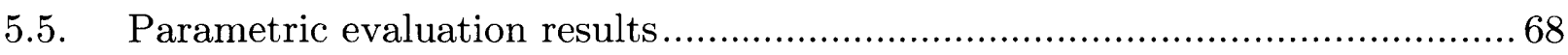

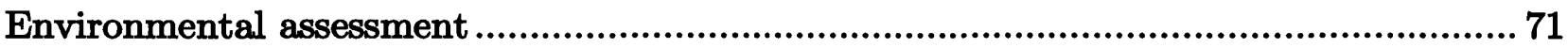

6.1. Conventional aircraft equivalent emissions …............................................. 71

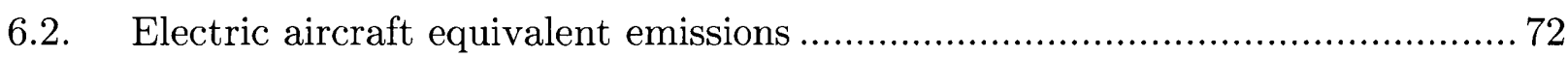

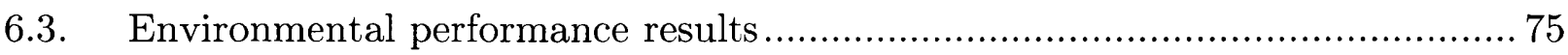

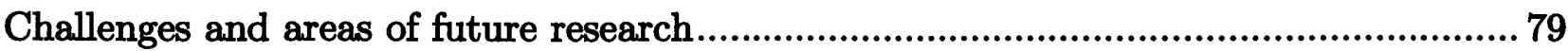

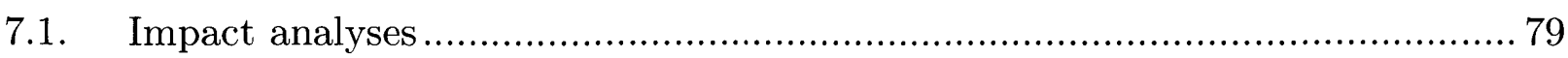

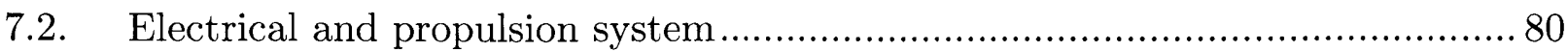

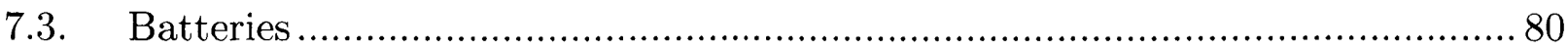

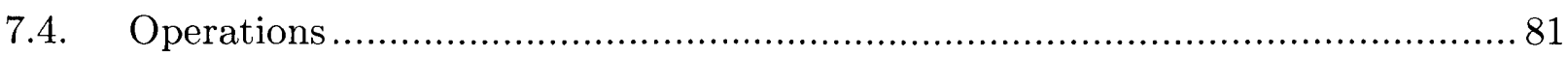

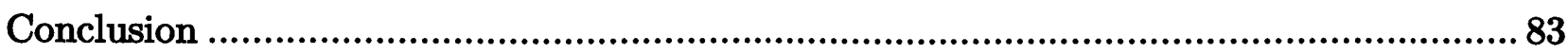




\section{List of Figures}

Figure 1. Electric aircraft propulsion system topologies.............................................. 20

Figure 2. Design missions of previously studied narrow-body all-electric aircraft............ 24

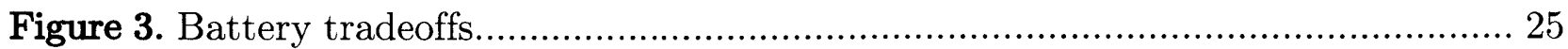

Figure 4. Lithium nickel manganese cobalt oxide battery design space.......................... 27

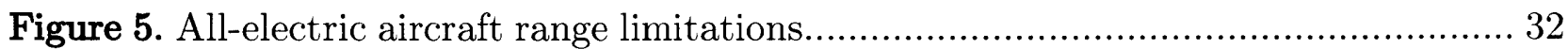

Figure 6. Specific energies of lithium-based batteries................................................ 32

Figure 7. Electrical and propulsion system architecture for a single propulsor................ 36

Figure 8. Calibrated fan polytropic efficiency contours for a 1.294 FPR fan.................. 39

Figure 9. Li-ion and Li-S battery discharge models................................................ 42

Figure 10. Example Ragone plots for Li-ion and Li-S batteries................................... 44

Figure 11. Main landing gear length parameters..................................................... 48

Figure 12. VT volume coefficient with varying propulsor spacing and count................ 49

Figure 13. U.S. and global stage lengths for A320 and narrow-body aircraft................ 58

Figure 14. $\mathrm{W}_{\text {MTO }}$ variation with propulsor count and design range.............................. 60

Figure 15. Mission energy variation with propulsor count and design range.................. 60

Figure 16. E/P variation with propulsor count and design range................................. 61

Figure 17. Aircraft planform view wireframe overlays with 2, 4, and 10 propulsors........ 61

Figure 18. OpenVSP A320neo aircraft wireframe model............................................. 62

Figure 19. OpenVSP AEA-800 aircraft wireframe model............................................ 62 
Figure 20. Conventional aircraft and AEA mission profiles.

Figure 21. Conventional aircraft and AEA physical weight breakdown........................ 66

Figure 22. Conventional aircraft and AEA fractional weight breakdown...................... 66

Figure 23. Effect of battery discharge model on battery efficiency.............................6 67

Figure 24. $\mathrm{W}_{\text {мTO }}$ variation with design range and battery specific energy ..................... 69

Figure 25. Mission energy variation with design range and battery specific energy........ 69

Figure 26. E/P variation with design range and battery specific energy ....................... 70

Figure 27. AEA to conventional aircraft energy ratio variation with design range and

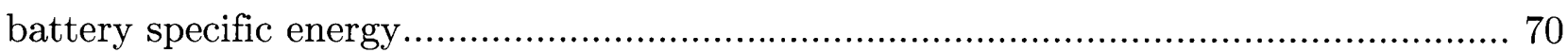

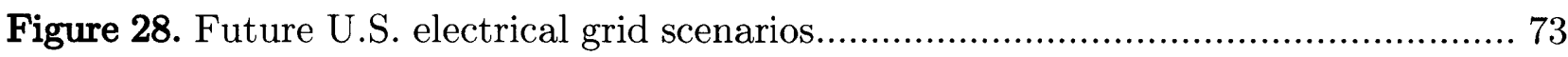

Figure 29. Combined electricity generation equivalent $\mathrm{CO}_{2}$ emissions by scenario......... 74

Figure 30. Conventional and AEA energy conversion chain comparison....................... 74

Figure 31. AEA to conventional aircraft equivalent $\mathrm{CO}_{2}$ emissions ratio, $\mathrm{AWP}_{100}$ basis 76

Figure 32. AEA to conventional aircraft equivalent $\mathrm{CO}_{2}$ emissions ratio, $\mathrm{NPV}_{3} \%$ basis $\quad 76$

Figure 33. AEA to conventional aircraft equivalent $\mathrm{CO}_{2}$ emissions ratio at reduced design

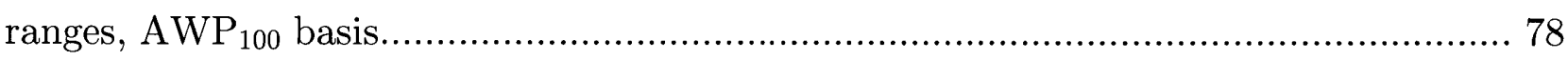

Figure 34. AEA to conventional aircraft equivalent $\mathrm{CO}_{2}$ emissions ratio at reduced design

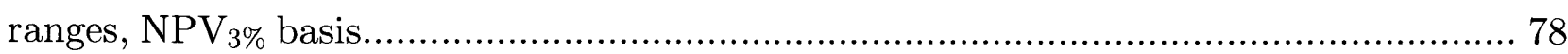




\section{List of Tables}

Table 1. ACARE Flightpath 2050 and NASA N+3 goals for emission reduction............ 16

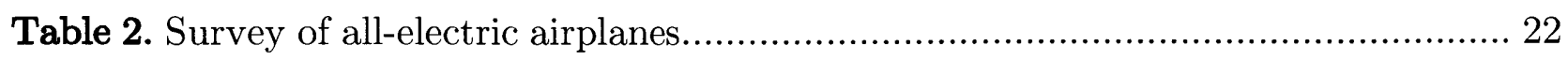

Table 3. Common cathode options for Li-ion batteries................................................ 26

Table 4. Theoretical parameters for potential aviation batteries................................ 29

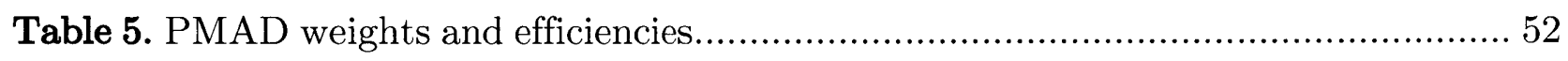

Table 6. Conventional and all-electric aircraft optimization variables........................... 56

Table 7. Optimized A320 and AEA key parameters................................................. 64

Table 8. Lifecycle emission intensities by generation source......................................... 73 


\section{Nomenclature}

\section{Acronyms and Abbreviations}

\begin{tabular}{|c|c|}
\hline $\mathrm{AC}$ & Alternating Current \\
\hline AEA & All-Electric Aircraft \\
\hline $\mathrm{AGWP}_{100}$ & 100-year Absolute Global Warming Potential \\
\hline Al-air & aluminum-air \\
\hline $\mathrm{BAU}$ & Business-As-Usual \\
\hline BHL & Bauhaus Luftfahrt e.V. \\
\hline BLI & Boundary Layer Ingestion \\
\hline BMS & Battery Management System \\
\hline $\mathrm{CO}_{2}$ & carbon dioxide \\
\hline $\mathrm{CO}_{2} \mathrm{e}$ & carbon dioxide equivalent \\
\hline DEP & Distributed Electric Propulsion \\
\hline ECS & Environmental Control System \\
\hline HRE & Highly Renewable Energy \\
\hline HT & Horizontal Tail \\
\hline HTS & High-Temperature Superconducting \\
\hline ISA & International Standard Atmosphere \\
\hline LG & Landing Gear \\
\hline Li-air & lithium-air \\
\hline Li-ion & lithium-ion \\
\hline $\mathrm{Li}-\mathrm{S}$ & lithium-sulfur \\
\hline Li-Se & lithium-selenium \\
\hline LSA & Light-Sport Aircraft \\
\hline LTO & Landing and Takeoff \\
\hline MEA & More-Electric Aircraft \\
\hline MIT & Massachusetts Institute of Technology \\
\hline NASA & National Aeronautics and Space Administration \\
\hline NB & Narrow-Body \\
\hline $\mathrm{nmi}$ & nautical miles \\
\hline $\mathrm{NO}_{\mathrm{x}}$ & nitrogen oxides \\
\hline $\mathrm{NPV}_{3 \%}$ & Net Present Value at a 3\% Discount Rate \\
\hline NREL & National Renewable Energy Laboratory \\
\hline OAG & Official Airline Guide \\
\hline ODM & On-Demand Mobility \\
\hline OEI & One Engine Inoperative \\
\hline PMAD & Power Management and Distribution \\
\hline
\end{tabular}




$\begin{array}{ll}\text { SSPC } & \text { Solid State Power Controller } \\ \text { TASOPT } & \text { Transport Aircraft System OPTimization } \\ \text { TASOPTe } & \text { Transport Aircraft System OPTimization - electric } \\ \text { ULA } & \text { Ultra-Light Aircraft } \\ \text { USD } & \text { U.S. Dollar } \\ \text { VAN } & \text { Variable Area Nozzle } \\ \text { VT } & \text { Vertical Tail } \\ \text { VTOL } & \text { Vertical Takeoff and Landing } \\ \text { Zn-air } & \text { zinc-air }\end{array}$

\section{Symbols}

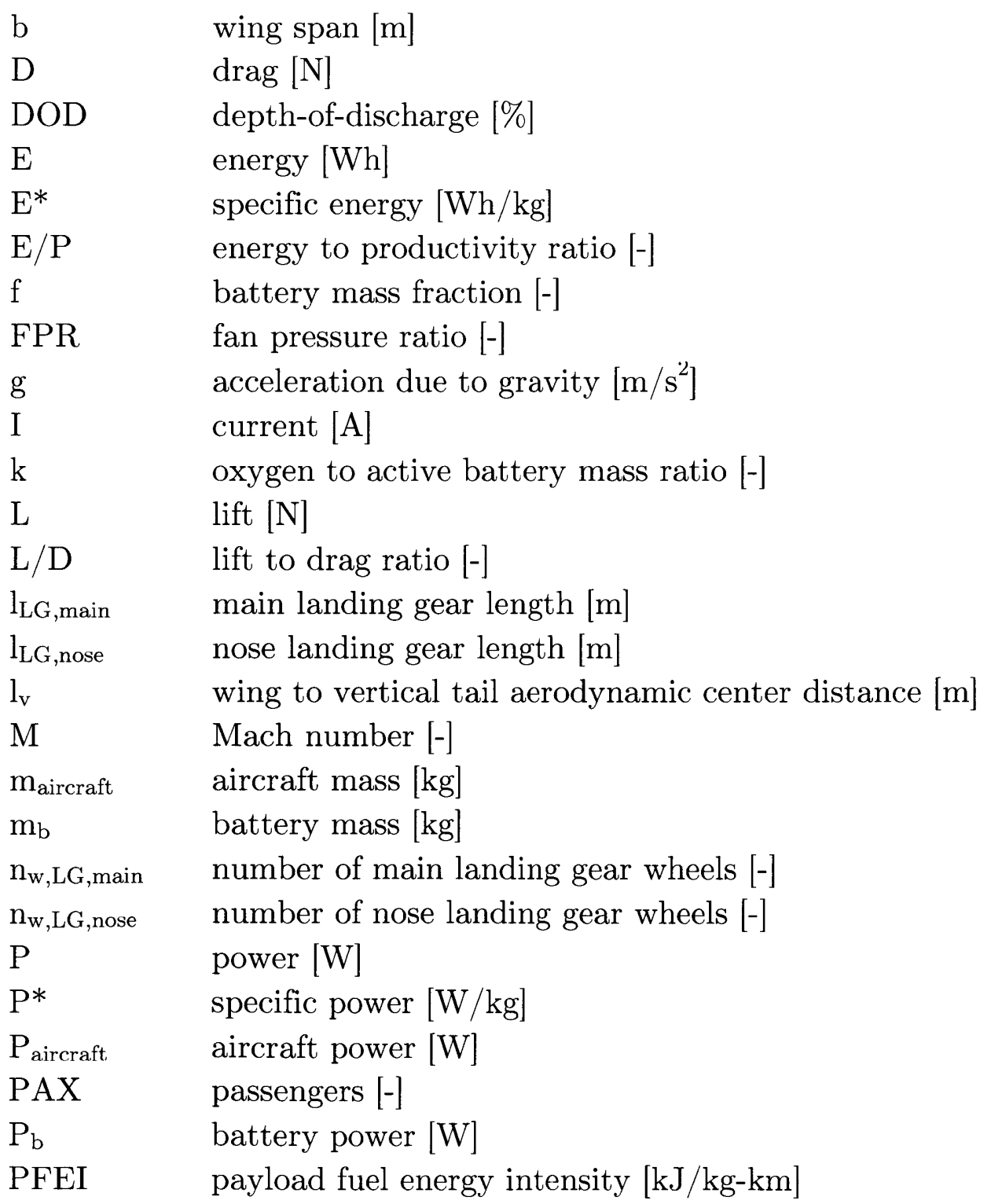




\begin{tabular}{|c|c|}
\hline $\mathrm{R}$ & range $[\mathrm{m}, \mathrm{nmi}]$, resistance $[\Omega]$ \\
\hline S & wing planform area $\left[\mathrm{m}^{2}\right]$ \\
\hline $\mathrm{SOC}$ & state-of-charge $[\%]$ \\
\hline $\mathrm{S}_{\mathrm{v}}$ & vertical tail planform area $\left[\mathrm{m}^{2}\right]$ \\
\hline $\mathrm{t}$ & time $[s]$ \\
\hline $\mathrm{U}$ & voltage $[\mathrm{V}]$ \\
\hline $\mathrm{U}_{\mathrm{oc}}$ & open-circuit voltage [V] \\
\hline$V_{\infty}$ & flight speed $[\mathrm{m} / \mathrm{s}, \mathrm{kt}]$ \\
\hline $\mathrm{v}_{\text {stall }}$ & stall speed $[\mathrm{m} / \mathrm{s}, \mathrm{kt}]$ \\
\hline $\mathrm{W}_{\mathrm{LG}, \text { main }}$ & main landing gear weight $[t]$ \\
\hline$W_{\text {LG, nose }}$ & nose landing gear weight [t] \\
\hline $\mathrm{W}_{\mathrm{ML}}$ & maximum landing weight $[\mathrm{t}]$ \\
\hline $\mathrm{W}_{\text {Мто }}$ & maximum takeoff weight $[\mathrm{t}]$ \\
\hline $\mathrm{W}_{\text {pay }}$ & payload weight $[t]$ \\
\hline $\mathrm{Z}$ & active to total battery mass ratio [- \\
\hline$\eta_{\text {overall }}$ & overall aircraft efficiency [-] \\
\hline & polytropic efficiency [-] \\
\hline
\end{tabular}




\section{Chapter 1}

\section{Introduction}

Climate change, due to aviation and other sources, poses risks for humans and the ecosystem in the form of rising sea levels, more frequent extreme weather episodes, changes in disease vectors and crop productivity, loss of biodiversity, and increased heat stress [1]. Aviation contributes to climate change, as it was responsible for $2.5 \%$ of global $\mathrm{CO}_{2}$ emissions in 2016 [2]. Moreover, airline traffic projections by Airbus and Boeing indicate that aviation will continue its historical growth through 2036 at approximately $4.5 \%$ per year $[3,4]$. Due to this growth, aviation-related $\mathrm{CO}_{2}$ emissions are expected to double or triple by 2050 .

An almost unique feature of aviation is that a significant portion of the aviationattributable climate warming is due to non- $\mathrm{CO}_{2}$ emissions, especially contrails and contrail-cirrus clouds. Contrails are white line-shaped clouds that form behind aircraft. They have about the same radiative impact as all aviation-related $\mathrm{CO}_{2}$ emissions, thereby approximately doubling the net climate impact of aviation [5]. In turn, aircraft that do not combust fuel and thus do not emit water vapor at high-altitude, would have the potential for greatly reducing the climate impacts of aviation. Furthermore, studies have shown that the air quality impacts of aviation, which are caused by fuel combustion, have led to approximately 16,000 premature mortalities per year [6]. All-electric aircraft have the potential to avert the negative externalities of aviation without deterring societal and economic globalization.

Historically, decreases in fuel consumption have been achieved by advancing aircraft technologies, such as the development of high-bypass ratio turbofans and winglets. These efforts have resulted in continuous economic and environmental benefits. However, marginal evolutionary improvements in aircraft propulsion and aerodynamics ( $\sim 1 \%$ p.a. fleet average) are outstripped by aviation growth ( $\sim .5 \%$ p.a.). Additionally, recent 
emissions regulations, such as the 2016 global aviation $\mathrm{CO}_{2}$ emissions standard, provide regulatory stimuli to reduce the environmental footprint of air transportation [7]. As exemplified in Table 1, ACARE and NASA have also set forth a series of emission reduction objectives for Europe and the U.S., respectively. Driven by these motivating factors, advanced aircraft technology would enable aviation to flourish in the future. One such novel concept, the focus of this work, is battery-powered all-electric aircraft.

Table 1. ACARE Flightpath 2050 and NASA N+3 goals for emission reduction [8, 9].

\begin{tabular}{|c|c|c|}
\hline Emission & Flightpath $2050^{2}$ & $\mathrm{~N}+3^{\mathrm{b}}$ \\
\hline Noise & $-65 \%^{\mathrm{c}}$ & $-71 \mathrm{~dB}^{\mathrm{d}}$ \\
\hline LTO $\mathrm{NO}_{\mathrm{x}}$ & $0^{\mathrm{e}}$ & $-75 \%{ }^{\mathrm{t}}$ \\
\hline $\mathrm{NO}_{\mathrm{x}}$ & $-90 \%$ & - \\
\hline $\mathrm{CO}_{2}$ & $-75 \%$ & - \\
\hline Fuel Burn & - & $-70 \%^{\mathrm{g}}$ \\
\hline \multicolumn{3}{|c|}{$\begin{array}{l}{ }^{a} 2050 \text { implementation, relative to state of the art aircraft in } 2000 \\
b 2035 \text { implementation } \\
{ }^{c} \text { perceived noise of flying aircraft } \\
{ }_{d}^{d} \text { relative to FAA Stage } 4 \text { noise regulation } \\
{ }^{e} \text { emission-free taxiing } \\
\text { f relative to CAEP } 6 \\
{ }^{g} \text { relative to state of the art aircraft in } 2008\end{array}$} \\
\hline
\end{tabular}

There are multiple reasons this concept may lead toward air transportation with reduced environmental impacts. First, unlike gas turbine technology, electric propulsion is not limited to the same thermodynamic efficiency limits. Thus, all-electric aircraft have the potential to achieve a higher on-board energy conversion efficiency (e.g. $\sim 85 \%$ rather than $\sim 50 \%$ ), thereby significantly reducing the energy required per flight [10]. Second, these aircraft would likely use a system of electric motor-ducted fans, which, unlike gas turbines, have efficiencies that are nearly constant with scale [11]. Hence, using more numerous, smaller motor-fan assemblies allows for distributed electric propulsion (DEP), which may be lighter and quieter, offers increased redundancy and propulsion efficiency, and facilitates overall efficiency improvements during off-design stages of flight. Finally, 
battery-powered aircraft would not release emissions in-flight. While $\mathrm{CO}_{2}$ would still be released at ground level to charge batteries in the near-term, the climate impact of aviation would be diminished through avoidance of high-altitude water vapor emissions and the resulting contrails. In the long-term, electricity supplied from emission-free sources may further reduce the environmental impacts.

Other options to reduce the environmental consequences of aviation include using biofuels and more fuel-efficient aircraft routing, but both of these options are of limited impact compared to the scale of global aviation growth $[12,13]$. Additionally, any future air transportation system that remains reliant on in-flight fuel combustion, even "clean" fuels like hydrogen, will still produce contrails, which have a significant effect on global climate change. This work evaluates a technological change that would reduce atmospheric aviation emissions and allow for independence from the current fossil fuel economy. 


\section{Chapter 2}

\section{Electric aircraft overview}

In recent years, the aerospace industry has seen the emergence of aircraft electrification. This concept has led to fundamental changes to aircraft design, construction, and operation. Aircraft manufacturers have begun incorporating electric technologies into their aircraft with more-electric aircraft (MEA), such as the Airbus A380 and Boeing 787 [14]. In MEA, the hydraulic, mechanical, and/or pneumatic systems are replaced with electrical systems in an effort decrease weight and increase reliability. More recent research has shifted toward turboelectric, hybrid-electric, and all-electric aircraft, all of which are forms of electric propulsion [15]. This section discusses possible electric aircraft configurations and present a review of past and present all-electric aircraft research and development.

\subsection{Propulsion system arrangements}

Similar to ground-based electric vehicles, various hybrid-electric and turboelectric aircraft designs have been investigated, often without batteries due to the lack of opportunity for regenerative breaking [16]. Shown in Figure 1 is a visualization of the various options for electric aircraft propulsion.

Hybrid-electric types can be defined based on which devices supply power and how the powertrain is arranged. The primary options are series hybrid, parallel hybrid, and series/parallel hybrid. A series hybrid-electric configuration has an electrical coupling, such as an electric generator and battery both supplying electrical power to an electric motor [18]. A parallel hybrid-electric configuration has a mechanical coupling between power supplying components, such as a shared gas turbine and electric motor shaft. A series/parallel hybrid is combination of the preceding two options. Examples of series and parallel hybrid-electric aircraft concepts are the Airbus/Rolls-Royce E-Thrust and Boeing 
SUGAR Volt and, respectively $[19,20]$. Another concept, which is close to commercialization, is the 12-passenger Zunum Aero series hybrid-electric aircraft [21].

In a turboelectric configuration, a gas turbine drives an electric generator, which provides electrical power to an electric motor. An example turboelectric aircraft concept is the NASA N3-X [22]. Additionally, a partial-turboelectric aircraft uses a combination of electric and gas turbine propulsion.

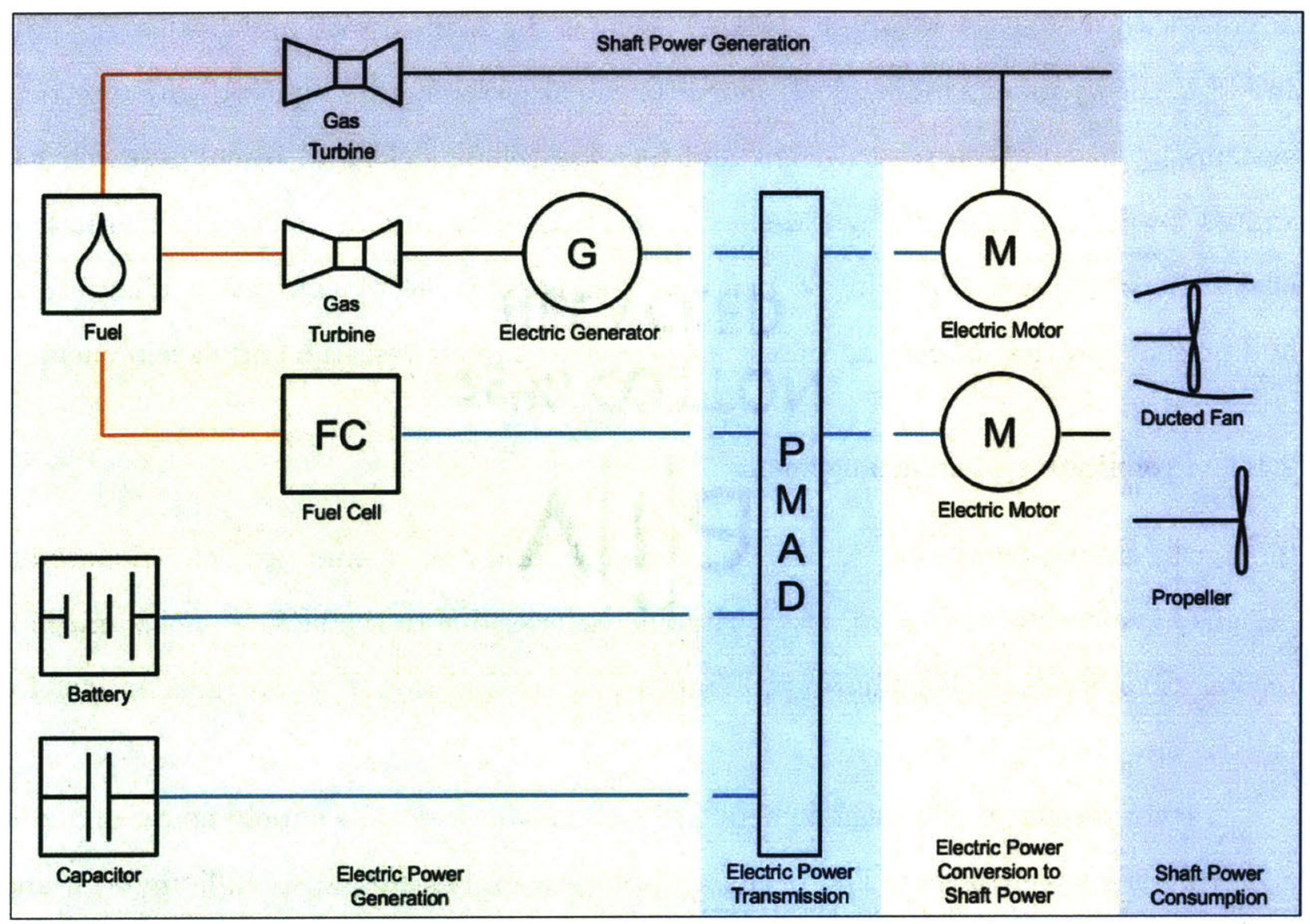

Figure 1. Electric aircraft propulsion system topologies. Modified from [17].

The designs mentioned thus far provide comparatively modest environmental benefits given they still entail high-altitude emissions and non- $\mathrm{CO}_{2}$ impacts. In contrast, all-electric aircraft use only electrical energy and power for propulsion, so no in-flight emissions occur. A variety of additional terminologies are used in aviation literature to describe this aircraft concept, including "battery-electric", "electric-propulsion", "full- 
electric", "fully-electric", and "universally-electric" aircraft. In this work, all-electric aircraft (AEA) is used, with the only energy source being stored electrical energy (e.g. batteries). In reference to the propulsor specifically being electrically powered, "all-electric propulsor" or "all-electric engine" is appropriate.

\subsection{All-electric aircraft under study}

Amongst the options for electrification, AEA will likely be last to reach commercial aviation, primarily due to battery technology limitations. Nonetheless, in the past decade AEA have been widely researched. Shown in Table 2 is a survey of all-electric airplanes that have previously been or are currently being evaluated. Only aircraft with fixed wings (airplanes) are included, not rotorcraft, such as the CityAirbus or Volocopter 2X. Also excluded are solar powered aircraft, such as the Aero Electric Sun Flyer or PC-Aero Elektra One, or gliders, such as the Lange Antares 20E or Pipistrel Taurus Electro.

As indicated in Table 2 by the seat counts, electric propulsion is currently targeted at smaller aircraft. This is due to a variety of reasons. First, flights for these aircraft are typically expected to have short ranges, thus current battery technology is less of a limitation. Second, projects of smaller scale pose less cost and risk for aircraft manufacturers. Finally, greater benefits can be realized in transitioning to electric propulsion from internal combustion engines for small aircraft (e.g. $\eta_{\text {thermal }} \approx 25 \%$ ) than from turbofans for large aircraft (e.g. $\eta_{\text {thermal }} \approx 50 \%$ ).

\subsubsection{VTOL aircraft}

Telecommunications advancements and increased smartphone usage have led to the emergence of on-demand mobility (ODM) in automobile transportation [23]. ODM providers connect customers with transport service in real-time. Lyft and Uber, two of the largest ODM providers, now service the majority of cities in the U.S. and many cities

worldwide. This concept has now moved into the aviation industry, led by Uber Elevate, 
Table 2. Survey of all-electric airplanes. Data Compiled from [24-82].

\begin{tabular}{|c|c|c|c|c|c|c|}
\hline Aircraft & Location & \begin{tabular}{|c|} 
Seat \\
Count $^{\mathrm{a}}$
\end{tabular} & $\begin{array}{c}\text { Range } \\
\text { [nmil] }\end{array}$ & $\begin{array}{c}\text { Cruise } \\
\text { Speed [kt] }\end{array}$ & $\begin{array}{c}\text { Status }^{\mathrm{c}} \\
\text { (Last Update) }\end{array}$ & Type \\
\hline Pipistrel eVTOL (unnamed) & Ajdovščina, Slovenia & TBA & 52 & 130 & Dev & VTOL \\
\hline Zee.Aero Z-P1 & Mountain View, CA, USA & 1 & - & - & Dev & VTOL \\
\hline Flight of the Century Long-ESA & Aliso Viejo, CA, USA & 1 & - & - & Demo (2012) & Light \\
\hline Lazair eLazair & Hammondsport, NY, USA & 1 & $4^{\mathrm{b}}$ & 38 & Demo (2011) & ULA \\
\hline APEV Demoichellec & Peynier, France & 1 & $13^{b}$ & 38 & Demo (2012) & ULA \\
\hline APEV Pouchelec & Peynier, France & 1 & $19^{\mathrm{b}}$ & 38 & Demo (2012) & ULA \\
\hline Electravia MC15E Cri-Cri & Vaumeilh, France & 1 & 25 & 100 & Demo (2015) & Light \\
\hline Electravia BL1E Electra & Vaumeilh, France & 1 & 27 & 49 & Demo (2007) & ULA \\
\hline Airbus Electric Cri-Cri & Toulouse, France & 1 & $30^{b}$ & 60 & Demo (2010) & Light \\
\hline Yuneec-Flightstar Espyder E280 & Cable, CA, USA & 1 & $33^{b}$ & 33 & Canc (2013) & LSA \\
\hline Airbus $A^{\wedge} 3$ Vahana & Santa Clara, CA, USA & 1 & 43 & 95 & Dev & VTOL \\
\hline NASA Puffin & Hampton, VA, USA & 1 & 43 & 130 & Con $(2010)$ & VTOL \\
\hline LSA MC30E Firefly & Redange, Luxembourg & 1 & $82^{b}$ & 89 & Demo (2011) & ULA \\
\hline Airbus E-Fan & Toulouse, France & 1 & 86 & 86 & Canc (2017) & Light \\
\hline NASA X-57 Maxwell & Edwards, CA, USA & 1 & 87 & 152 & Dev & Light \\
\hline JAXA Hornisse Type 2B & Tokyo, Japan & 2 & - & - & Dev & VTOL \\
\hline Aurora eVTOL (unnamed) & Manassas, VA, USA & 2 & 35 & 108 & Dev & VTOL \\
\hline Extra 330LE & Hünxe, Germany & 2 & $57^{b}$ & 170 & Demo (2016) & Light \\
\hline Liaoning Ruixiang RX1E & Shenyang, China & 2 & $65^{b}$ & 65 & Prod & LSA \\
\hline Autonomous Flight Y6S & Sevenoaks, UK & 2 & 70 & 61 & Dev & VTOL \\
\hline Sonex Electric Sport Aircraft & Oshkosh, WI, USA & 2 & 76 & 115 & Dev & LSA \\
\hline ACS-Itaipu Sora-e & Putim, Brazil & 2 & 77 & 103 & Demo (2015) & LSA \\
\hline Pipistrel WATTsUP & Ajdovščina, Slovenia & 2 & 81 & 85 & Demo (2014) & LSA \\
\hline Pipistrel Alpha Electro & Ajdovščina, Slovenia & 2 & 81 & 108 & Prod & LSA \\
\hline Evektor SportStar EPOS & Kunovice, Czech Republic & 2 & $92^{b}$ & 92 & Dev & LSA \\
\hline Liaoning Ruixiang RX1E-A & Shenyang, China & 2 & 97 & 59 & Prod & LSA \\
\hline DeLorean DR-7 & Laguna Beach, CA, USA & 2 & 104 & 130 & Dev & VTOL \\
\hline Yuneec E430 & Cable, CA, USA & 2 & $130^{b}$ & 52 & Canc (2013) & LSA \\
\hline EVA X01 & Toulouse, France & 2 & 162 & - & Dev & VTOL \\
\hline ACS Z-300 & Putim, Brazil & 2 & 162 & 120 & Dev & VTOL \\
\hline Lilium Jet & Gilching, Germany & 2 & 162 & 162 & Dev & VTOL \\
\hline EAC ElectraFlyer-X & Cliffside Park, NJ, USA & 2 & $174^{\mathrm{b}}$ & 87 & Canc (2012) & LSA \\
\hline Joby S2 & Santa Cruz, CA, USA & 2 & 174 & 174 & Dev & VTOL \\
\hline Pipistrel Panthera & Ajdovščina, Slovenia & 2 & 216 & 198 & Dev & Light \\
\hline IFB-Stuttgart e-Genius & Stuttgart, Germany & 2 & 243 & 65 & Demo (2015) & Light \\
\hline Beyond Aviation Electric Cessna 172 & Broomfield, CO, USA & 2 & $244^{\mathrm{b}}$ & 122 & Canc (2012) & Light \\
\hline ACS LOONG-e & Putim, Brazil & 2 & 351 & 118 & Dev & LSA \\
\hline SKYLYS Aircraft AO & Dover, DE, USA & 3 & 81 & 108 & Dev & VTOL \\
\hline Joby S4 & Santa Cruz, CA, USA & 4 & - & - & Dev & VTOL \\
\hline AirSpaceX MOBi & Birmingham, MI, USA & 4 & 62 & 130 & Dev & VTOL \\
\hline Carter Electric CarterCopter Air Taxi & Wichita Falls, TX, USA & 4 & 98 & 152 & Dev & VTOL \\
\hline HopFlyt & Lusby, MD, USA & 4 & 174 & 120 & Dev & VTOL \\
\hline Pipistrel Taurus G4 & Ajdovščina, Slovenia & 4 & 243 & 87 & Demo (2011) & Light \\
\hline
\end{tabular}




\begin{tabular}{|c|c|c|c|c|c|c|}
\hline Aircraft & Location & $\begin{array}{c}\text { Seat } \\
\text { Count }^{\mathrm{a}}\end{array}$ & $\begin{array}{c}\text { Range } \\
\text { [nmi] }\end{array}$ & $\begin{array}{c}\text { Cruise } \\
\text { Speed [kt] }\end{array}$ & $\begin{array}{c}\text { Status }^{\mathrm{c}} \\
\text { (Last Update) }\end{array}$ & Type \\
\hline Eviation Alice & Kadima, Israel & 9 & 521 & 240 & Dev & NB \\
\hline 328 (Martin Hepperle) $^{\mathrm{d}}$ & Braunschweig, Germany & 28 & 109 & 162 & Con (2012) & NB \\
\hline 328-LBME ${ }^{2}$ (Martin Hepperle) ${ }^{\mathrm{d}}$ & Braunschweig, Germany & 28 & 786 & 138 & Con (2012) & NB \\
\hline Stanford Aluminum-Air Aircraft & Stanford, CA, USA & 30 & 1150 & 287 & Con (2016) & NB \\
\hline Airbus VoltAir & Ottobrunn, Germany & 68 & 900 & 270 & Con (2012) & NB \\
\hline Electrified ATR 72-500 & Munich, Germany & 68 & 883 & 241 & Con (2012) & NB \\
\hline Stanford Lithium-Air Aircraft & Stanford, CA, USA & 114 & 2376 & 447 & Con (2015) & NB \\
\hline Wright One & Los Angeles, CA, USA & 150 & 261 & - & Dev & NB \\
\hline BHL Ce-Liner & Munich, Germany & 189 & 900 & 436 & Con (2014) & NB \\
\hline
\end{tabular}

a passenger seat count for narrow-body aircraft, total seat count otherwise

${ }^{b}$ range estimated with cruise speed and endurance

${ }^{c}$ Canc: cancelled project, Con: conceptual design, Demo: demonstration design, Dev: currently in development, Prod: currently in production

${ }^{d}$ intermediate designs between 328 and $328-L B M E^{\wedge} 2$ not shown

who envision vertical takeoff and landing (VTOL) aircraft for aviation ODM [83, 84]. VTOL aircraft are capable of taking off and landing without a runway, allowing for use away from airports. As shown in Table 2, there are 16 different all-electric VTOL with fixed wings currently in development. These aircraft are designed primarily for travel within urban areas, thus all are limited in passenger capacity ( $<5 \mathrm{PAX})$, maximum range $(<200 \mathrm{nmi})$, and design cruise speed $(<200 \mathrm{kt})$.

\subsubsection{Light aircraft}

A variety of ultra-light aircraft (ULA), light-sport aircraft (LSA), and other light aircraft have been studied as well. Many of these were demonstrator aircraft, such as the NASA Green Flight Challenge competitors, IFB-Stuttgart e-Genius and Pipistrel Taurus G4 [51]. Some projects, including the Airbus E-Fan, Beyond Aviation Electric Cessna 172, Electric Aircraft Corporation ElectraFlyer-X, Yuneec-Flightstar Espyder E280, and Yuneec E430, were cancelled before reaching production. Currently the two-passenger Sonex Electric Sport Aircraft, Evektor SportStar EPOS, Pipistrel Panthera, and ACS LOONG-e aircraft designs are in development, with plans for future production. Additionally, the NASA X57 Maxwell is currently under construction. This aircraft will enable the investigation of 
distributed electric propulsion by using 12 high-lift electric motors with folding propellers on the wing leading edge and $60 \mathrm{~kW}$ wingtip cruise motors $[85,86]$. Finally, the increasingly popular Pipistrel Alpha Electro trainer aircraft and recently developed Liaoning Ruixiang RX1E and RX1E-A are the only AEA currently in production.

\subsubsection{Narrow-body aircraft}

Most relevant to this work are narrow-body AEA. A visualization of the design missions for these aircraft is shown in Figure 2. Currently 2 regional airliners, the 9-passenger Eviation Alice and 150-passenger Wright One, are being developed by startup aviation companies. The other 7 narrow-body AEA listed in Table 2 are conceptual designs that are highly dependent on future technology assumptions. The focus of this work is an AEA designed for a maximum of 180 passengers (PAX). The only previously researched AEA of this size is the BHL Ce-Liner, which features a C-wing and two aft-mounted ducted fans [87]. Thus, this is the primary design from aviation literature used for comparisons.

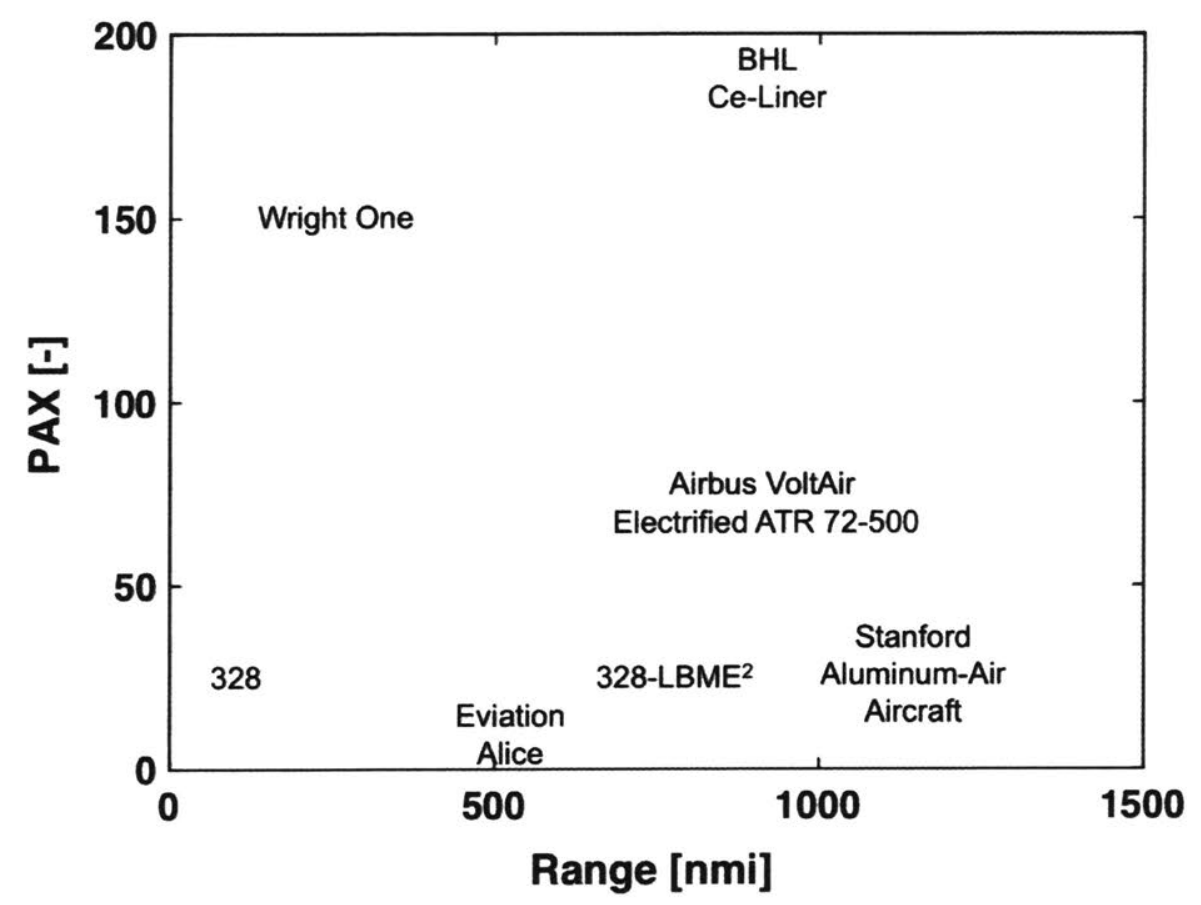

Figure 2. Design missions of previously studied narrow-body all-electric aircraft. Not shown is the 114 PAX, $2376 \mathrm{nmi}$ Stanford Lithium-Air Aircraft. 


\subsection{Battery technology status}

For AEA to become feasible, the critical development required is battery technology, especially the specific energy and power. These terms represent the energy and power per unit mass of battery, respectively. Recently battery research has come to the forefront, largely due to the growing popularity of electric vehicles. Projects, such as the DOE Battery500, aim to accelerate the development of advanced batteries [88]. Li-ion batteries are the state of the art battery type, but other battery chemistries, specifically Li-S, have emerged as contenders for aviation applications.

\subsubsection{Tradeoffs}

The battery chosen for a given application is dependent on many battery properties, as illustrated in Figure 3. The mass properties, specific energy and power, are crucial for aircraft performance. However, energy density $[\mathrm{Wh} / \mathrm{L}]$ is key as well, as aircraft have a limited wing and fuselage volume available for energy storage. Though not considered in this work, other parameters are also of importance. The cycle life, calendar life, cost, and charge rate capability all impact the economic and operational feasibility of AEA. Finally, airlines consider the safety and operating temperature range to be of upmost importance.

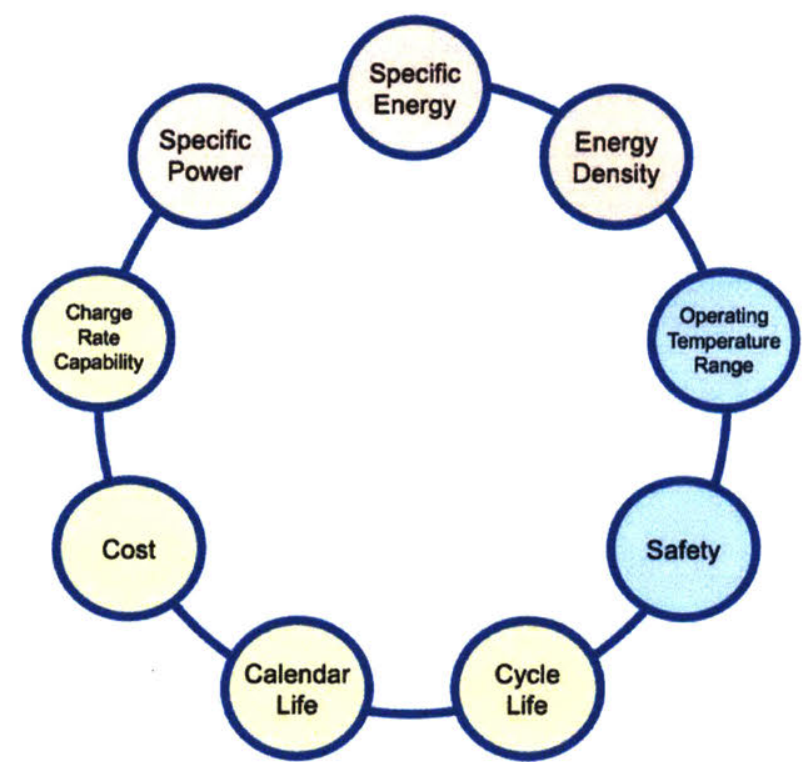

Figure 3. Battery tradeoffs. Modified from [89, 90]. 


\subsubsection{Li-ion overview}

Many different types of Li-ion batteries currently exist. The anode and cathode composition define the Li-ion battery type. Nearly all current anodes are either graphite or lithium titanate oxide (LTO). While LTO anodes have a higher discharge rate capability and better stability, graphite anodes have a higher specific capacity $[\mathrm{Ah} / \mathrm{kg}]$, Researchers are seeking to increase the specific capacity in graphite anodes through silicon addition [91].

Table 3. Common cathode options for Li-ion batteries. Data from [95, 96, 97, 98].

\begin{tabular}{|c|c|c|c|c|c|c|}
\hline \multirow{2}{*}{$\begin{array}{l}\text { Li-ion } \\
\text { Type }\end{array}$} & \multirow{2}{*}{ Chemical Description } & \multicolumn{2}{|c|}{ Specific Capacity $[\mathrm{Ah} / \mathrm{kg}]$} & \multicolumn{2}{|c|}{ Voltage [V] } & \multirow{2}{*}{ Electric Vehicle Applications } \\
\hline & & Typical & Theoretical & Avg. & Mid. & \\
\hline LCO & $\begin{array}{l}\text { Lithium cobalt oxide } \\
\mathrm{LiCoO}_{2}\end{array}$ & 150 & 274 & 3.8 & 3.9 & $\begin{array}{c}\mathrm{N} / \mathrm{A} \\
\text { Note, original B787 battery }\end{array}$ \\
\hline LMO & $\begin{array}{l}\text { Lithium manganese } \\
\text { oxide } \\
\mathrm{LiMn}_{2} \mathrm{O}_{4}\end{array}$ & 120 & 148 & 4.1 & 4.0 & $\begin{array}{c}\text { 2011/2013 Nissan Leaf } \\
2012 \text { Mitsubishi i-MiEV } \\
2013 \text { Ford Focus EV }\end{array}$ \\
\hline NCA & $\begin{array}{l}\text { Lithium nickel cobalt } \\
\text { aluminum oxide } \\
\mathrm{LiNi}_{0.8} \mathrm{Co}_{0.15} \mathrm{Al}_{0.05} \mathrm{O}_{2}\end{array}$ & 190 & 278 & 3.7 & 3.7 & $\begin{array}{l}2014 \text { Tesla Model S } \\
2015 \text { Mercedes-Benz B-Class ED } \\
2016 \text { Tesla Model X }\end{array}$ \\
\hline NMC & \begin{tabular}{|c|} 
Lithium nickel \\
manganese cobalt oxide \\
$\mathrm{LiNi}_{\mathrm{x}} \mathrm{Mn}_{\mathrm{y}} \mathrm{Co}_{1-\mathrm{x}-\mathrm{y}} \mathrm{O}_{2}$
\end{tabular} & 170 & $\begin{array}{c}278 \\
(\mathrm{NCM} 333)\end{array}$ & 3.7 & 3.8 & $\begin{array}{c}2014 \text { BMW i3 } \\
2015 \text { Chevrolet Spark EV } \\
2017 \text { Nissan Leaf, Tesla Model } 3\end{array}$ \\
\hline LFP & $\begin{array}{c}\text { Lithium iron phosphate } \\
\mathrm{LiFePO}_{4}\end{array}$ & 160 & 170 & 3.4 & 3.4 & $\begin{array}{c}2011 \text { Chevrolet Spark EV } \\
\text { eBuses }\end{array}$ \\
\hline
\end{tabular}

The cathode options are listed in Table 3. Early Li-ion batteries used LCO and early electric vehicle batteries used LMO, but now NCA, NMC, and LFP are the most popular options. The highest specific energy batteries available commercially use NCA, such as the Panasonic NCR18650A cells in current Tesla battery packs [92]. Batteries with NMC have slightly lower specific energies than those with NCA, but offer improved cycle lives and safety. Batteries with LFP are reliable, relatively low cost, and offer long 
cycle lives and high-power capabilities, but have low specific energies. It is believed that NMC-type batteries will dominate over the next decade [93]. These batteries have their own design space, shown in Figure 4. It is desirable to move away from the LCO region, as cobalt (Co) is expensive and sourced from regions with questionable mining ethics [94].

Many Li-ion batteries today are actually Li-ion polymer ( $\mathrm{LiPo})$ battereis, and feature a semisolid polymer electrolyte. Solid-like and solid-state Li-ion batteries are actively being research worldwide for increased safety and potentially improved mass and volume properties as well $[99,100,101]$.

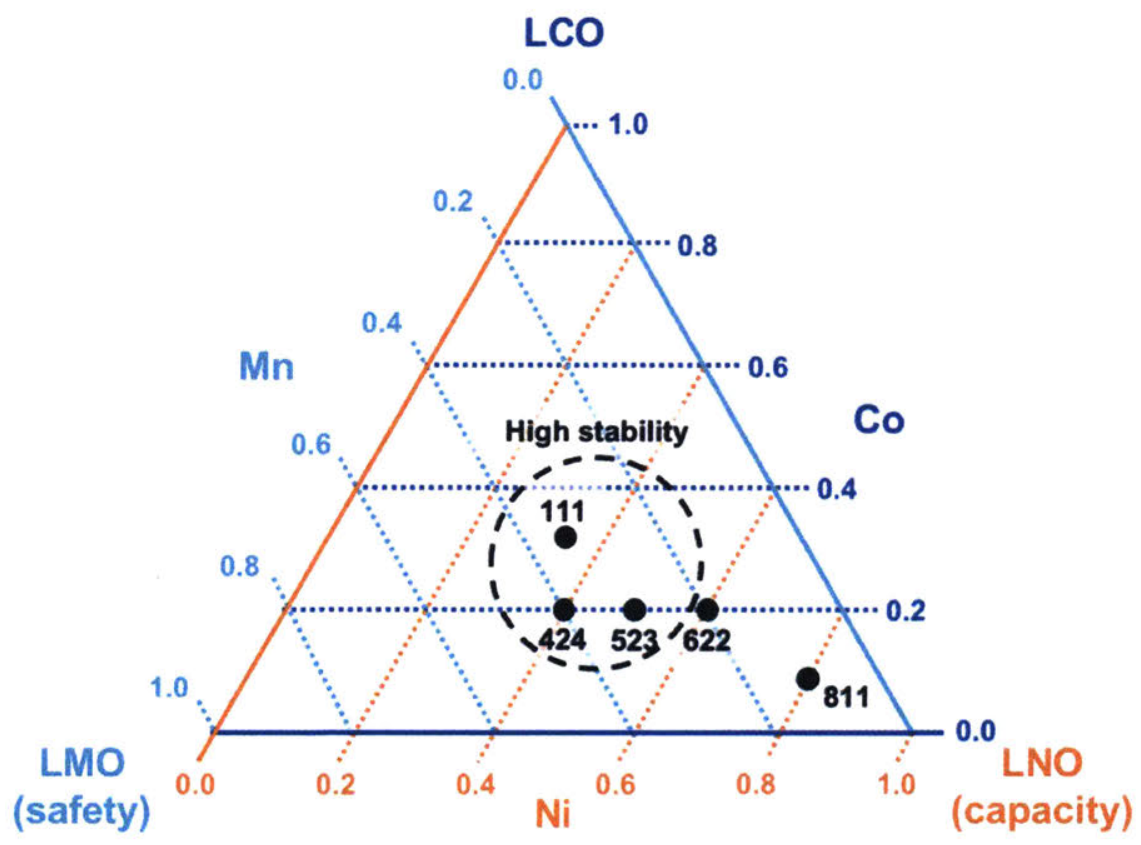

Figure 4. Lithium nickel manganese cobalt oxide battery design space. Modified from $[102,103]$.

\subsubsection{Li-S overview}

Li-S batteries feature a sulfur cathode and lithium anode. Sulfur is abundant and nontoxic, so this battery chemistry would offer high energy economy and environmental friendliness. It also has a high theoretical specific energy of $2567 \mathrm{Wh} / \mathrm{kg}$. However, many issues currently restrict this technology, including the low electrical conductivity of sulfur, excessive volumetric expansion during discharge, and parasitic lithium polysulfide 
intermediate reactions $[104,105]$. Solutions to these issues are available, such as conducting agents, robust structures, and electrolyte additives, respectively. However, these solutions add weight, thus penalizing the specific energy. Current Li-S batteries also have limited cycle lives presently.

\subsubsection{Li-air overview}

One of the other often-mention battery chemistries for aviation, Li-air, is not considered in this work. Though it has the largest theoretical specific energy of all secondary batteries, many practical issues restrict implementation. Li-air batteries would require an air feed system, and pressurization, as the available battery capacity increases with pressure [106]. Additionally, they have poor rate capabilities (e.g. order of $\mathrm{mW} / \mathrm{kg}$ ) and would require

high performance $\mathrm{O}_{2}$-selective membranes to prevent contamination [107, 108]. Finally, Li-air batteries gain mass and expand, resulting in structural design difficulties.

\subsubsection{Theoretical battery parameters}

Based on the chemical reaction of each battery chemistry, theoretical values for the battery specific energy and energy density can be determined, as shown in Table 4 . The limitations of the Li-ion battery chemistry are clearly observed, though these theoretical values would increase with silicon addition to the graphite anode [91]. Li-S batteries are the most promising option that do not gain mass during discharge, while Li-air batteries have the highest theoretical values. Li-metal batteries, not discussed previously, use a lithium anode. These batteries offer mass and volume improvements over Li-ion batteries, but current cycle lives are not suitable for aviation [109]. The other battery chemistries listed in Table 4 may be reasonable for aviation, but are not used in this work and are only listed for reference. 
Table 4. Theoretical parameters for potential aviation batteries.

\begin{tabular}{|c|c|c|c|c|c|c|}
\hline $\begin{array}{l}\text { Battery } \\
\text { Type }\end{array}$ & Discharge Reaction & $\begin{array}{c}\text { Nominal } \\
\text { Cell } \\
\text { Voltage [V] }\end{array}$ & $\begin{array}{l}\text { Cathode } \\
\text { Specific } \\
\text { Capacity } \\
{\text { [Ah } / \mathrm{kg}]^{\mathrm{a}}}\end{array}$ & $\begin{array}{c}\text { Specific } \\
\text { Energy } \\
{[\mathrm{Wh} / \mathrm{kg}]^{\mathrm{b}}}\end{array}$ & 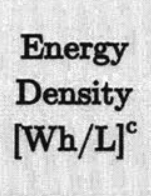 & Ref. \\
\hline Li-ion $^{e}$ & $\begin{array}{c}L i_{1-x} C_{6}+L i_{x} M O_{2} \\
\leftrightarrow C_{6}+L i M O_{2}\end{array}$ & $3.4-4.1$ & $148-278$ & $396-607$ & $\sim 1000$ & Table 3 \\
\hline Li-metal & $\begin{array}{l}L i_{1-x}+L i_{x} M O_{2} \\
\leftrightarrow L i M O_{2}\end{array}$ & $3.4-4.1$ & $148-278$ & $578-1054$ & $>1000$ & Table 3 \\
\hline Li-S & $2 L i+S \leftrightarrow L i_{2} S$ & 2.2 & 1167 & 2567 & 2189 & {$[110]$} \\
\hline Li-air & $2 L i+\bigotimes_{2} \leftrightarrow L i_{2} O_{2}$ & 3.0 & 1168 & 3505 & 3492 & [110] \\
\hline $\mathrm{Li}-\mathrm{Se}$ & $2 \mathrm{Li}+\mathrm{Se} \leftrightarrow \mathrm{Li}_{2} \mathrm{Se}$ & 2.0 & 577 & 1155 & 1824 & [111] \\
\hline Al-air & $\begin{array}{c}4 \mathrm{Al}+6 \mathrm{H}_{2} \mathrm{O}+3 \mathrm{O}_{2} \\
\leftrightarrow 4 \mathrm{Al}(\mathrm{OH})_{3}\end{array}$ & 2.71 & 1031 & 2793 & 3147 & {$[107]$} \\
\hline Zn-air & $2 \mathrm{Zn}+\mathrm{O}_{2} \leftrightarrow 2 \mathrm{ZnO}$ & 1.65 & 659 & 1087 & 3736 & {$[110]$} \\
\hline
\end{tabular}

${ }^{a}$ Discharged state (calculated)

${ }^{b}$ All active materials, including oxygen (calculated). Without oxygen, values for metal-air batteries are Li-air: $11584 \mathrm{Wh} / \mathrm{kg}, \mathrm{Al}$-air: $8075 \mathrm{Wh} / \mathrm{kg}, \mathrm{Zn}$-air: $1353 \mathrm{Wh} / \mathrm{kg}$.

${ }^{c}$ Charged anode and discharged cathode (calculated)

${ }^{d}$ References for nominal cell voltage

${ }^{e}$ Graphite anode

\subsubsection{Theoretical all-electric aircraft range}

Similar to the Breguet range equation for conventional aircraft, the all-electric aircraft range can be estimated with an assumed specific energy and aircraft parameters.

The range $[\mathrm{m}]$ of an aircraft is

$$
R=v_{\infty} t
$$

where $v_{\infty}[\mathrm{m} / \mathrm{s}]$ is flight speed and $t[\mathrm{~s}]$ is flight time. The flight time for a battery-powered all-electric aircraft is approximated as

$$
t=\frac{m_{b} E^{*}}{P_{b}}
$$

where $m_{b}[\mathrm{~kg}]$ is battery mass, $E^{*}[\mathrm{~J} / \mathrm{kg}]$ is battery (pack) specific energy, and $P_{b}[\mathrm{~W}]$ is battery power. The required battery power is 


$$
P_{b}=\frac{P_{\text {aircraft }}}{\eta_{\text {overall }}}
$$

where $P_{\text {aircraft }}[\mathrm{W}]$ is aircraft power and $\eta_{\text {overall }}[-]$ is overall aircraft efficiency. The aircraft power is

$$
P_{\text {aircraft }}=v_{\infty} D
$$

where $D[\mathrm{~N}]$ is aircraft drag. Assuming lift equals weight, the aircraft drag is

$$
D=\frac{m_{\mathrm{aircraft}} g}{L / D}
$$

where $m_{\text {aircraft }}[\mathrm{kg}]$ is aircraft mass, $g\left[\mathrm{~m} / \mathrm{s}^{2}\right]$ is acceleration due to gravity, and $L$ is lift [N]. Substituting (4) and (5) into (3), the battery power is

$$
P_{b}=\frac{v_{\infty} m_{\text {aircraft }} g}{\eta_{\text {overall } L / D}}
$$

Rearranging, the flight speed is

$$
v_{\infty}=\frac{P_{b} \eta_{\text {overall }} L / D}{m_{\text {aircraft }} g}
$$

The battery mass fraction $\mathrm{f}[-]$ is

$$
f=\frac{m_{b}}{m_{\text {aircraft }}} .
$$

Substituting (2), (7), and (8) into (1) and rearranging, the constant mass aircraft range is defined as

$$
R=\frac{\eta_{\text {overall }} E^{*} L / D f}{g} .
$$

For a mass gaining aircraft the rate of mass gain $[\mathrm{kg} / \mathrm{s}]$ is

$$
\frac{d m}{d t}=\frac{k z P_{b}}{E^{*}}
$$

where $k[-]$ is the fraction of oxygen mass gained to active battery mass (chemistry based) and $z[-]$ is the active to total battery mass ratio. Thus, the product of $k$ and $z$ is the oxygen mass gained to total battery mass fraction. Note the $P_{b}$ divided by $E^{*}$ is the rate of battery use $[\mathrm{kg} / \mathrm{s}]$. Substituting (6) into (10) and rearranging,

$$
\frac{d m}{m_{\text {aircraft }}}=\frac{k z v_{\infty} g}{\eta_{\text {overall } E^{*} L / D}} d t \text {. }
$$

Using (1) and integrating,

$$
\ln \left(\frac{m_{\text {final }}}{m_{\text {initial }}}\right)=\frac{k z g R}{\eta_{\text {overall }} E^{*} L / D}
$$


where $m_{\text {initial }}[\mathrm{kg}]$ is initial aircraft mass and $m_{\text {final }}[\mathrm{kg}]$ is final aircraft mass. The final aircraft mass is

$$
m_{\text {final }}=m_{\text {initial }}+f k z \text {. }
$$

Substituting (13) into (12) and rearranging, the mass gaining aircraft range is defined as

$$
R=\frac{\eta_{\text {overall } E^{*} L / D}}{g} \frac{\ln (1+f k z)}{k z}
$$

where $E^{*}[\mathrm{~J} / \mathrm{kg}]$ is specific energy based on initial battery mass. The specific energy $[\mathrm{J} / \mathrm{kg}]$ based on the final battery mass is

$$
E_{\text {final }}^{*}=\frac{E^{*}}{1+k z} \text {. }
$$

Note that the flight speed does not directly impact the range for any electric aircraft, as shown in (9) and (14), but it may impact the overall efficiency and lift to drag ratio.

As shown by Figure 5, the range of AEA with current technology assumptions is limited in relation to conventional aircraft. For example, Li-S batteries can only achieve around $1000 \mathrm{nmi}$ subject to modest assumptions for future battery and aircraft technology. Li-air batteries have the potential for a longer range, but must overcome other practical issues, such as low specific power.

\subsubsection{Packing efficiency}

Shown in Figure 6 is a summary of state-of-the-art, projected, and theoretical cell specific energies for various lithium-based battery chemistries. It is crucial to note the difference between cell and pack specific energy. Battery manufacturers typically specify cell values, while pack values are important at the vehicle level. Current electric vehicles have a 65$75 \%$ packing efficiency, which is the ratio of cell to pack mass $[78,92,97,112,113,114$, $115,116]$. However, it is expected that AEA will have values greater than $80 \%$, as more focus will be placed on mass minimization rather than impact safety $[113,117,118]$. 


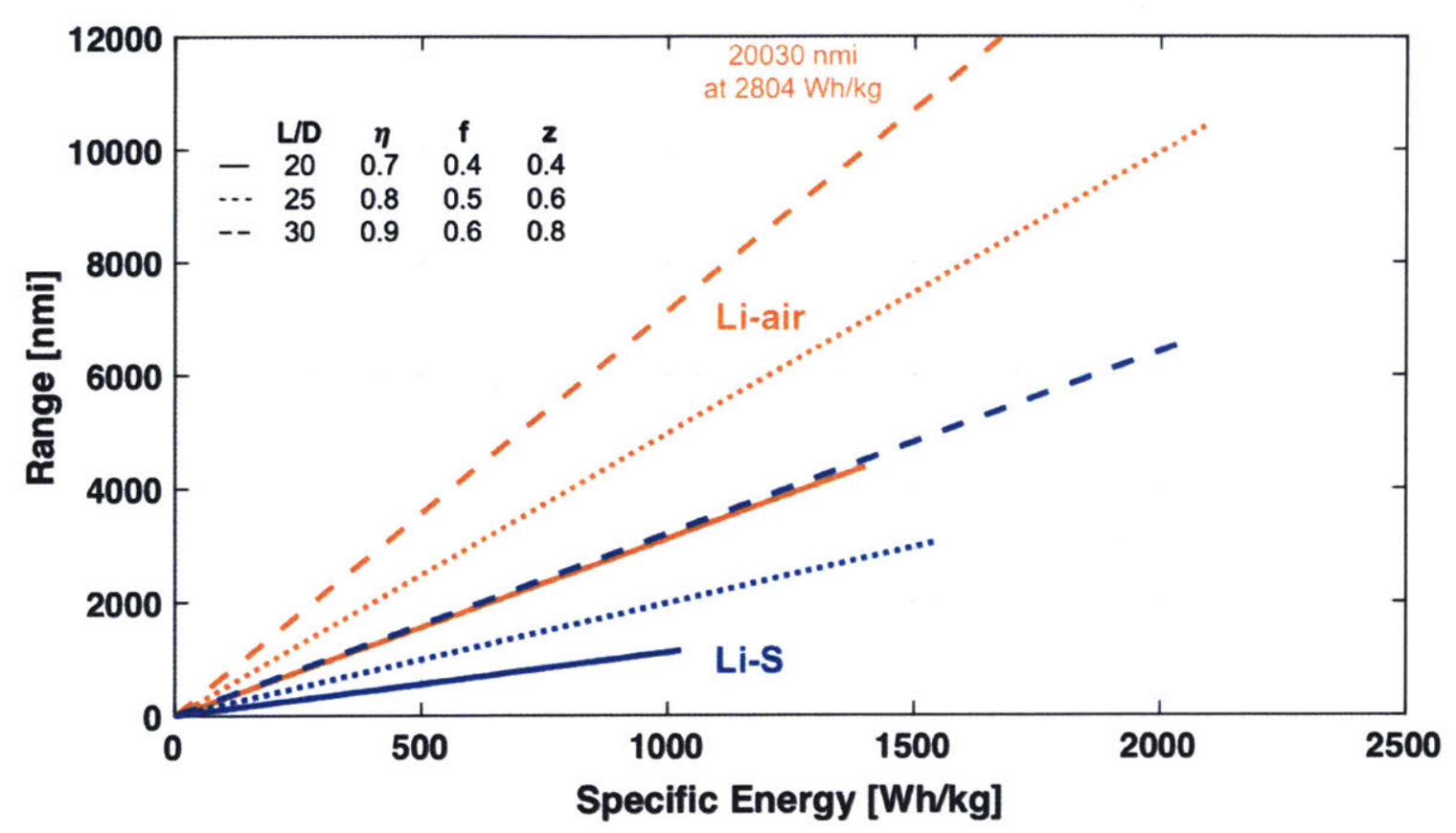

Figure 5. All-electric aircraft range limitations. Two commonly proposed battery chemistries for aviation and various technology assumptions are displayed. Discharged specific energies are used for Li-air, which has $k=2.305$.

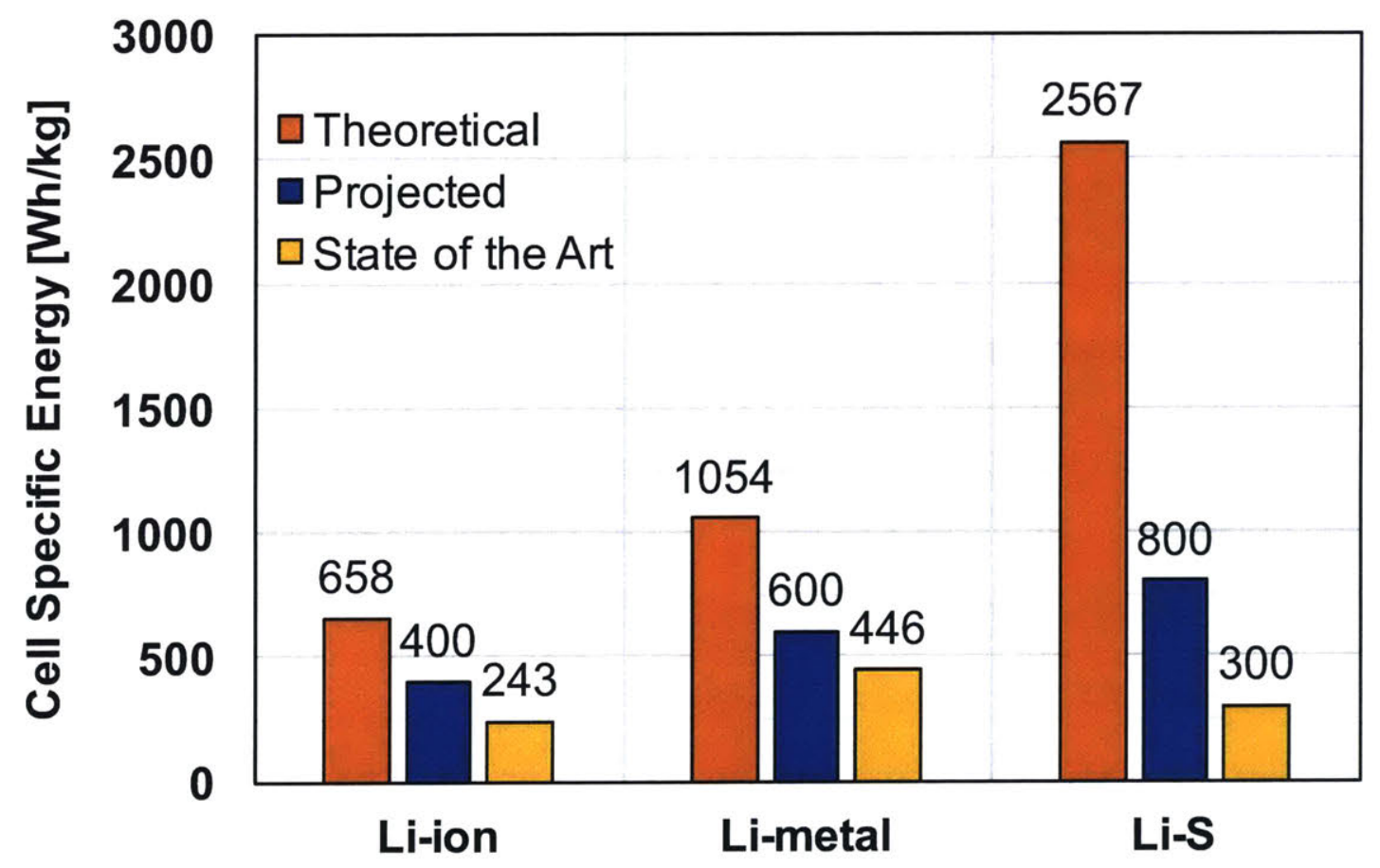

Figure 6. Specific energies of lithium-based batteries. State of the art Li-ion, Li-metal, and Li-S batteries are manufactured by Panasonic [119], SolidEnergy [109], and Oxis Energy [120], respectively. 


\section{Chapter 3}

\section{Aircraft sizing methodology}

Specification, performance, and optimization of all-electric aircraft was performed with Transport Aircraft System OPTimization - electric (TASOPTe). This program was developed specifically for this work. TASOPTe is an electric propulsion-based version of the Transport Aircraft System OPTimization (TASOPT) code, which was developed at MIT to evaluate conventually-fueled aircraft [121]. TASOPT was utilized to design the D8 "double bubble" aircraft, and is currently used by multiple research groups [122].

Both TASOPT and TASOPTe are multidisciplinary design optimization (MDO) programs that can simultaneously optimize the airframe, propulsor, and operation of a given transport aircraft. The key benefit of these programs is the use of first-principles methods rather than reliance on empirical data, which can have limited ranges of validity. This allows for confidence in the results of innovative designs. Only where necessary are historical correlations used, particularly for some non-structural aircraft equipment and secondary structure weights [121]. The design space is limited to tube-and-wing aircraft topology, but unconventional aircraft features can be included, such as boundary layer ingestion, strut-braced wings, "double bubble" fuselages, and composite materials [122].

\subsection{Common TASOPT and TASOPTe features}

Though TASOPT has been heavily modified for all-electric aircraft analysis, many features remain unchanged. The methodology of TASOPT is well-documented $[121,123$, 124], so only a high-level summary of the unmodified features is provided here.

\subsubsection{Inputs and outputs}

Aircraft are designed using basic input parameters, some of which can be selected for optimization. The fuselage dimensions are specified using basic dimensional inputs (e.g. 
length, radius, etc.), but the majority of inputs are dimensionless. For example, inputs for the airframe, propulsor, and aircraft operation include the fan pressure ratio, nonstructural weight fractions, and cruise Mach number, respectively. Using dimensionless inputs aids in designing various size aircraft with the same underlying shape and weight assumptions.

In addition to design parameters, aircraft design constraints may also be stipulated. These include maximum balanced field length, minimum top-of-climb gradient, maximum wing span, and maximum energy storage (jet fuel or battery) volume. These constraints are implemented via optimizer penalty functions.

To evaluate performance, aircraft missions must be specified. The parameters that define each mission include, range, passenger count and weight (payload), and takeoff/landing altitude and temperature. A single design mission is always specified, and optional off-design missions (e.g. shorter range) may also be assessed. Optimization is optionally performed using mission-averaged weights across a set of defined design and off-design missions.

Using the design inputs and constraints, aircraft sizing is completed based on the design mission, and then performance is computed for off-design missions. If optimization variables are selected, then the result is an optimized aircraft, rather than just a sized aircraft. In either case, outputs include key dimensions and weights (e.g. fan diameter and battery weight), along with a complete flight profile and mission energy requirements.

\subsubsection{Aerodynamic performance}

Rather than traditional wetted-area or full 3D CFD approaches, wing airfoil performance is determined from a family of precomputed transonic airfoils. Performance for the airfoil family is calculated using $2 \mathrm{D}$ viscous/inviscid CFD for a range of airfoil thicknesses, lift coefficients, and Mach numbers. Similarly, fuselage profile drag is found using compressible viscous/inviscid CFD with axisymmetric simplifications. The use of CFD 
presented here allows accurate and widely applicable results to be obtained without a large computational expense. Traditional wetted area approaches with supervelocity corrections are utilized to obtain the drag of minor components, such nacelles. TrefftzPlane analysis is used to determine induced drag [121].

\subsubsection{Airframe structure and weight}

The primary structural airframe elements are treated as simple geometric shapes, with the material gauges sized for each element at critical loading cases. The fuselage is modeled as a pressure vessel with spherical or ellipsoidal endcaps, which has additional bending and torsion loads. The wing is modeled as a double piecewise linear taper planform with sweep. It is assumed to be cantilevered or optionally have a strut support at the planform panel-break. The wing cross-section is modeled as a structural box with front and rear shear webs and curved top and bottom spar caps. The tails use the same model as the wing, except for the optional strut. The sized material gauges, along with specified material densities, provide the primary structure weight. The floor weight is determined from a payload-loading analysis. Weights of the secondary structure (e.g. slats, flaps, etc.)

and non-structural aircraft equipment (e.g. windows, seats, etc.) are estimated with historical weight fractions and are assumed to be proportional to the passenger count (payload) or cabin size, as appropriate [121].

\subsection{Electrical and propulsion system architecture}

Though TASOPTe is largely based on TASOPT [121], substantial modifications have been made that allow for the analysis of all-electric aircraft. The primary differences are a consequence of the fundamentally distinct energy storage and propulsion system. Rather than gas turbines, all-electric aircraft use electric motor-ducted fan assemblies. A schematic of the electrical and propulsion system architecture is shown in Figure 7. Propulsion is provided by ducted fans, which are connected to AC electric motors. 
Intermediate motor-fan gearboxes may optionally be included. Electrical power is provided to the electric motors from the battery through the power management and distribution (PMAD) system. Power offtakes are required for aircraft subsystems (e.g. anti-icing, avionics, etc.) and the electrical cooling system. Each component in the electrical and propulsion system has an associated weight and efficiency. The weight calculations are discussed in the following sections, while constant efficiencies are assumed for each component, except the batteries. Though no system of this type currently exists, NASA is researching a similar system in the NASA Electric Aircraft Test bed (NEAT) [125].

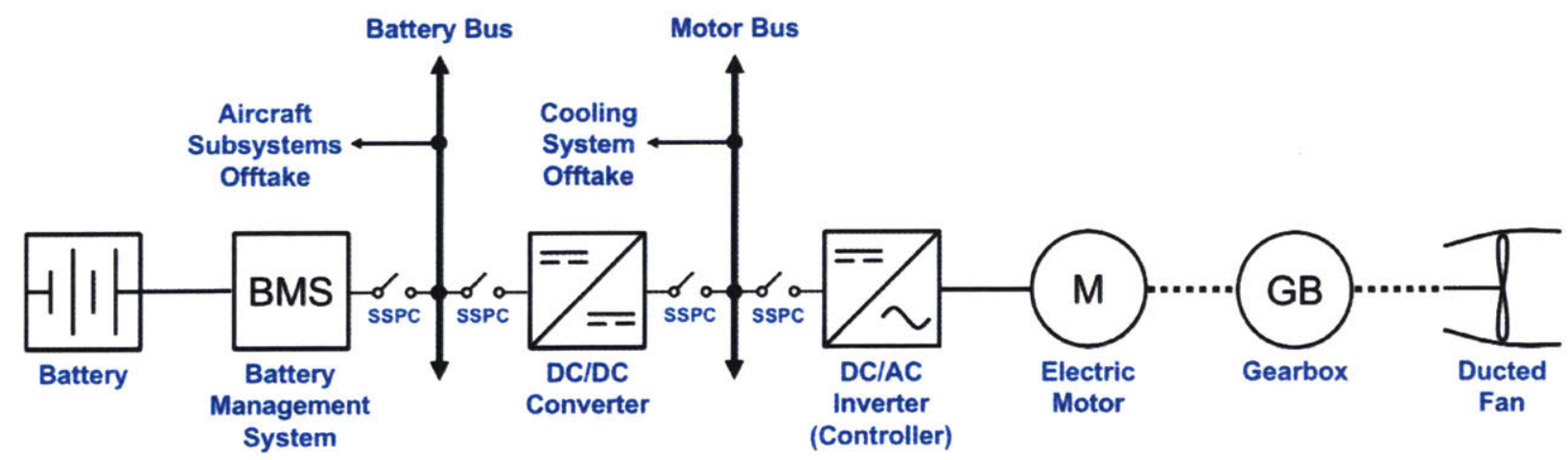

Figure 7. Electrical and propulsion system architecture for a single propulsor. Modified from $[22,126,127,128,129]$.

\subsubsection{AC electric motors}

The AC electric motors may be specified as conventional or high-temperature superconducting (HTS). In either case, the particular type used is the brushless DC motor, also known as the electronically commutated motor. The name of this motor type can be misleading, as the power supply is $\mathrm{DC}$, but a DC/AC inverter (controller) allows for variable frequency AC motor operation. Not using brushes or commutators has many benefits, including less maintenance, higher reliability, and the ability to operate in reverse as a generator. Conventional motors are assumed to use strong permanent magnets, while HTS motors use wound HTS coils [130, 131, 132, 133]. 
The electric motor weight is scaled with shaft power, with HTS motors having more favorable scaling exponents $[134,135]$. The motors and electrical system are sized for takeoff, which is the most power demanding condition. Specific power benefits can be achieved with high power and/or HTS motors, rather than low power and/or conventional motors. For example, 1 and $10 \mathrm{MW}$ conventional motors have specific powers of 2.2 and $2.8 \mathrm{~kW} / \mathrm{kg}$, respectively, while 1 and 10 MW HTS motors have specific powers of 10 and $22 \mathrm{~kW} / \mathrm{kg}$, respectively. For comparison, the combined shaft power of modern turbofans is near $10 \mathrm{~kW} / \mathrm{kg}$, and state of the art lightweight electric motors (Siemens, $0.25 \mathrm{MW}$ ) have achieved $5 \mathrm{~kW} / \mathrm{kg}$ [136]. Considering the higher efficiencies also possible in a superconducting system, HTS motors are appropriate for commercial aviation at the 180 PAX scale, where motor power requirements are of $10 \mathrm{MW}$ magnitude. NASA estimates that electric motors of this type will be available around 2050, which drives the expected entry into service [137].

\subsubsection{PMAD system}

In the present context, the PMAD consists of $\mathrm{DC} / \mathrm{DC}$ converters, cables, $\mathrm{DC} / \mathrm{AC}$ inverters, buses, and solid state power controllers (SSPCs). The battery output DC voltage is stepped up with a DC/DC converter before the main cable transmission to limit currents. Just prior to the electric motors, the DC voltage is inverted to AC voltage with an inverter, which also acts as a controller. SSPCs allow loads to be removed from the system if a fault is detected, allowing protection from short circuits and overloads [138]. Each of these electrical system components has an associated weight. The total cable weight is determined based on an assumed value of cable weight/length and the length between the fuselage and each propulsor. The weights of the other components are determined using specified specific powers and calculated powers at the respective components. 


\subsubsection{Electrical system cooling}

The heat from the electric motors must be dissipated, so a cooling system is included. Cooling for a conventional electrical system is fulfilled with a water-cooled radiator. The weight in this case is determined from an assumed specific power and a calculated heat removal requirement [135]. A cryocooler is used for cooling in a HTS system, with the weight determined from cryocooler scaling trends [126, 139].

\subsubsection{Aircraft subsystems power offtakes}

Unlike conventional aircraft that offtake power from the low-pressure gas turbine spool, all-electric aircraft draw power directly from the battery for aircraft subsystems (e.g. ECS, flight controls, etc.). More-electric aircraft, such as the Boeing 787 and Airbus A380 require up to $2 \mathrm{~kW} /$ seat, which is expected to increase to $4-5 \mathrm{~kW} /$ seat $[14,140,141]$. The required power offtake is estimated from the design aircraft passenger count and maximum takeoff weight ( $\mathrm{W}_{\mathrm{MTO}}$ ), with $1 \mathrm{~kW} / \mathrm{PAX}$ and $0.50 \mathrm{~W} / \mathrm{N}$ assumed, respectively.

\subsubsection{Ducted fans}

The ducted fan model in TASOPTe has a 1D flowpath simulation, which was developed from the gas turbine flowpath simulation in TASOPT. Diffuser, fan, and nozzle pressure ratios are specified for the design point (cruise). Fan stage polytropic efficiencies are determined using one of two methods. In the first, a linear relationship between the polytropic efficiency $\left(\eta_{p}\right)$ and fan pressure ratio $\left(\pi_{f}\right)$ is represented by

$$
\eta_{p}=0.909-0.282\left(\pi_{f}-1.284\right) .
$$

The constants in Eq. (16) were determined using low design FPR (1.294) test data and an assumed stator and duct efficiency of 0.985 [142]. A second, more complex model generates polytropic efficiency contours, as shown in Figure 8. This fan map was calibrated using the same low FPR test data. 


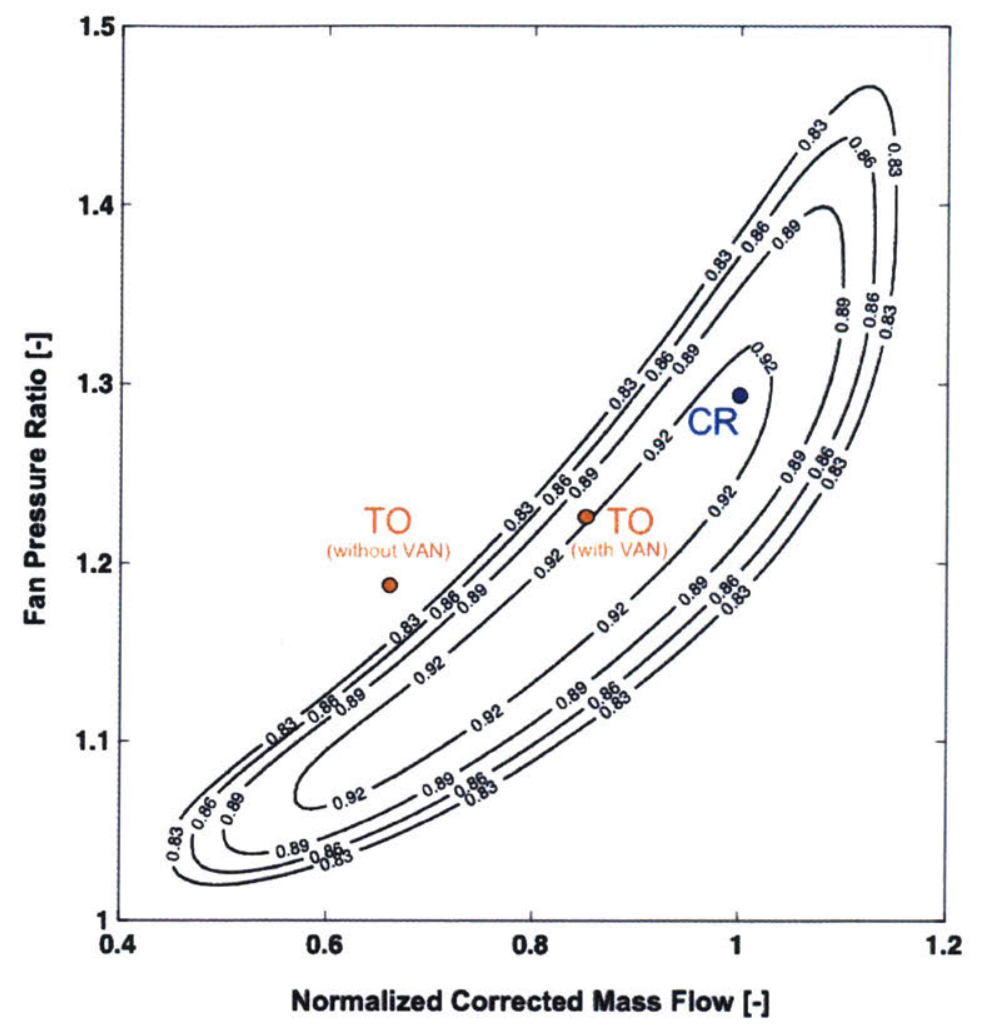

Figure 8. Calibrated fan polytropic efficiency contours for a 1.294 FPR fan. Increased flutter margin is provided by using a VAN with a $15 \%$ increase in nozzle area during takeoff (TO) in reference to the design cruise (CR) nozzle area.

A variable area nozzle (VAN) may optionally be included. Without a VAN, the takeoff condition approaches the flutter boundary (surge/stall for a higher FPR fan), as shown in Figure 8. In this region, low efficiency and damage to the fan may occur. The VAN weight penalty is represented by an increase in the fan exhaust cowl weight, which is proportional to the increase in nozzle area from the design condition [143]. However, the VAN weight is highly dependent on the design and mechanism for area variation [144]. Ongoing work with shape memory alloy actuation may lead to lower weight VANs in the future $[145,146]$.

The fan weight, including rotor blades, hub, spinner, stator blades, outer casing, and support struts, is using fan scaling trends [147, 148]. Preliminary weight calculations for a $2.5 \mathrm{~m}$ diameter fan agree with the WATE ++ simulations for similar size PW4462 and PW4168 fans [124]. 


\subsubsection{Motor-fan gearboxes}

Between the electric motor and ducted fan, a gearbox may optionally be incorporated. A conventional motor is generally assumed to not need a gearbox, as the efficiency remains constant across a wide range of speeds. However, a gearbox is likely required for a HTS motor, as the high efficiencies often stated for HTS motors occur at higher speeds ( 10000 rpm) than typical speeds for high fan efficiency (2000-5000 rpm) [149, 150, 151].

Epicyclic gearing is assumed with a sun input, carrier output, and fixed ring. For this configuration, the gear ratio theoretically approaches $6: 1$ when 3 to 9 planetary gears are used. Similar to the Pratt \& Whitney PW1000G turbofan, a gearbox with 5 planetary gears is assumed. With constraints on the number of teeth for all of the gears, the maximum gear ratio is 4.33:1, which is assumed to be suitable for a HTS system.

The gearbox weight is determined using the specified gear ratio and calculated maximum torque $[152,153]$. This calculation is based on historical trends, with a future weight decrease assumption. Similar trends have been mentioned in other aviation literature $[71,154]$.

\subsubsection{Distributed electric propulsion}

In TASOPT, it is assumed that at most one propulsor per wing would be used, as the aircraft industry trend is to use two ultrahigh bypass ratio fans for high propulsive efficiency. However, electric aircraft can achieve high propulsive efficiency through the use of many small propulsors, also known as distributed electric propulsion (DEP). Thus, TASOPTe is robust to the number of wing mounted propulsors permitted.

\subsection{Battery specification and operation}

A key aspect of TASOPTe is battery performance modelling. During discharge, battery capacity decreases until reaching a physical or prescribed limit. The performance 
(efficiency) of a battery depends on the rate of discharge, which varies throughout the mission. Many analyses neglect battery efficiency or assume values of $98 \%$ or greater [10, 134, 155, 156]. This implies that the rate of discharge has no impact on battery performance, which is fundamentally incorrect. AEA capabilities, especially takeoff and balanced field length, are limited due to battery performance. This section describes how batteries are specified and operated within TASOPTe.

\subsubsection{Discharge models}

The battery is modeled as a lumped internal resistance-voltage source with the voltage and power estimated as

and

$$
U=U_{o c}-I R
$$

$$
P=I U
$$

The required power $(P)$ is set by the mission operating point, which then determines the current $(I)$ and voltage $(U)$ if the open-circuit voltage $\left(U_{o c}\right)$ and resistance $(R)$ are known. The open-circuit "no load" voltage is the voltage in the absence of current and may vary with state-of-charge (SOC) and temperature. The resistance is the sum of the cell ionic and electronic resistances and may vary with current, SOC, temperature, and age. It is common practice to neglect the effect of current and age on resistance for conceptual design, and it is assumed that the battery has temperature control. Thus, the open-circuit voltage and resistance are functions of SOC only. SOC represents the remaining capacity normalized by the nominal (maximum) available capacity. As a battery is discharged, the SOC decreases from a maximum of $100 \%$ to a minimum of $0 \%$, though a partial range is typically used. Similarly, the depth-of-discharge (DOD) is the used capacity normalized by the nominal capacity and ranges from 0 to $100 \%$. 

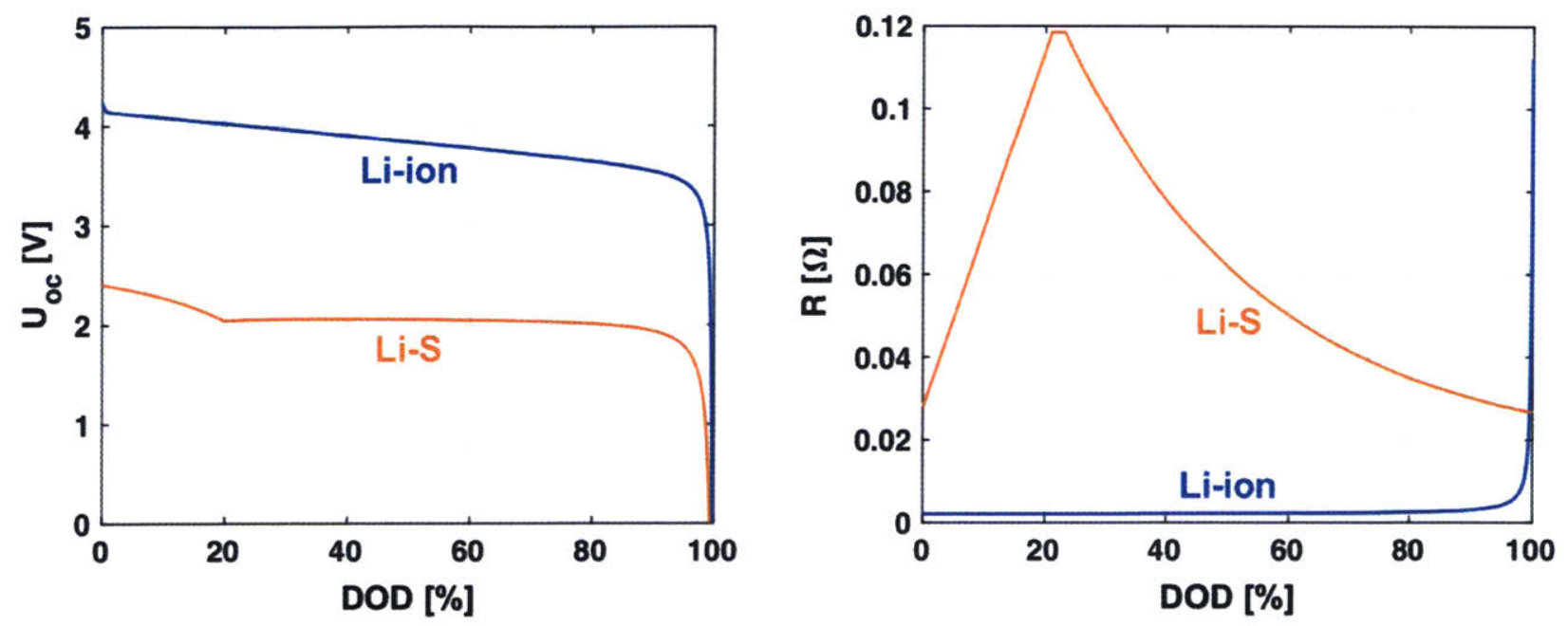

Figure 9. Li-ion and Li-S battery discharge models. The open-circuit voltage models have the same general form, but the Li-S model has a lower magnitude and is piecewise in nature. The resistance models vary substantially in magnitude and form. The Li-S model has abrupt changes due to varying polysulfide reactions occurring during distinct phases of discharge.

The functions of open-circuit voltage and resistance against SOC are termed battery discharge models $(\mathrm{BDM})$ in this work. Numerous BDM are available from literature, especially for the well-established Li-ion battery chemistry [131, 157, 158, 159]. The two primary BDM used in this work are illustrated in Figure 9. Rather than using older models from literature, these BDM were fit to battery test data. The Li-ion models were extracted from a fit of 9 recent electric vehicle tests performed by the Advanced Vehicles group at the Idaho National Laboratory [96]. The Li-ion batteries for these electric vehicles were all of the LMO or NMC type and represent state of the art transportation batteries. The Li-S models were fit to Oxis Energy Ltd. cell test data [160]. As shown by Figure 9, the shape and magnitude of the open-circuit voltage and resistance varies considerably for different battery chemistries. To account for battery technology improvement, the resistance model can be scaled an assumed technology factor. For convenience, the models used to generate Figure 9 are shown in Eq. (19) and (20) for Liion and (21) and (22) for Li-S batteries. 


$$
\begin{array}{ll}
R=0.00197+\frac{0.000110}{S O C} & \\
U_{o c}=3.55+0.100 e^{-300(1-S O C)}+0.593 S O C-0.00792 \frac{1-S O C}{S O C} \\
R=0.459-0.431 S O C & \text { SOC }>0.790 \\
R=0.119 & 0.790 \geq \text { SOC } \geq 0.768 \\
R=0.0513 e^{0.896 S O C}-0.0755 e^{1.81 S O C}+0.0509 e^{2.39 S O C} & \text { SOC }<0.768 \\
U_{o c}=2.50-\frac{1.16(1-S O C)}{2 S O C-1}-0.0888 S O C & \text { SOC }>0.801 \\
U_{o c}=2.07-0.0149 \frac{1-S O C}{S O C}-0.440 e^{-15.0(1-S O C)} & \text { SOC } \leq 0.801
\end{array}
$$

Note that other analyses use the empirical Peukert's Law to determine the change in available capacity at various discharge rates. However, this equation was developed for lead-acid batteries, and is not applicable to the lithium-based battery chemistries relevant for aircraft [161].

\subsubsection{Battery specification}

Specific energy and power, two often-mention battery parameters, are set at inputs. However, it is important to define under what conditions the energy is used and the power is drawn. Battery manufacturers state the specific energy at a specified C-rate and SOC, which represents the "nominal" condition of the battery. Typically, the chosen C-rate is $1 / 5$ or $1 / 3$ and the SOC is $50 \%$. The C-rate $[1 / \mathrm{h}]$ is defined as the current $[\mathrm{A}]$ divided by the nominal capacity [Ah] and represents the rate of discharge. Thus, a C-rate of unity indicates that the battery discharges in approximately one hour.

The specific power definition is not as clearly defined. As Larminie states, "it is a highly variable and rather anomalous quantity, since the power given out by the battery depends far more upon the load connected to it than the battery itself" [132]. Multiple reasonable power choices could be used to define this parameter, including the maximum possible output power or the available power at the nominal battery condition. However, 
these values would over and under represent the true battery power capability, respectively. In this work, the specific power is defined using the USABC peak power definition at $80 \%$ SOC [162]. The power at this point is that which decreases the battery voltage to $2 / 3$ of the open-circuit voltage, due to resistance loses.

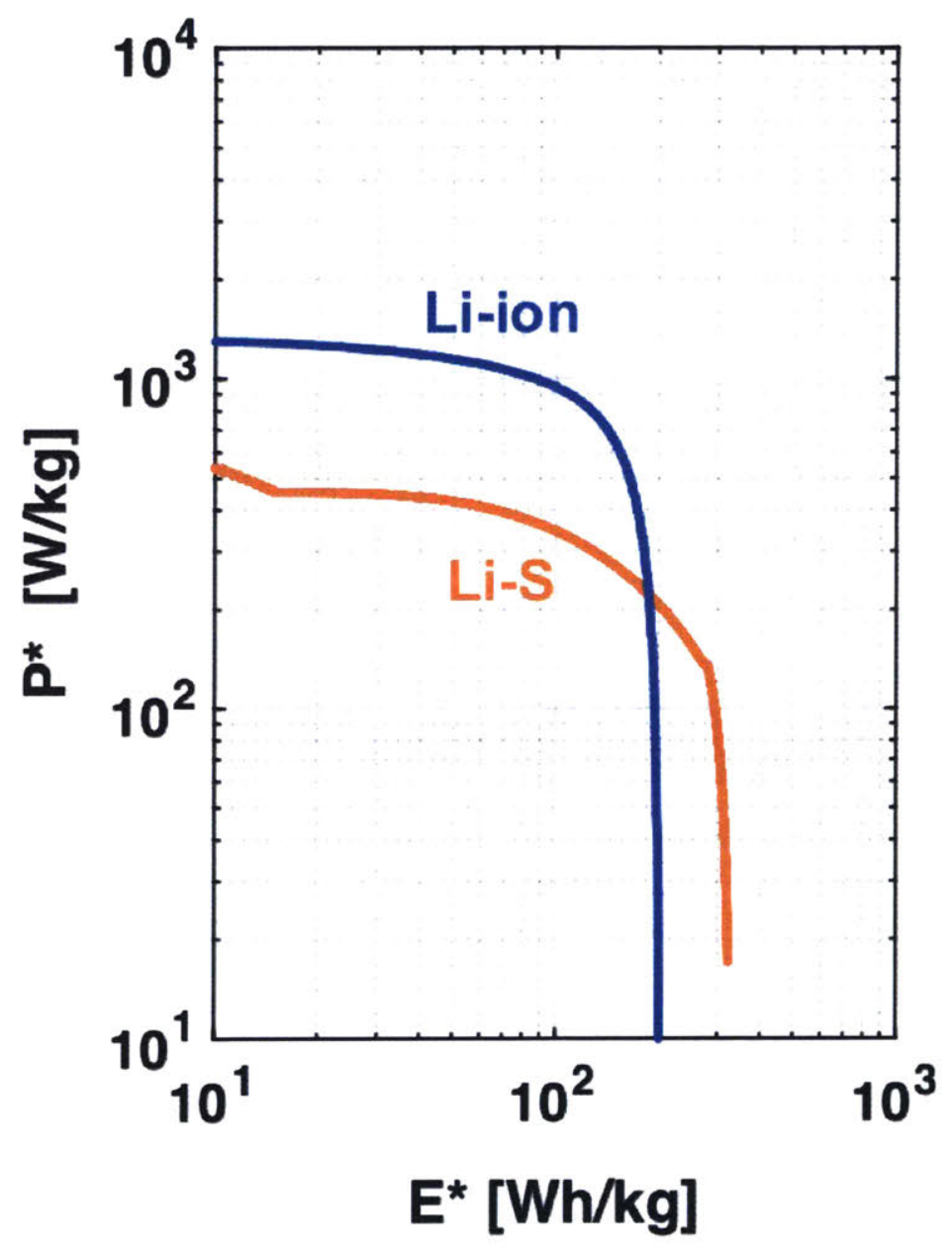

Figure 10. Example Ragone plots for Li-ion and Li-S batteries. The battery discharge models from Figure 9 are used. Representative state of the art values for specific energy and power are assumed, specifically, $200 \mathrm{Wh} / \mathrm{kg}$ and $1200 \mathrm{~W} / \mathrm{kg}$ for Li-ion and 300 $\mathrm{Wh} / \mathrm{kg}$ and $600 \mathrm{~W} / \mathrm{kg}$ for Li-S. The unusual Li-S curvature appears due to its unique open-circuit voltage and resistance models. 


\subsubsection{Ragone plots}

With the BDM, specific energy, and specific power defined, it is possible to examine the tradeoff between available energy and power capability. This is illustrated on a Ragone plot, as in Figure 10. This plot is generated by time integrating a range of powers to find the corresponding available battery energy for each power. Approximately, the horizontal position, vertical position, and curvature depend on the specific energy, specific power, and $\mathrm{BDM}$ assumptions, respectively. At higher rates of discharge, the available energy decreases due to higher resistance loses.

\subsubsection{Battery operation}

The power drawn from the battery is determined by the propulsion system requirement, which varies during the mission. The battery SOC is integrated throughout the mission from an assumed initial value of unity to a prescribed end value. The remaining battery operating parameters (e.g. voltage, current, efficiency, etc.) are determined at each mission point based on the required power and current SOC. The total mission energy requirement is calculated by integrating the battery power drawn throughout the mission.

\subsubsection{Reserve requirements}

The reserve "fuel" requirement for AEA is not well-defined, but clearly some battery capacity must remain unused in case of an aborted landing, hold, or diversion. For AEA, the reserve metric is end SOC. Previous analyses have assumed 10 to $25 \%$ SOC at the end of the mission $[132,163,164]$. In this work, the end SOC is set to $30 \%$, representing 30 minutes battery discharge at a C-rate of 0.4 and $10 \%$ SOC left unused for maintaining battery health and a longer cycle life. 


\subsubsection{Charge and swap}

One of three options for battery handling may be specified. First, the "swap" option allows the battery to be sized for each individual mission, analogous to fueling a conventional aircraft. Second, the "full charge" option indicates that the same battery, corresponding to the design mission, is always used and the SOC begins at one. Finally, the "partial charge" is similar to the "full charge" option, but the SOC begins at less than one. This option is useful if minimum charging time is desired between missions.

\subsubsection{Auxiliary batteries}

The option for an auxiliary takeoff battery is implemented in TASOPTe. It is assumed to be non-mass gaining (not metal-air) and the same for all missions (not swapped). This additional battery should have a high rate capability, allowing for an increased maximum takeoff power and decreased takeoff and balanced field length.

\subsection{Mission flight profiles}

The flight trajectory for a traditional gas turbine powered aircraft includes "cruise climb" due to aircraft weight reduction as fuel is burned. However, the weight remains constant during AEA flight, or even increases in the case of metal-air (e.g. Li-air, Al-air) batteries, which can result in "cruise decent". Variable flight trajectory is implemented in TASOPTe that can account for increasing weight throughout the mission.

\subsection{Landing gear length and weight}

In TASOPT and other studies, landing gear (LG) weight is scaled with $\mathrm{W}_{\mathrm{MTO}}$. Common values for nose and main LG weight fractions are approximately $1 \%$ and $3 \%$, respectively $[165,166,167]$. However, the underlying assumption with this method is that aircraft 
weight is largest at takeoff. While this holds true for conventional aircraft, AEA may gain mass throughout flight if metal-air batteries are used. Thus, the maximum landing weight $\left(\mathrm{W}_{\mathrm{ML}}\right)$ is better suited for AEA analysis in TASOPTe.

Furthermore, various trends for LG weights are available from aviation literature. Most of these trends present LG weights or LG weight fractions primarily as a function of $\mathrm{W}_{\text {MTO }}[168,169,170,171,172]$. However, Raymer presents LG weights as a function of WML and other parameters [173]. Modified versions of these main and nose LG weight [t] equations are

and

$$
W_{\mathrm{LG}, \text { main }}=0.0214 \mathrm{~W}_{M L}^{0.888} l_{\mathrm{LG}, \text { main }}{ }^{0.4} n_{w, \mathrm{LG}, \text { main }}{ }^{0.321} v_{\text {stall }}^{0.1}
$$

$$
W_{\text {LG, nose }}=0.0178 \mathrm{~W}_{M L}^{0.646} l_{\mathrm{LG}, \text { nose }}{ }^{0.5} n_{w, \mathrm{LG}, \text { nose }}{ }^{0.450}
$$

To arrive at Eq. (23) and (24) no kneeling (ability to vertically translate) is assumed, along with an ultimate landing load factor of 4.5, and 2 main LG shock struts. Both equations are scaled to $85 \%$ of their original values in [173] to fit modern aircraft data. The required inputs are $\mathrm{W}_{\mathrm{ML}}[\mathrm{t}]$, nose and main LG lengths $[\mathrm{m}]$, number of nose and main LG wheels [-], and stall speed [m/s]. $\mathrm{W}_{\mathrm{ML}}$ and stall speed are determined during the aircraft sizing process. However, the number of main LG wheels is dependent on $\mathrm{W}_{\mathrm{ML}}$ and the nose and main LG lengths are dependent on the aircraft and propulsor dimensions.

A survey of over 50 aircraft with $\mathrm{W}_{\mathrm{ML}}$ between 40 and $160 \mathrm{t}$ indicated that below $79 \mathrm{t}$ current aircraft use two dual-wheels for the main LG, such as on the Airbus A320 and Boeing 737. Above this value, two four-wheel trucks (bogies) are typical, such as on the Airbus A310 and Boeing 767. Thus, below and above $79 \mathrm{t}$ it is assumed that 4 and 8 main LG wheels are required, respectively. Nearly all current aircraft with WML of 40-160 t use a tricycle arrangement with dual nose wheels. 
As noted by Seitz, rather than constraining the propulsor size, it is more appropriate to size the LG appropriately [174]. Two requirements set the LG length, including maintaining a minimum ground clearance and avoiding propulsor damage in the case of a nose LG collapse. The first of these is illustrated in Figure 11. Per FAA AC150, the minimum ground clearance $\left(\Delta z_{\text {clear }}\right)$ is $0.4572 \mathrm{~m}$ (18 in) [175]. The wing vertical and horizontal placement $\left(\Delta z_{\text {wing }}\right.$ and $\left.y_{o}\right)$, main LG and propulsor spanwise placement $\left(y_{\mathrm{LG}, \text { main }}\right.$ and $\left.y_{\mathrm{eng}, \text { in }}\right)$, nacelle-wing offset $\left(\Delta_{z_{\text {nace }}}\right)$, and wing dihedral $(\Gamma)$ are specified values. Thus, the main LG length ( $\left.l_{\mathrm{LG}, \text { main }}\right)$ is set during the sizing process based on the nacelle diameter $\left(d_{\text {nace }}\right)$.

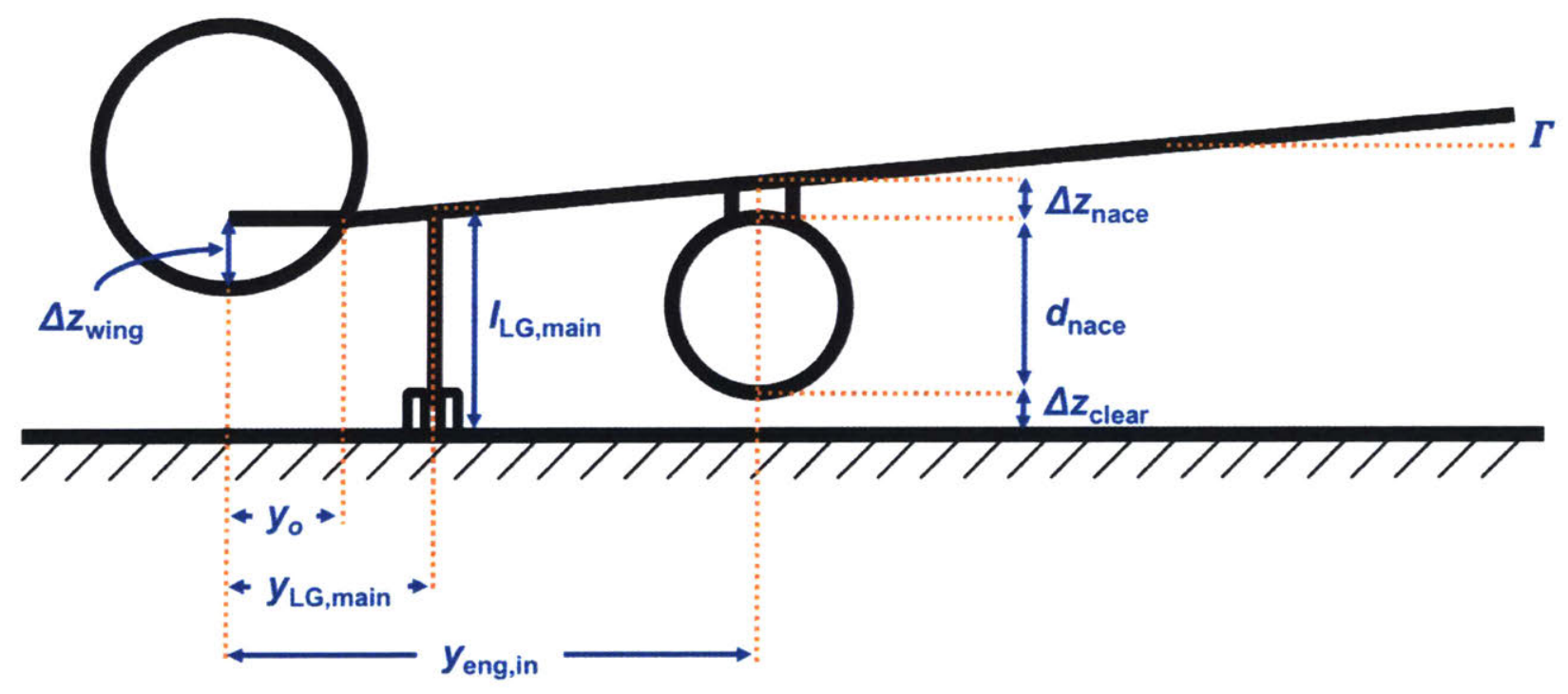

Figure 11. Main landing gear length parameters. Landing gear length is partially set by the minimum nacelle ground clearance $\left(\Delta z_{\text {clear }}\right)$. All other parameters shown are specified, except the nacelle diameter $\left(d_{\text {nace }}\right)$, which is determined during aircraft sizing. Modified from [176]. 


\subsection{Vertical tail sizing}

AEA may use DEP, thus using more than two electrically-powered propulsors. One of the often-mentioned benefits of DEP is the possibility for a smaller vertical tail (VT). In TASOPTe the VT can be sized via a specified volume coefficient or through maintaining one engine inoperative (OEI) yaw trim. The VT volume coefficient is

$$
V_{v}=\frac{s_{v} l_{v}}{s b},
$$

where $S_{V}, I_{V}, S$, and $b$ represent the VT planform area, wing to VT aerodynamic center distance, wing planform area, and wing span, respectively. Various values can be assumed for $\mathrm{V}_{\mathrm{v}}$, such as 0.074 [171], 0.09 [173], and 0.10 [168]. $\mathrm{V}_{\mathrm{v}}$ is approximately 0.085 and 0.094 for the geometry of an A320 and B737, respectively.

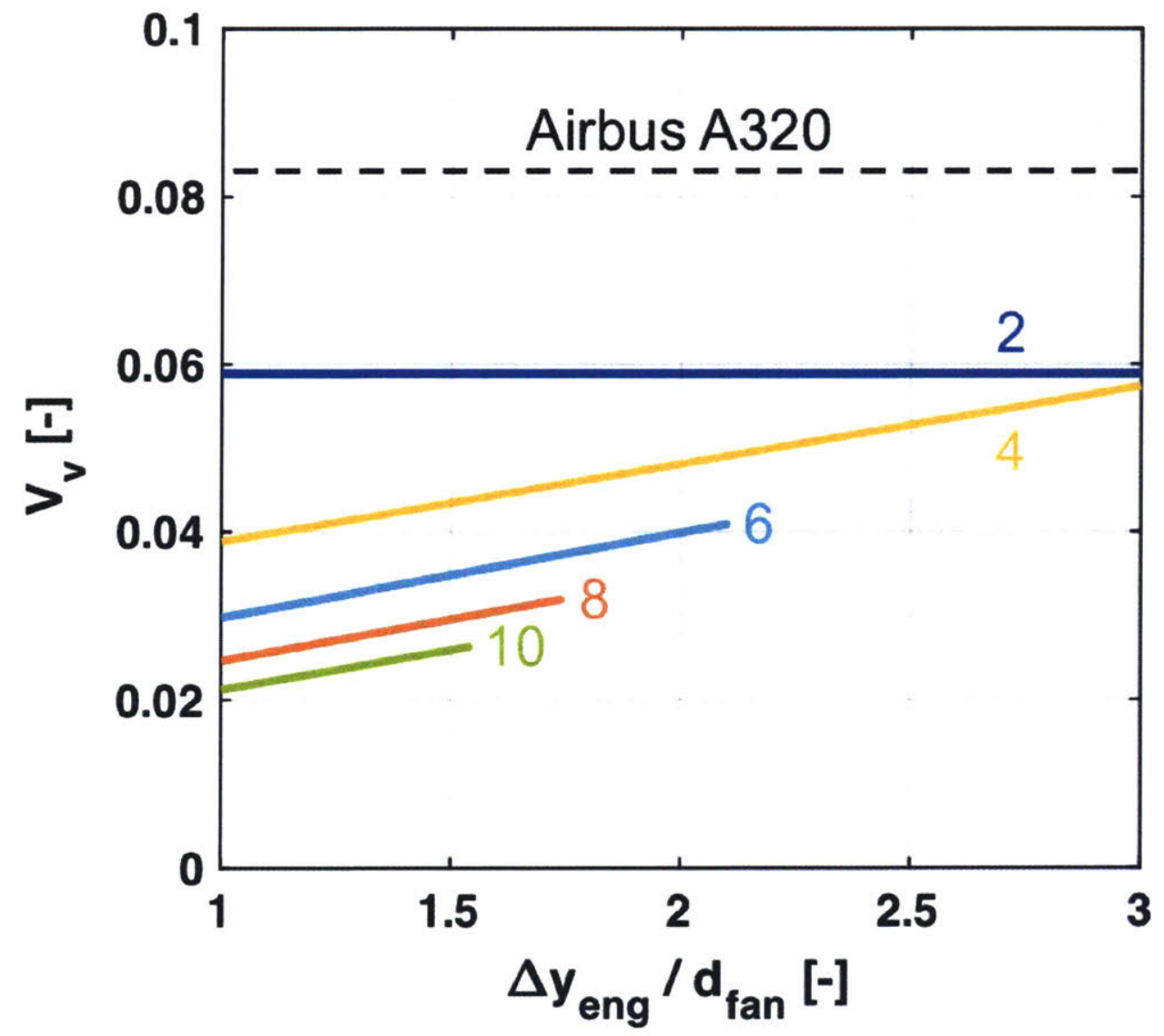

Figure 12. VT volume coefficient with varying propulsor spacing and count. The propulsor spacing is measured from center to center of the propulsors. Due to a finite wing length, the propulsor spacing is limited with more than four propulsors. 
To analyze the potential VT sizing benefits of DEP, an effective $\mathrm{V}_{\mathrm{v}}$ is calculated for the OEI yaw trim VT sizing option as well. Based on preliminary AEA sizing results, this effective $V_{v}$ is plotted in Figure 12 as a function of the propulsor spacing and propulsor count. An assumed innermost propulsor placement, that of an A320, is used here. As expected, benefits in VT sizing are seen with a smaller propulsor spacing and an increased propulsor count. However, the calculated $A 320 \mathrm{~V}_{\mathrm{v}}$ is used in this work.

The number of propulsors is varied in this work, as discussed later. Preliminary results indicated that the propulsor spacing has a minimal effect on aircraft performance. To allow for sufficiently clean inlet airflow and reduce the risk of multiple propulsor failure, the dimensionless propulsor spacing is set to 2.0. The innermost propulsor placement is an optional optimization variable, but many other considerations drive this placement. Increasing the propulsor distance from the fuselage has the following qualitative advantages $(+)$ and disadvantages $(-)$ :

+ Less risk of fuselage damage due to a blade or disk failure

+ Less cabin noise

+ Less interference drag from fuselage interaction

+ Increased wing bending moment relief in air

+ More ground clearance and potentially shorter landing gear

- Increased wing bending moment on ground

- Possibly increased wing flutter

- Propulsor mounting difficulties due to a shorter outboard chord

- Increased electrical system weight due to longer cabling

- Increased OEI yawing moment

- Center of gravity moved aft 


\section{Chapter 4}

\section{Aircraft configuration, mission, and technology assumptions}

The overall aim is to devise all-electric aircraft designs as a function of key technology assumptions (e.g. batteries). Design characteristics and performance are then compared with conventional aircraft designed with the same technology assumptions where relevant.

\subsection{Top-level requirements}

The specific aircraft under study is based on the geometry of an Airbus A320neo. Basic sizing parameters (e.g. fuselage length, wing sweep, etc.) were acquired from publically available aircraft data or appropriate estimates [177]. An A320 was chosen as the design basis in order to properly isolate and observe the benefits of electric propulsion applied to a modern, widely-used commercial aircraft configuration.

An A320 seats a maximum of $190 \mathrm{PAX}$, with typically $164 \mathrm{PAX}$ in a 1-class configuration and $150 \mathrm{PAX}$ in a 2-class configuration [177]. Considering the A320 PAX counts and previous studies at MIT involving the D8 "double bubble" concept, the design payload is 180 PAX assuming $97.5 \mathrm{~kg} / \mathrm{PAX}$ [178]. The contingency reserve charge (end SOC) is set to $30 \%$. The balanced field length is limited to $2438.4 \mathrm{~m}(8000 \mathrm{ft})$ at ISA sea level, which is a typical runway length for wide-body aircraft. The wing span is constrained to $35.97 \mathrm{~m}$ (118.0 ft), which conforms with the FAA Group III and ICAO Code C airport gate limitations [179].

An A320 is designed for Mach 0.78 cruise at an altitude of approximately $11 \mathrm{~km}$. However, for very short missions (e.g. 200 nmi), optimized AEA fly at lower "cruise" altitudes (e.g. $8 \mathrm{~km}$ ). Maintaining Mach 0.78 results in excessive fuselage drag and poor aircraft performance, causing convergence issues in some cases. Considering this, the design aircraft speed is maintained at $448 \mathrm{kt}$, corresponding to the original A320 design speed at M0.78 and $11 \mathrm{~km}$. 


\subsection{Electrical and propulsion system components}

As previously discussed, a HTS electrical and propulsion system is used for weight and efficiency benefits. Future gearboxes (gear ratio of 4.33:1) and HTS motors and are expected to have high efficiencies of $98.0 \%$ and $99.5 \%$, respectively [151, 156]. Table 5 . lists the weight and efficiency assumptions for the PMAD.

Table 5. PMAD weights and efficiencies.

\begin{tabular}{|c|c|c|c|}
\hline Component & Specific Power [kW/kg] & Efficiency [\%] & References \\
\hline Solid State Power Controller & 44 & 99.7 & {$[22,180,127]$} \\
\hline DC/DC Converter & 26 & 99.5 & {$[126,180,181,182]$} \\
\hline Transmission Cable & $7[\mathrm{~kg} / \mathrm{m}]$ & 99.9 & {$[181,183,184]$} \\
\hline DC/AC Inverter (Controller) & 26 & 99.5 & {$[126,180,181]$} \\
\hline
\end{tabular}

\section{3. $\quad$ Battery parameters}

Two BDM, shown in Figure 9, are available for analysis. The Li-ion BDM model is used for all AEA designs in this work, and the Li-S BDM is also used for a subset of cases to evaluate the impact of the discharge profile on battery and aircraft performance. However, the magnitude of the Li-S resistance model is scaled to match the average $\mathrm{Li}$-ion resistance model between 10 and 100\% SOC, representing an assumed technology improvement.

The full charge is option used, meaning excessive battery capacity is available for shorter missions. Using this method allows for the necessary takeoff battery power. In practice, the same size battery could be swapped for quicker turnaround.

Energy density $[\mathrm{Wh} / \mathrm{L}]$ is not directly specified, but rather an effective battery density of $2000 \mathrm{~kg} / \mathrm{m}^{3}$ is used for all cases. The battery volume for all runs is near or below the wing box volume limit. Due to the high uncertainty in this parameter and available cargo hold space, volume considerations do not constrain the aircraft design and are not discussed further. Battery pack specific energy and power are swept in this work, as discussed later. 


\subsection{Structural materials and aerodynamics}

Though the primary objective of this work is to evaluate propulsion benefits, it is reasonable to assume advanced structural materials and aerodynamics for both future conventional aircraft and AEA. Recent aircraft designs, such as the Airbus A350, Boeing 787, Bombardier CS300, and Irkut MC-2, use polymer composites rather than aluminum for the primary structure $[171,185,186,187]$. Carbon fiber reinforced polymer (CFRP) is assumed, as it has low density and high strength [188]. Laminar flow wings are an active area of research, but require low magnitudes of wing sweep and are not implemented in this work $[73,171,189,190]$. However, a $10 \%$ maximum wing lift coefficient improvement is assumed. A VAN with a $15 \%$ area increase during takeoff and initial climb is included for conventional aircraft in TASOPT, while the takeoff opening area is optimized for AEA in TASOPTe. 


\section{Chapter 5}

\section{Parametric aircraft sizing and performance}

A set of AEA are generated and compared against baseline conventional aircraft. Parameter sweeps are utilized to see the impact of uncertain design parameters on aircraft performance.

\subsection{Optimization metric}

All aircraft in this work are optimized across a weighted set of design and/or off-design missions. The objective function target for minimization in previous TASOPT-based studies was the payload fuel energy intensity (PFEI) metric [123, 191, 192]. In this work, the optimization target is a similar, but dimensionless, energy/productivity $(\mathrm{E} / \mathrm{P})$ metric. This metric calculated as

$$
E / P=\frac{E}{W_{\text {pay }} R g},
$$

where the amount of energy required for a given mission $(E)$ is non-dimensionalized by the mission productivity, which is represented by the product of payload ( $\left.W_{\text {pay }}\right)$, range $(R)$, and the acceleration due to gravity $(g)$. For conventional aircraft fuel energy based on the lower heating value of jet fuel is used, while for AEA battery energy is used.

\subsection{Baseline aircraft}

For comparison purposes, TASOPT was used to generate optimized conventional aircraft results. First, an aircraft based on the original A320 design, A320neo-OPT, was created. A representative design range of $2600 \mathrm{nmi}$ was taken from an A320 payload-range diagram at the design payload of 180 PAX, and this aircraft embodies a current narrow-body aircraft [177]. 
However, the baseline aircraft for environmental performance comparisons with AEA use future gas turbine propulsion technology assumptions, including component polytropic efficiencies greater than $90 \%$ and lower weight engine model. The same structural and aerodynamic improvements applied to AEA are also applied here. The overall configuration is still an A320 with 180 PAX, but the design range is varied to agree with that of AEA under different technology and operation assumptions, which are discussed in the next section. An additional conventional aircraft, A320adv-OPT, that uses future technology assumptions, but the original design range of $2600 \mathrm{nmi}$, is assessed. All conventional aircraft were globally optimized with the optimization variables listed in Table 6 and had a reserve fuel requirement of $20 \%$.

Table 6. Conventional and all-electric aircraft optimization variables.

\begin{tabular}{|c|c|c|c|}
\hline Variable & Description & Conventional & All-Electric \\
\hline $\mathrm{C}_{\mathrm{L}, \mathrm{CR}}$ & cruise lift coefficient & $\bullet$ & $\bullet$ \\
\hline $\mathrm{AR}$ & aspect ratio & $\bullet$ & $\bullet$ \\
\hline$\Lambda$ & wing sweep angle & $\bullet$ & $\bullet$ \\
\hline$(\mathrm{t} / \mathrm{c})_{\mathbf{o}}$ & root airfoil thickness ratio & $\bullet$ & $\bullet$ \\
\hline$(\mathrm{t} / \mathrm{c})_{\mathbf{s}}$ & panel-break and tip airfoil thickness ratio & $\bullet$ & $\bullet$ \\
\hline$\lambda_{\mathbf{s}}$ & outer-panel taper ratio & $\bullet$ & $\bullet$ \\
\hline $\mathrm{r}_{\mathrm{cl}, \mathrm{s}}$ & local/root ce ratio at panel-break & $\bullet$ & $\bullet$ \\
\hline $\mathrm{r}_{\mathrm{cl}, \mathrm{t}}$ & local/root ce ratio at tip & $\bullet$ & $\bullet$ \\
\hline $\mathrm{FPR}_{\mathrm{D}}$ & design fan pressure ratio & $\bullet$ & $\bullet$ \\
\hline $\mathrm{h}_{\mathrm{CR}}$ & start-of-cruise altitude & $\bullet$ & $\bullet$ \\
\hline $\mathrm{BPR}_{\mathrm{D}}$ & design bypass ratio & $\bullet$ & \\
\hline $\mathrm{T}_{\mathrm{t} 4, \mathrm{TO}}$ & turbine inlet temperature at takeoff & $\bullet$ & \\
\hline $\mathrm{Tt}_{4, \mathrm{CR}}$ & turbine inlet temperature in cruise & $\bullet$ & \\
\hline $\mathrm{f}_{\mathrm{Pb}, \mathrm{TO}}$ & takeoff battery peak power fraction & & $\bullet$ \\
\hline
\end{tabular}




\subsection{Parametric values}

The aircraft configuration and technology assumptions previously discussed are independent design parameters that have been set to specified quantities. However, additional design parameters have not been selected, as their influence on the aircraft performance is largely unknown a priori. Thus, it is useful to determine the optimized aircraft sensitivity to these additional parameters through parameter sweeps [121].

Contemporary narrow-body aircraft use two ultrahigh bypass ratio fans. However, AEA may use more than two propulsors, as electric motor efficiency is approximately scale invariant. Preliminary results indicated decreased performance beyond six propulsors, so the propulsor count is evaluated between two and ten, inclusive.

Battery specific energy, at the pack level, is swept between 400 and $2000 \mathrm{Wh} / \mathrm{kg}$ in $400 \mathrm{Wh} / \mathrm{kg}$ increments. $400 \mathrm{Wh} / \mathrm{kg}$ may be achievable with Li-ion or Li-metal batteries, while $800 \mathrm{Wh} / \mathrm{kg}$ is representative of a mature Li-S battery and is used for the nominal design in this work. Values of 1200,1600 , and $2000 \mathrm{Wh} / \mathrm{kg}$ are unlikely based on current forecasts. However, an unforeseen development in battery research may emerge, such as the closed-system Li-air battery [193].

Current $200 \mathrm{Wh} / \mathrm{kg} \mathrm{Li}$-ion batteries are capable of achieving specific powers near $1200 \mathrm{~W} / \mathrm{kg}$ [96]. Li-S manufacturer projections indicate that specific power will increase with specific energy in future batteries [120]. However, it is unlikely that specific power will scale linearly with specific energy, as power is limited by surface area, while energy is more closely related to volume. In this work, the specific power improvement scales with the square root of the specific energy improvement. For example, $800 \mathrm{Wh} / \mathrm{kg}$ batteries (factor of four improvement) are assumed to be capable of $2400 \mathrm{~W} / \mathrm{kg}$ (factor of two improvement).

Depending primarily on the battery specific energy assumption, the AEA design range is varied in $100 \mathrm{nmi}$ increments, starting with $200 \mathrm{nmi}$ and ending with nonconvergence. Shown in Figure 13 are U.S. and global stage lengths for both A320 and 
narrow-body aircraft, sourced from 2015 OAG data [194]. An AEA capable of flying 1000 nmi could replace approximately $70 \%$ of missions that are currently completed with similar size conventional aircraft.

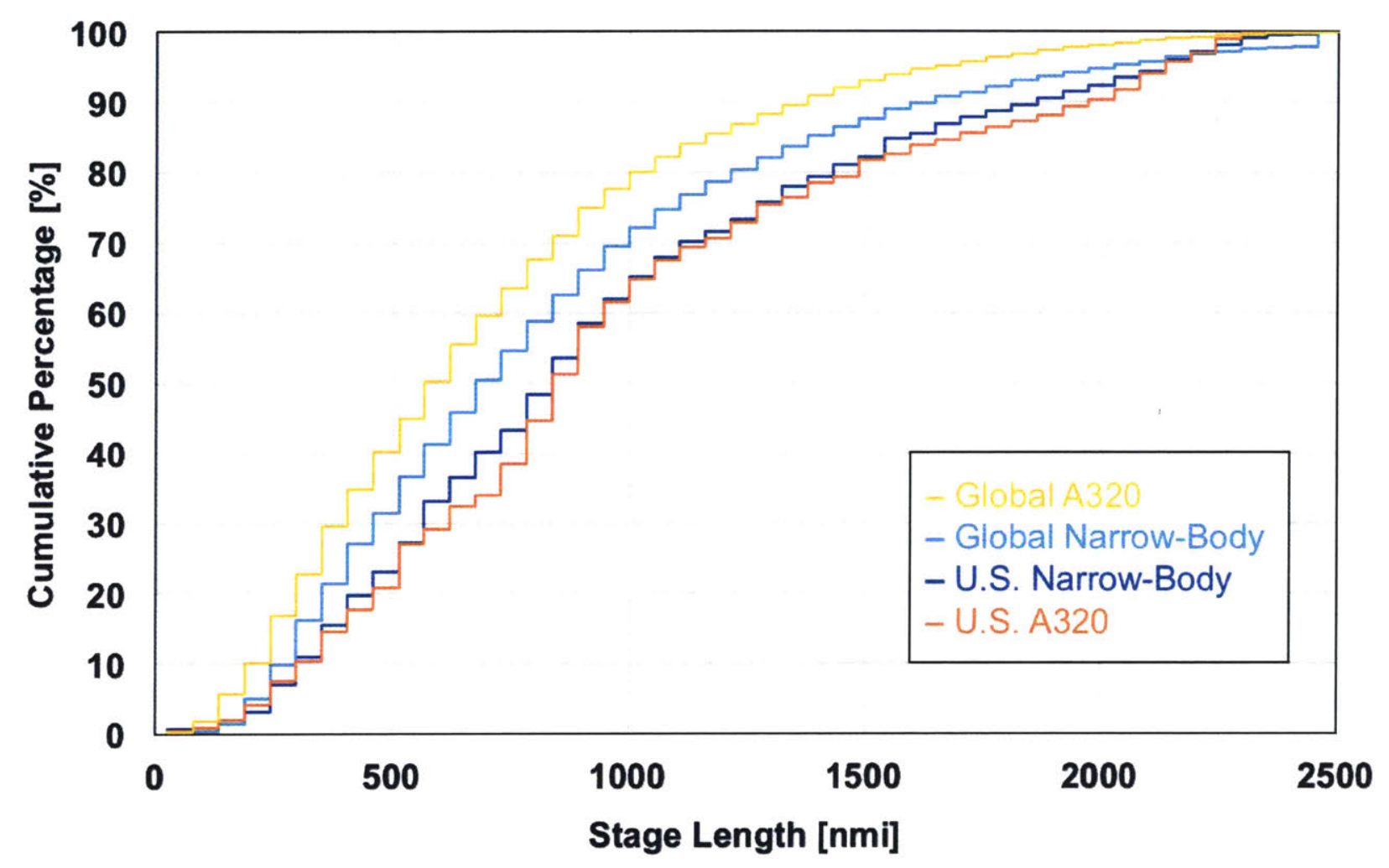

Figure 13. U.S. and global stage lengths for A320 and narrow-body aircraft. Data compiled from [194].

The aircraft is sized for the (varying) design range with 180 PAX. However, offdesign missions are used for optimization, which determine the fleet $\mathrm{E} / \mathrm{P}$ and the final, optimized design. These off-design missions have load factors of $83.3 \%$ (150 PAX), a slight increase from current Airbus and Boeing load factors of near $81 \%[3,4]$. The region of Figure 13 below $1000 \mathrm{nmi}$ is approximately linear. Considering this, each aircraft has 2 equally-weighted off-design missions at the design range and midway between the design range and $100 \mathrm{nmi}$. Missions of $300 \mathrm{nmi}$ or less use only 1 off-design mission at the design range. All AEA were globally optimized with the optimization variables listed in Table 6 . 


\subsection{Nominal design characteristics}

Through parameter sweeps of specific energy, design range, and propulsor count, 205 different AEA were designed and optimized in TASOPTe. Exemplary results with a battery pack specific energy of $800 \mathrm{Wh} / \mathrm{kg}$ are presented here to illustrate key AEA design characteristics.

Figures 14, 15, and 16 illustrate the impact of the design mission range and number of propulsors on $\mathrm{W}_{\mathrm{MTO}}$, mission energy, and $\mathrm{E} / \mathrm{P}$, respectively. Weight and mission energy penalties are increasingly severe as the design range increases, and beyond $600 \mathrm{nmi}$ TASOPTe is unable to size an aircraft. E/P for an AEA with $800 \mathrm{Wh} / \mathrm{kg}$ batteries is lowest with a $300 \mathrm{nmi}$ design range.

The best performing aircraft, in respect to mission energy and $\mathrm{E} / \mathrm{P}$, use four propulsors for each design range. A comparison of this design with the two and ten propulsor designs is shown in Figure 17. As the propulsors count increases, the individual propulsor inlet areas decrease, but the total inlet area remains approximately constant. Additional propulsors move the aircraft center of gravity aft, which in turn moves the wing aft to maintain pitch trim. This results in an increasing horizontal tail area, as the wing to horizontal tail distance (moment arm) is reduced. The key driver in the weight and performance discrepancy with propulsor count variation stems from the propulsion and electrical system assumptions. HTS motor specific power increases with maximum power, and more propulsors result in longer cable lengths. However, the two propulsor case leads to increased landing gear length and weight. Thus, the four propulsor design is a tradeoff between electrical and propulsion components and landing gear weight. 


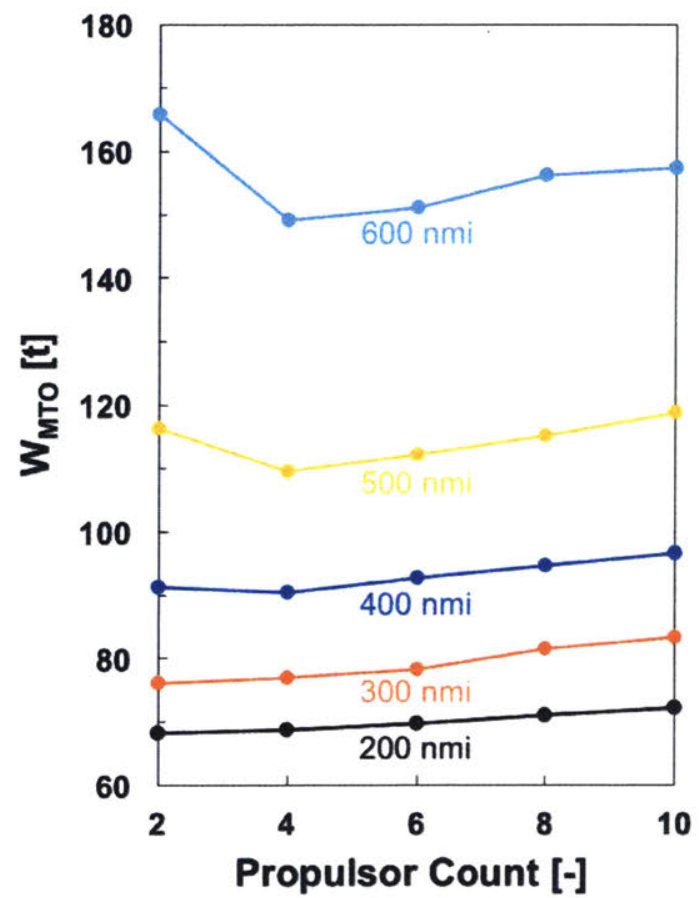

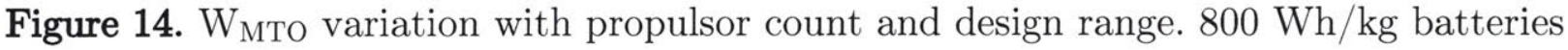
are used here, but similar trends appear for other specific energies.

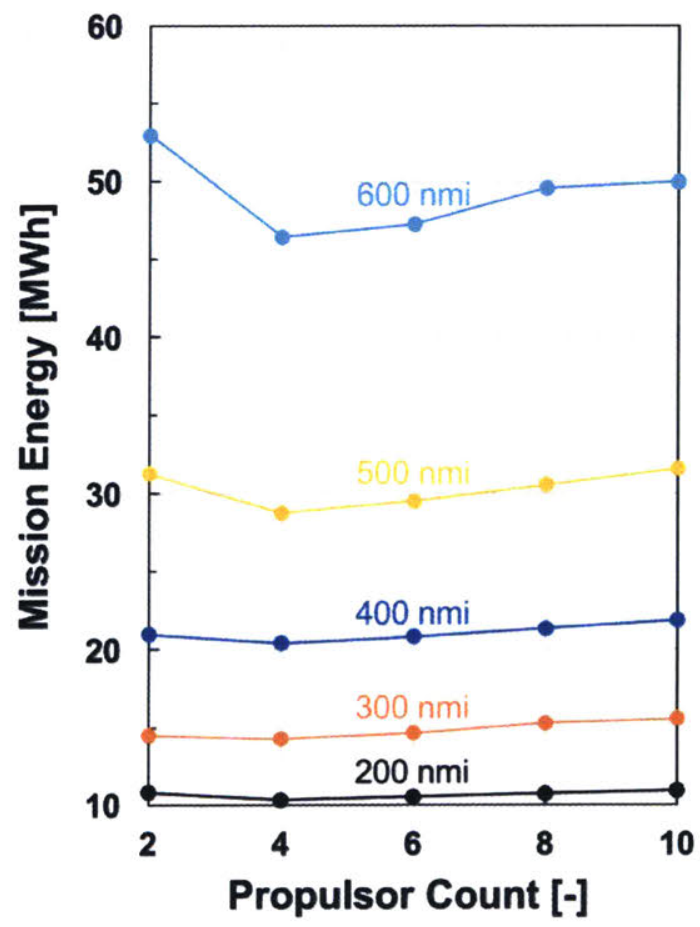

Figure 15. Mission energy variation with propulsor count and design range. $800 \mathrm{Wh} / \mathrm{kg}$ batteries are used here, but similar trends appear for other specific energies. 


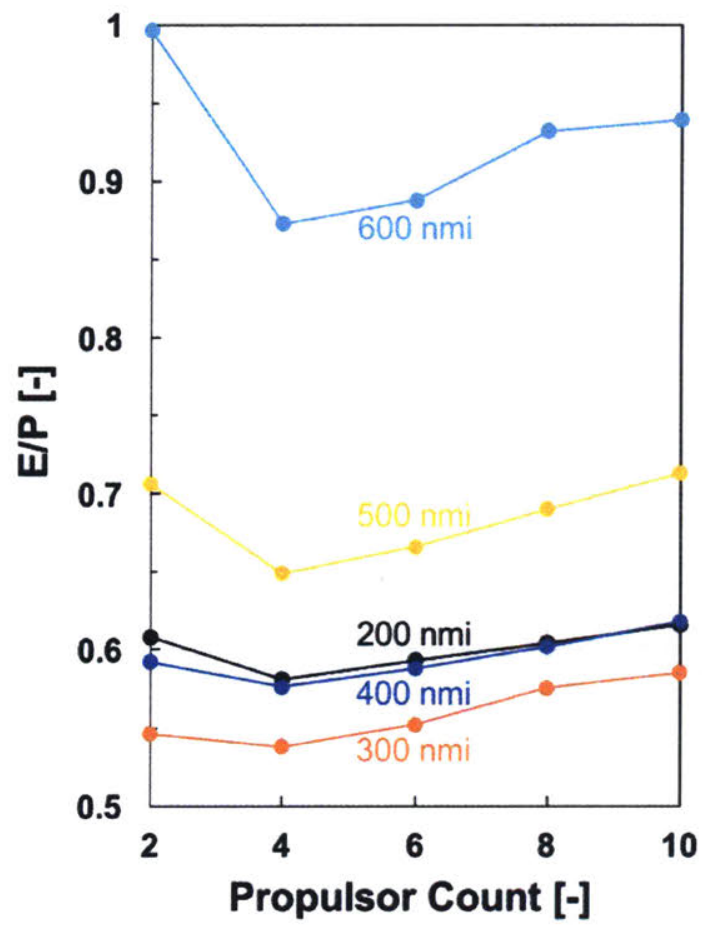

Figure 16. E/P variation with propulsor count and design range. $800 \mathrm{Wh} / \mathrm{kg}$ batteries are used here, but similar trends appear for other specific energies.

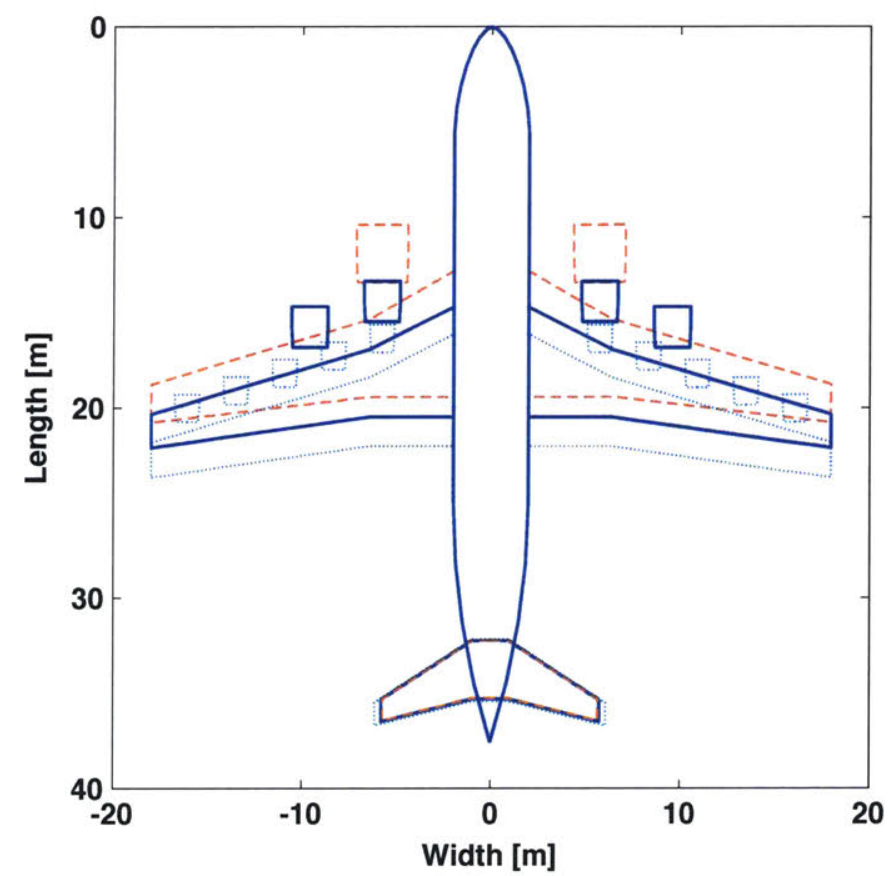

Figure 17. Aircraft planform view wireframe overlays with 2, 4, and 10 propulsors. This aircraft used $800 \mathrm{Wh} / \mathrm{kg}$ batteries and had a design range of $500 \mathrm{nmi}$. Note that the wing span was not selected, but rather optimized to the constraint limit of $36 \mathrm{~m}$. 


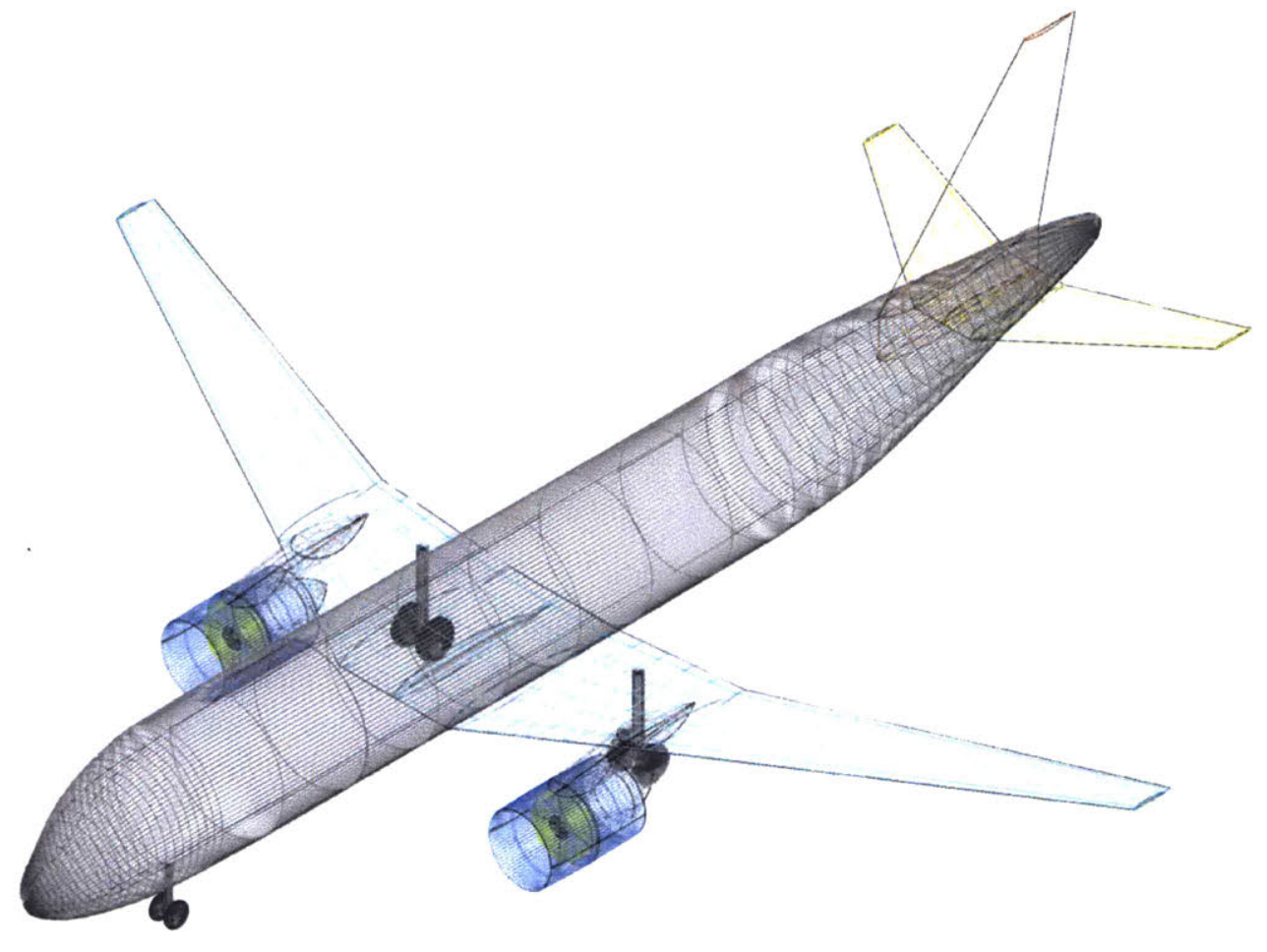

Figure 18. OpenVSP A320neo aircraft wireframe model. Winglets are not shown.

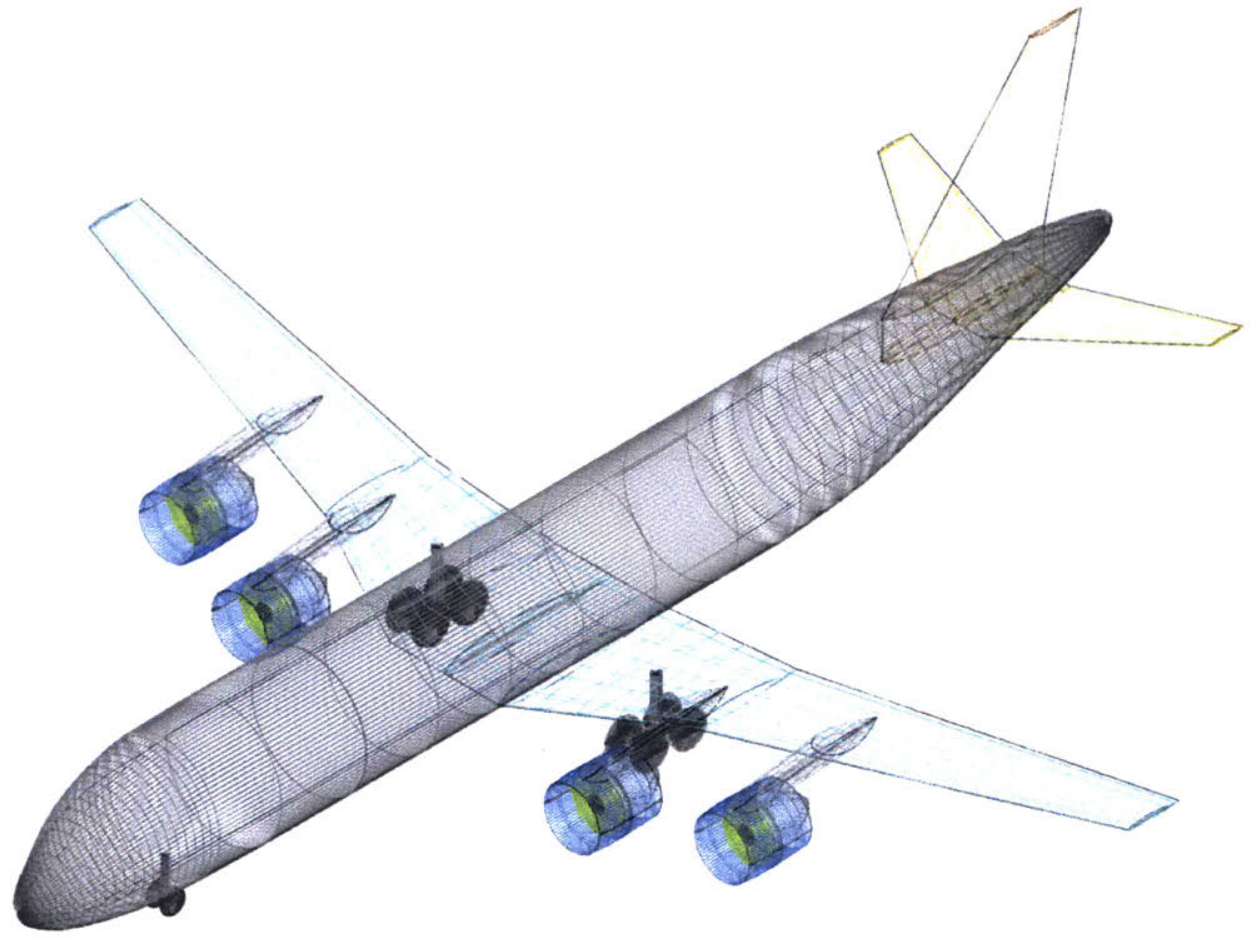

Figure 19. OpenVSP AEA-800 aircraft wireframe model. The fuselage size and shape are based on an Airbus A320neo, as shown in Figure 18. The best aircraft performance with $800 \mathrm{Wh} / \mathrm{kg}$ batteries and a $500 \mathrm{nmi}$ design range occurred with the 4 propulsors. 
Though AEA using $800 \mathrm{Wh} / \mathrm{kg}$ batteries are capable of a $600 \mathrm{nmi}$ design range, the weight and performance penalties render this design unreasonable. The $600 \mathrm{nmi}$ design has a $\mathrm{W}_{\text {MTO }}$ of $149.1 \mathrm{t}$, approximately twice that of an A320neo, which is illustrated in Figure 18. Rather, a design range of $500 \mathrm{nmi}$ is used for further examination, which has a $39.6 \mathrm{t}$ lower $\mathrm{W}_{\text {MTO }}$ for only a $100 \mathrm{nmi}$ decrease in range. As shown previously, the best performance for this design range occurs with four propulsors. This result comes from a tradeoff between a variety of considerations, including fan efficiency, propulsor drag, landing gear length and weight, wing shape, tail area, and electrical and propulsion system component weights. An OpenVSP model of this design, AEA-800, is shown in Figure 19. The wing is $34 \%$ less swept, but has approximately the same span $(36 \mathrm{~m})$, aspect ratio (10.3), and surface area $\left(125.6 \mathrm{~m}^{2}\right)$. The horizontal tail is $14 \%$ smaller, the vertical tail is $13 \%$ larger, and the total propulsor inlet area is $39 \%$ larger. Also, the landing gear is shorter, but heavier due to a larger $\mathrm{W}_{\mathrm{MTO}}$. As discussed previously, aircraft with $\mathrm{W}_{\mathrm{MTO}}$ greater than approximately $79 \mathrm{t}$ typically use two four-wheel trucks rather than two dualwheels for the main LG.

Shown in Table 7 is comparison of the nominal $800 \mathrm{Wh} / \mathrm{kg}$ AEA design with optimized A320 aircraft using conventional propulsion. An optimized A320neo configuration designed for the original design mission, A320neo-OPT, results in a design similar to an A320neo, as expected. Using advanced technology assumptions with the same overall configuration in the A320adv-OPT results in a $23 \%$ smaller $\mathrm{W}_{\mathrm{MTO}}$ and $41 \%$ lower energy requirement for the same design mission. Taking this design and lowering the design range to $500 \mathrm{nmi}$ results in the A320ref-800, which has $16 \%$ smaller $\mathrm{W}_{\text {MTO }}$ and $19 \%$ smaller wing area. The A320ref- 800 is the reference aircraft for comparisons with the AEA-800, an AEA designed with $800 \mathrm{Wh} / \mathrm{kg}$ batteries. The AEA-800 has a $161 \%$ larger $\mathrm{W}_{\mathrm{MTO}}$ and $65 \%$ larger wing area than the A320ref-800, a conventional aircraft with the same design mission of $500 \mathrm{nmi}$. 
Table 7. Optimized A320 and AEA key parameters.

\begin{tabular}{|c|c|c|c|c|c|}
\hline Parameter & Units & A320neo-OPT & A320adv-OPT & A320ref-800 & AEA-800 \\
\hline Design PAX & - & 180 & 180 & 180 & 180 \\
\hline Design Range & $\mathrm{nmi}$ & 2600 & 2600 & 500 & 500 \\
\hline $\mathrm{W}_{\mathrm{MTO}}$ & $\mathrm{t}$ & 65.3 & 50.0 & 42.0 & 109.5 \\
\hline Mission Energy & MWh & 142.1 & 84.3 & 18.2 & 28.8 \\
\hline Mission E/P & - & 0.617 & 0.366 & 0.412 & 0.649 \\
\hline Wing Span & $\mathrm{m}$ & 36.0 & 36.0 & 35.9 & 36.0 \\
\hline Wing Area & $\mathrm{m}^{2}$ & 109.5 & 94.1 & 76.3 & 125.6 \\
\hline Wing Sweep & $\operatorname{deg}$ & 23.7 & 23.1 & 25.2 & 13.9 \\
\hline Wing Aspect Ratio & - & 11.8 & 13.8 & 16.9 & 10.3 \\
\hline Wing Taper Ratio & - & 0.146 & 0.151 & 0.150 & 0.304 \\
\hline Cruise Altitude & $\mathrm{m}$ & 10891 & 11986 & 10936 & 7829 \\
\hline Cruise Speed & $\mathrm{kt}$ & 449 & 447 & 448 & 448 \\
\hline Cruise Mach & - & 0.780 & 0.780 & 0.778 & 0.747 \\
\hline Cruise L/D & - & 18.3 & 18.2 & 16.5 & 18.6 \\
\hline Cruise $\mathrm{C}_{\mathrm{L}}$ & - & 0.582 & 0.617 & 0.548 & 0.605 \\
\hline Propulsor Count & - & 2 & 2 & 2 & 4 \\
\hline Design BPR & - & 5.7 & 17.5 & 21.7 & - \\
\hline Design FPR & - & 1.69 & 1.50 & 1.41 & 1.25 \\
\hline Fan Diameter & $\mathrm{m}$ & 1.47 & 1.69 & 1.62 & 1.72 \\
\hline Propulsor Max. Thrust & $\mathrm{kN}$ & 73.6 & 73.9 & 58.1 & 61.6 \\
\hline
\end{tabular}

The cruise altitude for the AEA-800 is over $3000 \mathrm{~m}(28 \%)$ less than any of the conventional aircraft in Table 7, which is illustrated in Figure 20. Conventional aircraft also climb during cruise, while AEA with constant mass batteries remain at the same cruise altitude. Due to the additional aircraft weight and consequential lift required, AEA climb and descend at approximately $11 \%$ higher speeds than conventional aircraft performing the same mission. The descent angle for the missions in Figure 20 is specified at $3^{\circ}$, but the climb angle for AEA is $0.86^{\circ}$ less steep on average than the conventional aircraft counterpart. Due to a combination of these flight trajectory features, the total mission time is $4 \%$ less for the AEA-800 compared to the A320ref-800. 


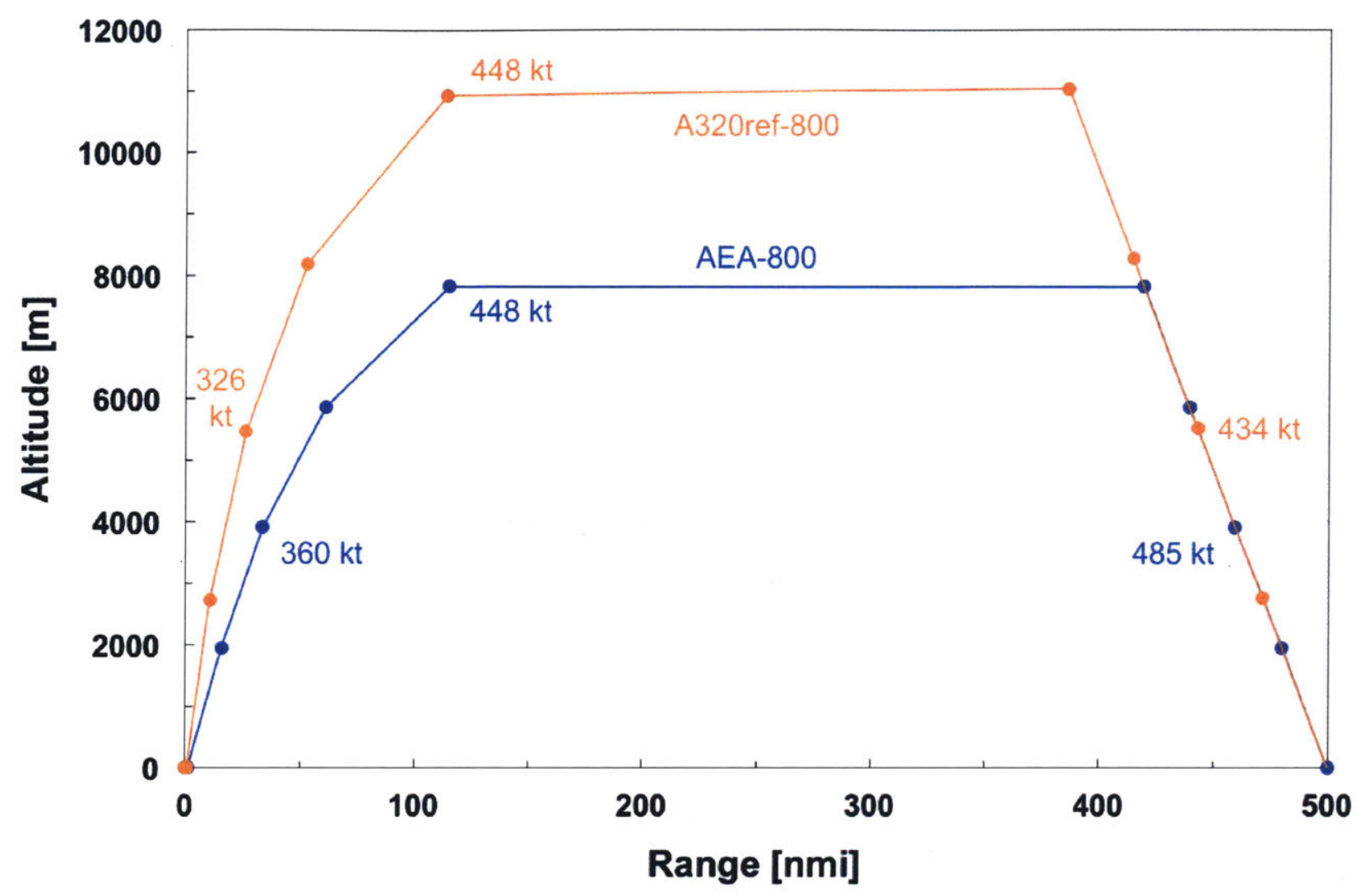

Figure 20. Conventional aircraft and AEA mission profiles.

Shown in Figure 21 is a weight distribution for the optimized A320 and AEA-800 aircraft previously discussed. Due to the advanced technology assumptions, the fuselage, wing, and tails are over 15\%,50\%, and $60 \%$ lighter, respectively, on the A30adv-OPT and A320ref-800 in comparison to the A320neo-OPT. These benefits are also observed in the AEA-800. However, the electrical and propulsion system for the AEA-800 is a factor of four larger than the A320-adv-800. This design also requires massive batteries (48.7 t), which weigh more than the entire conventional aircraft counterpart, the A320ref-800 (42.0 t). The battery fraction in the AEA-800 (44\%) is significantly greater than the fuel fraction in any of the optimized A320 designs (5-22\%), as shown in Figure 22. 


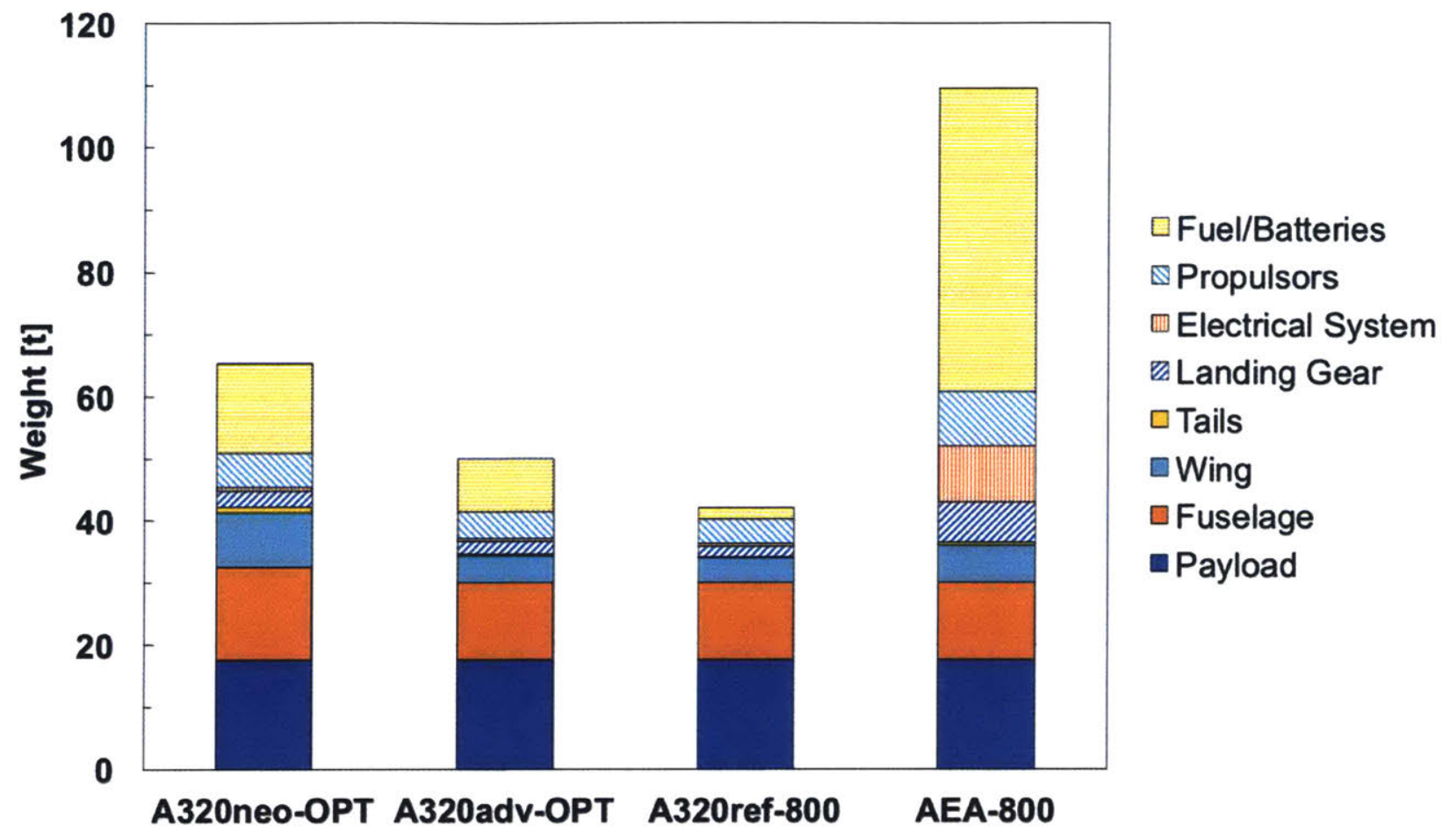

Figure 21. Conventional aircraft and AEA physical weight breakdown.

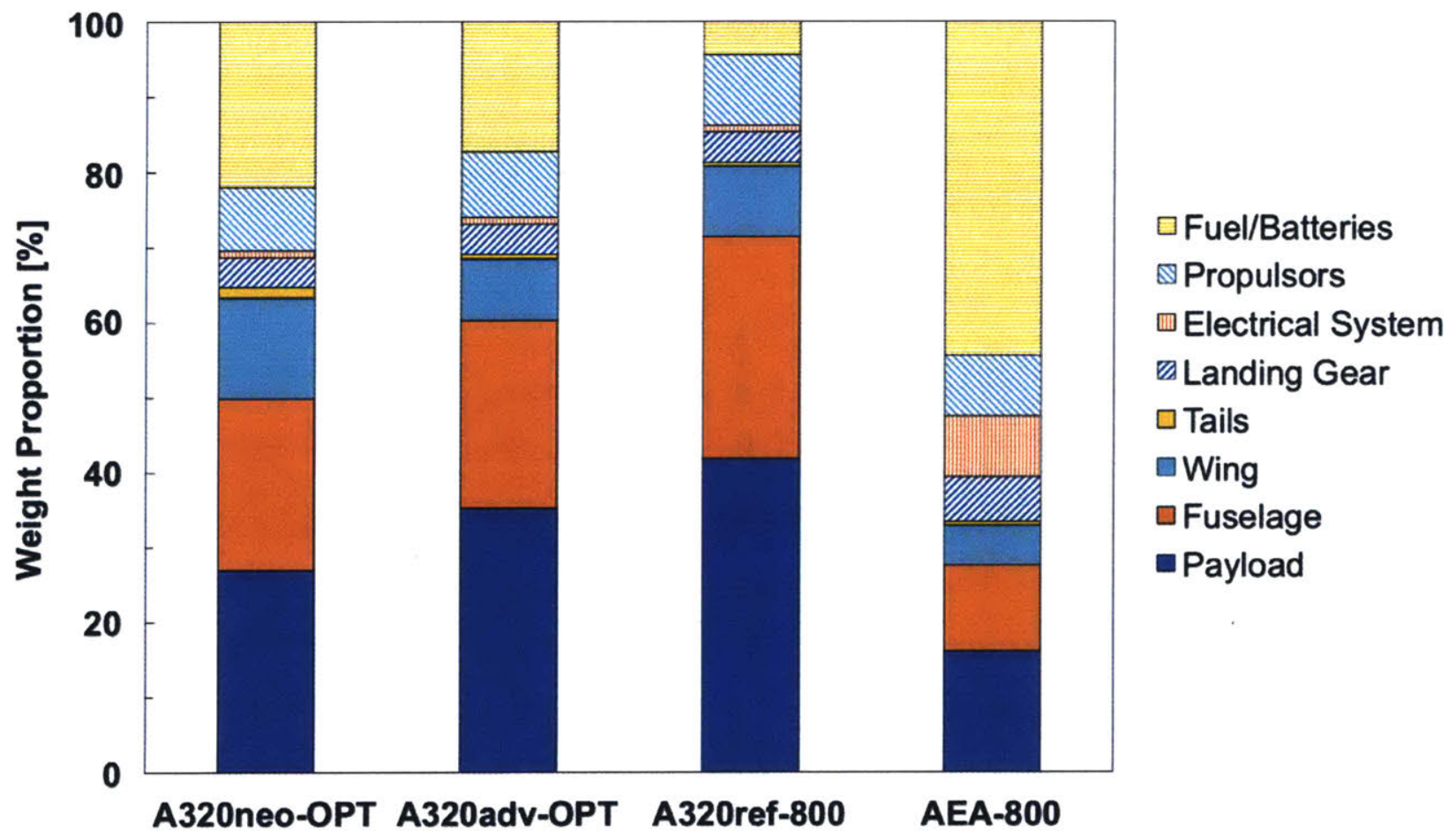

Figure 22. Conventional aircraft and AEA fractional weight breakdown. 


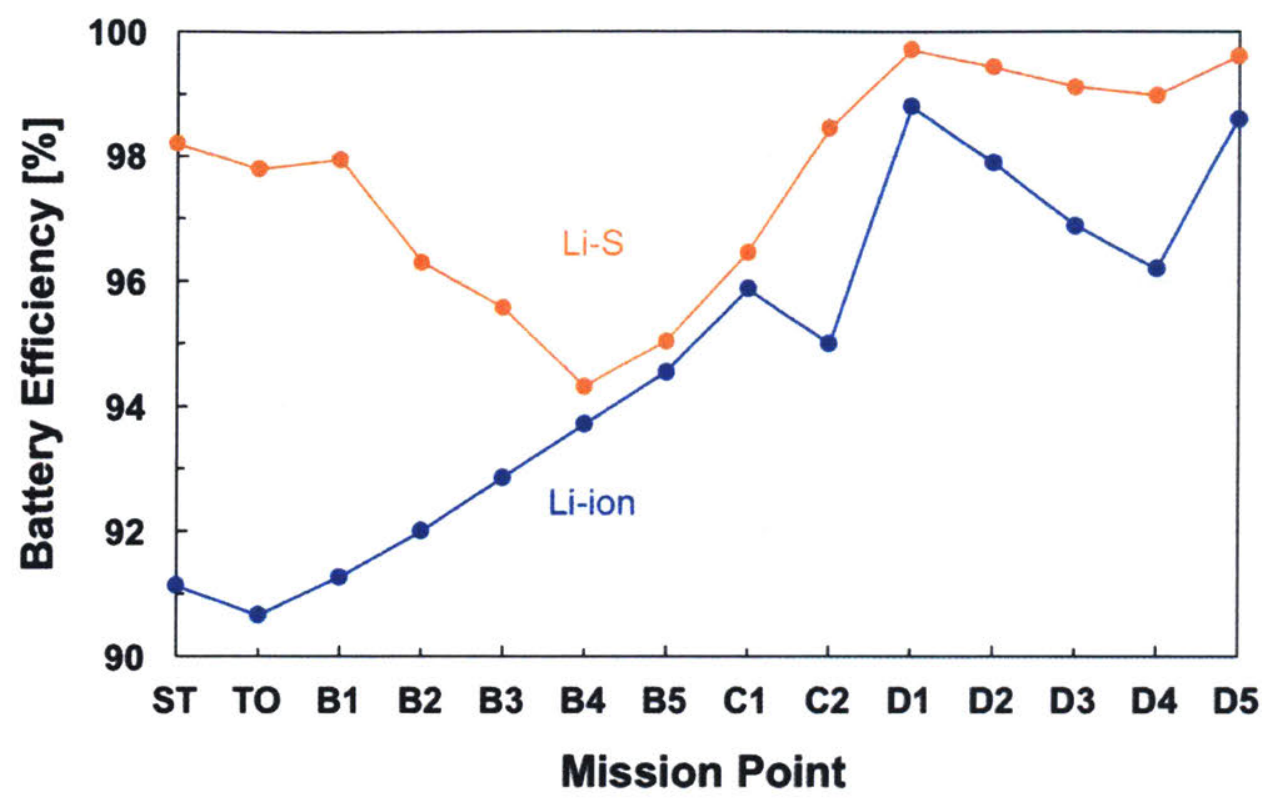

Figure 23. Effect of battery discharge model on battery efficiency. Both are $800 \mathrm{Wh} / \mathrm{kg}$ and $2400 \mathrm{~W} / \mathrm{kg}$ batteries with the same average internal resistance. The evaluated design range for evaluation was $500 \mathrm{nmi}$, and 4 propulsors performed best for each battery chemistry. The mission points are start (ST), takeoff (TO), climb (B1-5), cruise (C1-2), and descent (D1-5).

The discharge performance of future battery technology is uncertain, but Figure 23 illustrates the key differences between two potential battery chemistries, Li-ion and Li$\mathrm{S}$. The efficiency trend of the Li-ion battery roughly corresponds to the battery power required. Takeoff requires the most power and has the lowest efficiency, while descent requires the least power and has the highest efficiency. In contrast, the lowest efficiency for the Li-S battery occurs during climb. This is due to the discharge model, shown in Figure 9, where the resistance is highest at approximately $78 \%$ SOC.

The battery efficiencies shown in Figure 23 are all greater than 90\%, which agrees with values in other AEA work $[117,118]$. However, further increasing the design range and/or $\mathrm{W}_{\mathrm{MTO}}$ results in increased battery power requirements, and hence lower battery efficiencies. Thus, the battery modelling presented here captures not only energy storage limitations, but battery power restrictions as well. 


\subsection{Parametric evaluation results}

In addition to $800 \mathrm{Wh} / \mathrm{kg}$, aircraft were evaluated with specific energies between 400 and $2000 \mathrm{Wh} / \mathrm{kg}$. The propulsor count was again swept between two and ten propulsors, while the design range interval varied with the specific energy assumption. Key results of these parameter sweeps are shown in Figures 24-26. As expected, increasing the design range increases $\mathrm{W}_{\mathrm{MTO}}$ and mission energy requirements. The most efficient missions in respect to $\mathrm{E} / \mathrm{P}$ occur at intermediate design ranges, as shown in Figure 26. The mission productivity increases with range, but battery weight penalties offset this benefit at the upper end of the design range interval.

Most optimized AEA use four propulsors for the reasons discussed previously. However, many designs with high specific energy assumptions use two propulsors for short design ranges. The aircraft for these short missions have lower $\mathrm{W}_{\mathrm{MTO}}$ and consequentially require less thrust. The propulsor size is thus small enough where the motor specific power benefits with two large, high-power propulsors overshadow the landing gear size penalties. Also, slight kinks in the $\mathrm{W}_{\text {MTO }}$ trends are visible near $79 \mathrm{t}$ due to the LG sizing method.

For comparison, the BHL Ce-Liner is another battery-powered, narrow-body AEA design. This aircraft was designed with $2000 \mathrm{Wh} / \mathrm{kg}$ batteries for a mission of $189 \mathrm{PAX}$, $900 \mathrm{nmi}$, and M0.75 cruise [87]. The BHL Ce-Liner has a $\mathrm{W}_{\mathrm{MTO}}$ of $109.3 \mathrm{t}$ and mission energy requirement of $35.2 \mathrm{MWh}$, compared to $72.1 \mathrm{t}$ and $32.2 \mathrm{MWh}$ for a $2000 \mathrm{Wh} / \mathrm{kg}$, $900 \mathrm{nmi}$ AEA in this work. Both aircraft use two propulsors and advanced technology assumptions. However, this work assumes improved structural materials (composites), while the BHL Ce-Liner uses a C-wing and aft-mounted propulsors.

For consideration of environmental performance, the ratio of AEA battery energy to conventional aircraft fuel energy for the same mission is plotted in Figure 27. Design missions of $500 \mathrm{nmi}$ or less, before the onset of massive battery weight penalties, result in the best performance of AEA compared to conventional aircraft. However, significantly limiting the design range also limits the usability of AEA. 


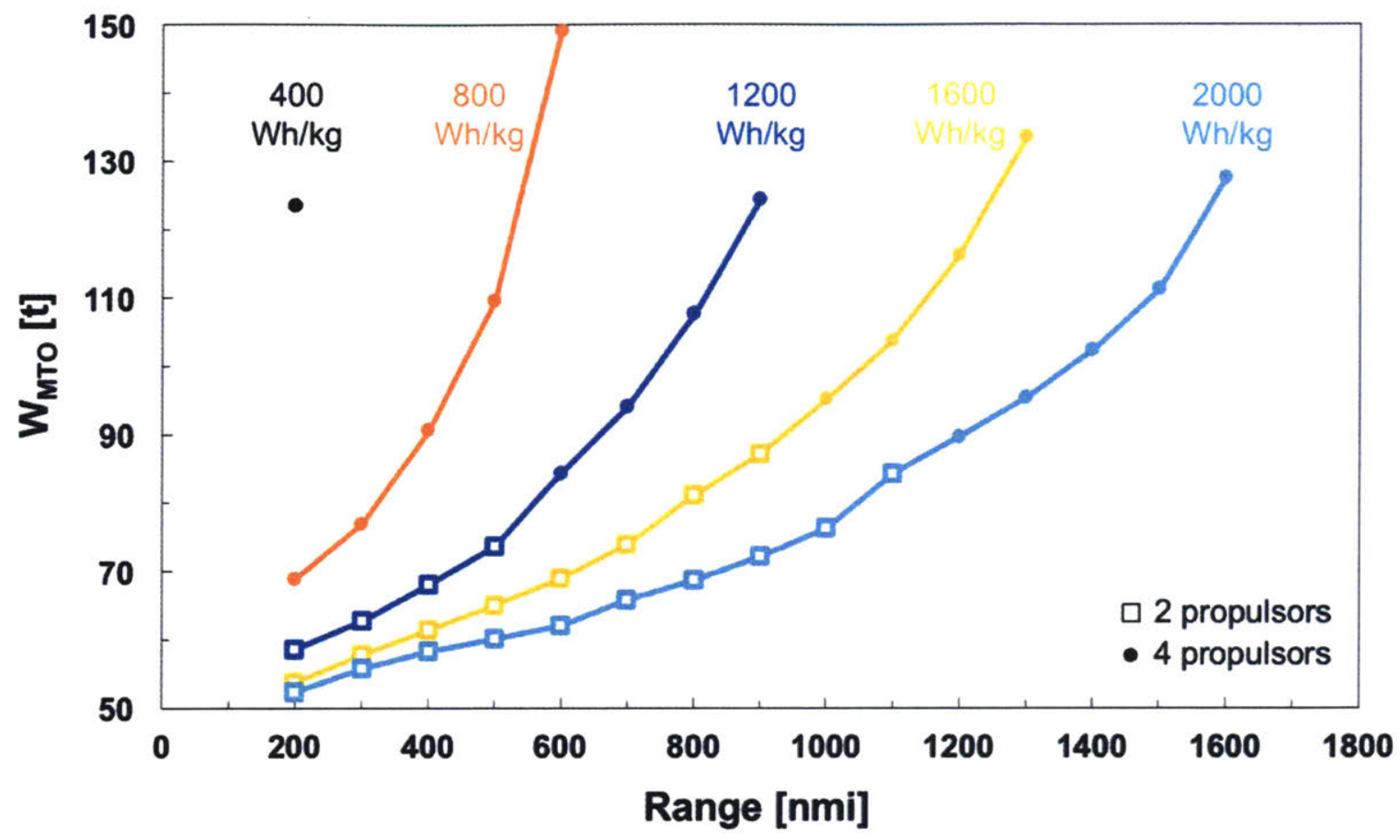

Figure 24. $\mathrm{W}_{\text {MTO }}$ variation with design range and battery specific energy. Bradley presented similar trends with approximately $50 \%$ greater range capabilities and determined that $1000 \mathrm{Wh} / \mathrm{kg}$ would be required for a $900 \mathrm{nmi}$ mission [195]. However, in this work the electrical and propulsion system is modeled with higher-fidelity.

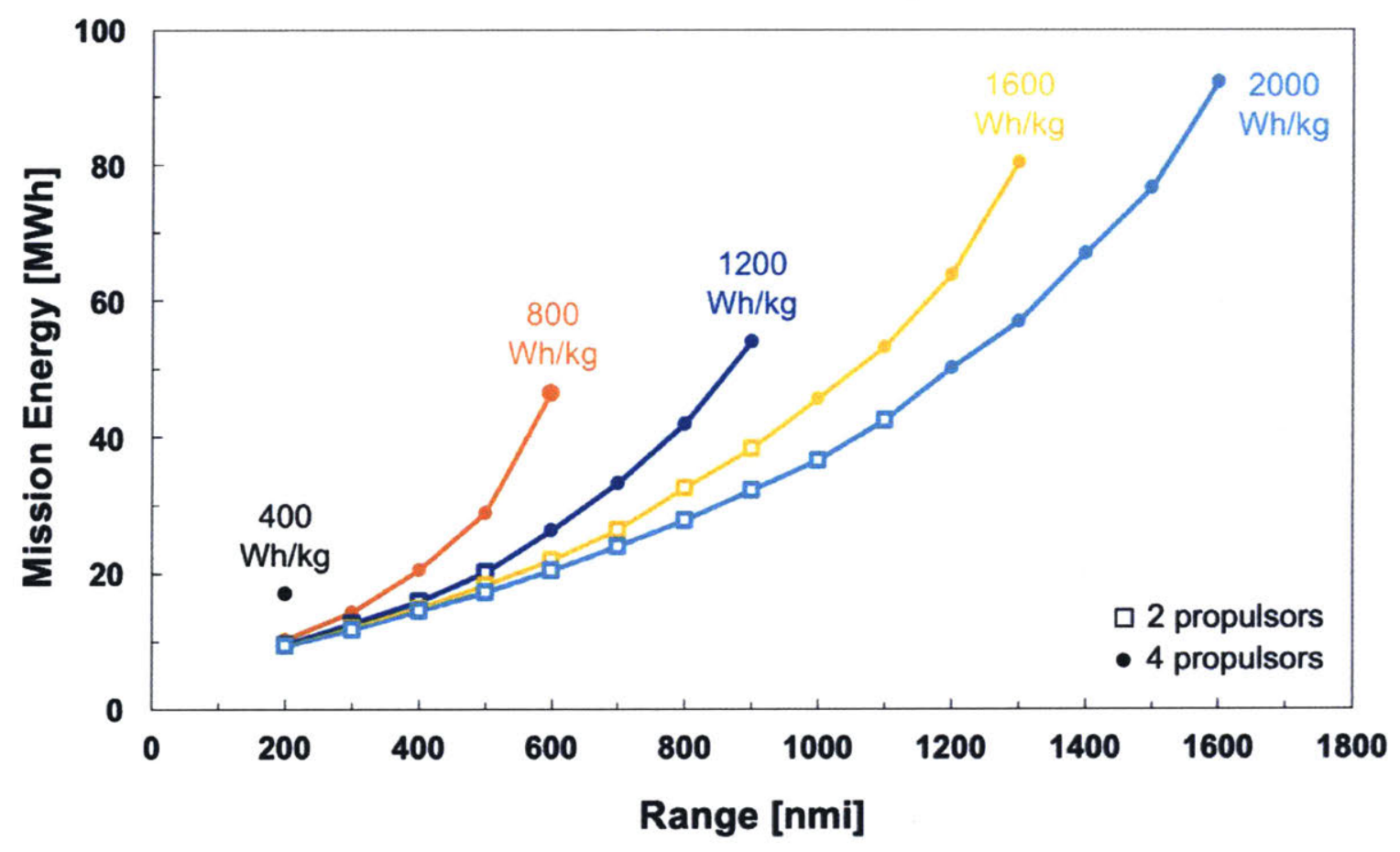

Figure 25. Mission energy variation with design range and battery specific energy. 


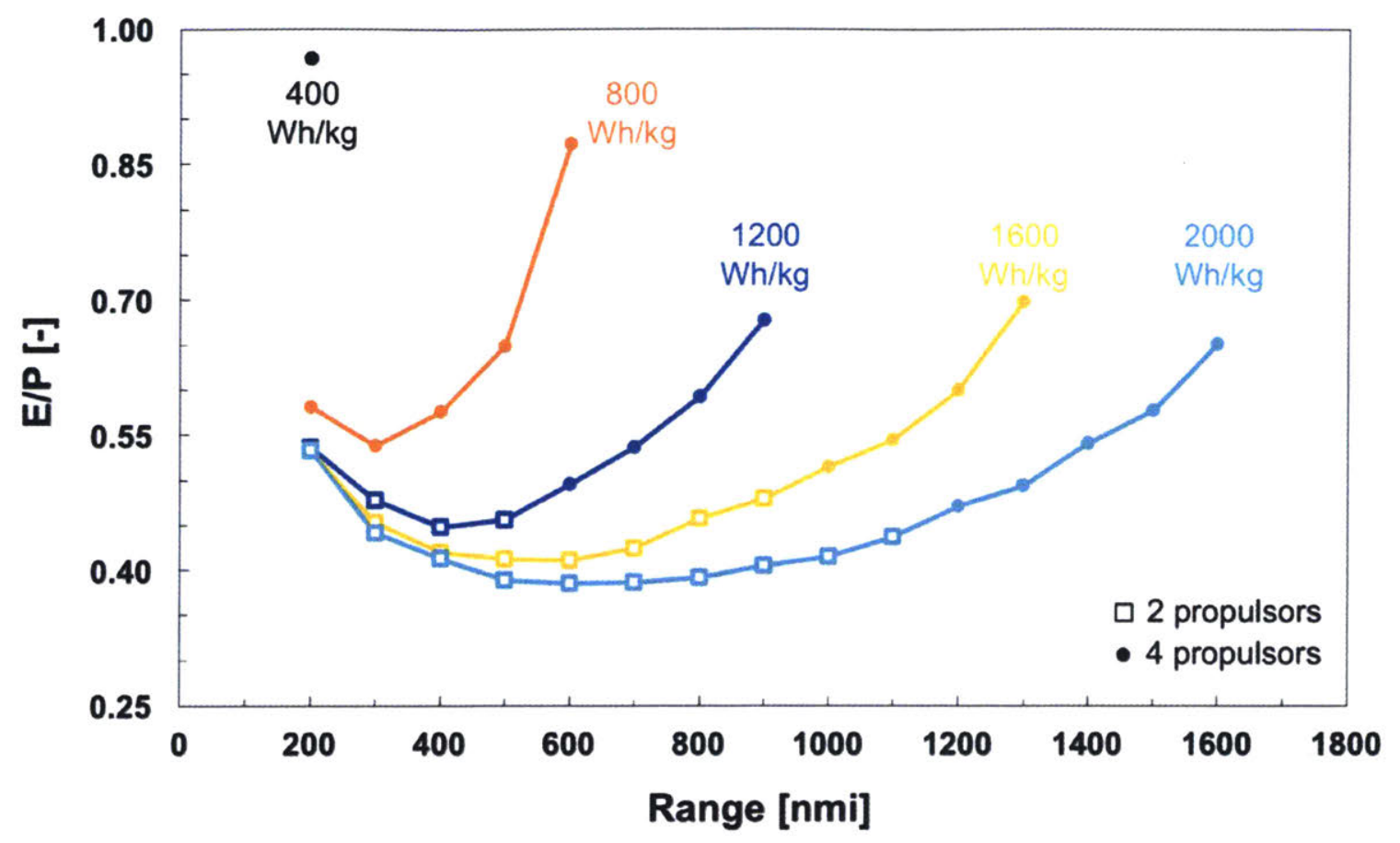

Figure 26. E/P variation with design range and battery specific energy.

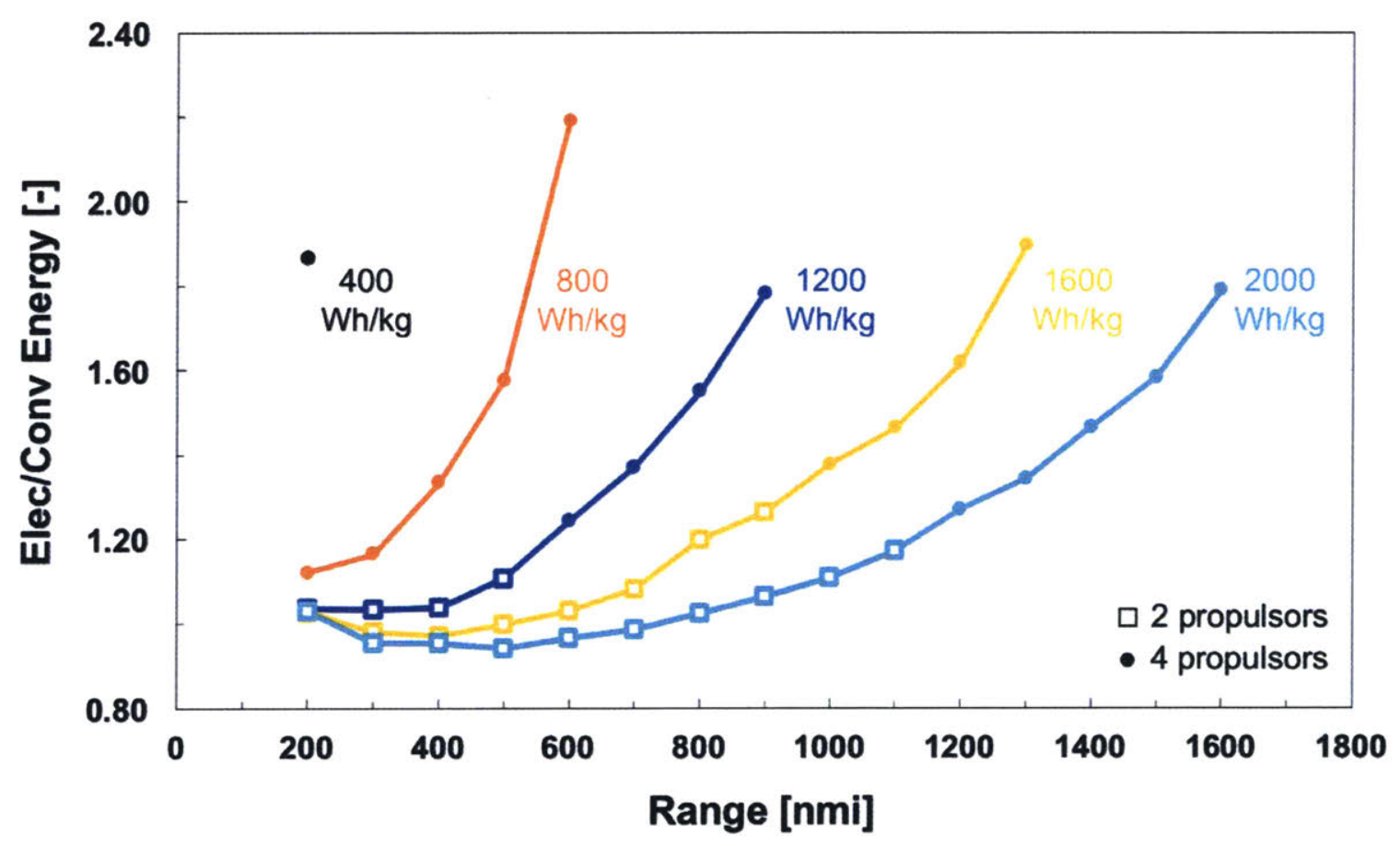

Figure 27. AEA to conventional aircraft energy ratio variation with design range and battery specific energy. Note that conventional aircraft use fuel energy based on the lower heating value of jet fuel and AEA use battery energy. 


\section{Chapter 6}

\section{Environmental assessment}

AEA are often cited as an option for environmentally friendly aviation. However, this is dependent on the entire energy chain, not just in-flight emissions. Here the energy and environmental impacts of AEA are evaluated and compared to conventional aircraft. In evaluating the future environmental performance of aircraft, two scenarios are used. The business-as-usual (BAU) scenario assumes limited environmental measures, while the highly renewable energy (HRE) scenario assumes substantial environmental measures.

\subsection{Conventional aircraft equivalent emissions}

Mission fuel requirements for conventional aircraft are directly computed by TASOPT. The equivalent carbon dioxide emissions $\left(\mathrm{CO}_{2} \mathrm{e}\right)$ are then determined using emission intensities. The standard $\mathrm{CO}_{2}$ emissions index for Jet-A is $3148 \mathrm{~g} \mathrm{CO}_{2} / \mathrm{kg}_{\text {fuel }}$ [196].

The current well-to-pump indirect equivalent emissions for Jet-A are $826.8 \mathrm{~g}$ $\mathrm{CO}_{2} \mathrm{e} / \mathrm{kg}_{\text {fuel }}$ [197]. This value is assumed to reduce to 616.9 or $821.3 \mathrm{CO}_{2} \mathrm{e} / \mathrm{kg}_{\text {fuel }}$ by 2050 , depending on future emission policy scenarios [197]. These values are paired with the HRE and BAU scenarios, respectively.

The current non- $\mathrm{CO}_{2}$ direct equivalent emissions are estimated as $2518 \mathrm{CO}_{2} \mathrm{e} / \mathrm{kg}$ fuel on a 100-year absolute global warming potential $\left(\mathrm{AGWP}_{100}\right)$ basis and $1259 \mathrm{CO}_{2} \mathrm{e} / \mathrm{kg}_{\text {fuel }}$ on a $3 \%$ discount rate net present value $\left(\mathrm{NPV}_{3} \%\right)$ basis [198]. The non- $\mathrm{CO}_{2}$ direct equivalent emissions are assumed to grow at $1.4 \%$ per year and include emissions from $\mathrm{NO}_{\mathrm{x}}$, sulfates, soot, water, and contrails [198].

Analysis of conventional aircraft equivalent emissions scales the well-to-pump emissions linearly and the non- $\mathrm{CO}_{2}$ emissions via the stated growth rate between 2015 and 2050 in correlation with the electricity generation assumptions discussed next. 


\subsection{Electric aircraft equivalent emissions}

Mission battery energy requirements for AEA are directly computed by TASOPTe. However, multiple inefficiencies exist further upstream in the energy supply chain. The electricity transmission and distribution efficiency is approximately 93\% [199]. The charging efficiency is assumed to be 95\%, which is typical for Li-ion batteries [200]. The round-trip (energy) efficiency is the ratio of the available battery discharge energy to the input energy required to restore the initial battery SOC [201]. This value varies depending on the battery chemistry and SOC range used, but $85 \%$ is assumed in this work [132]. This is typical for Li-ion batteries and reasonable for future Li-S batteries [10, 18, 200, $202,203]$. The combination of these losses results in an effective $75 \%$ efficiency between the aircraft and electricity source.

Current U.S. electricity generation consists of approximately $17 \%$ renewable energy, with the largest contributors being hydropower (7.4\%) and onshore wind (6.0\%) sources. The remaining electricity is primarily from natural gas (31\%), coal (31\%), and nuclear (20\%) sources. This results in a current U.S. emission intensity of approximately $500 \mathrm{~g} \mathrm{CO}_{2} / \mathrm{kWh}[199]$.

For analysis of AEA, two future electrical grid scenarios are assumed. The BAU scenario uses the U.S. Energy Information Administration Annual Energy Outlook 2017 predictions, as shown in Figure 28 [204]. Here, the renewable energy fraction grows rapidly until about 2023, then stabilizes, while coal is continually replaced with natural gas. The HRE scenario uses the NREL Renewable Electricity Futures Study predictions, as shown in Figure 28 [205]. The specific case used is the Incremental Technology Improvement with $80 \%$ renewable energy in 2050 (2014 update) [205]. Here, the renewable energy fraction grows linearly, while coal and natural gas fractions continually diminish. Knowing the generation mix, lifecycle equivalent $\mathrm{CO}_{2}$ emissions for each electricity source can be determined using emission intensities, which are shown in Table 8. The combined equivalent $\mathrm{CO}_{2}$ emissions for all sources is illustrated in Figure 29 for both scenarios. 

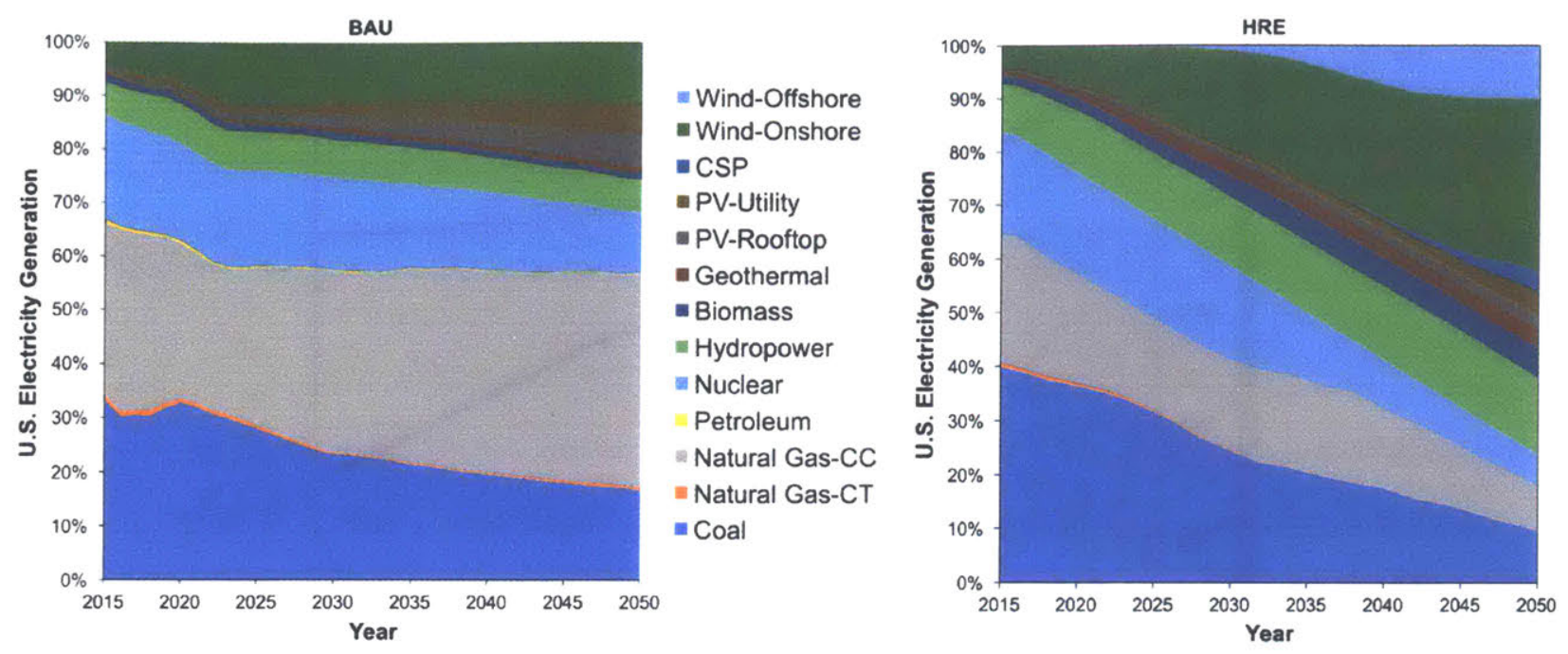

Figure 28. Future U.S. electrical grid scenarios. Data compiled from [204, 205].

Table 8. Lifecycle emission intensities by generation source.

\begin{tabular}{|c|c|c|}
\hline $\begin{array}{c}\text { Electricity } \\
\text { Generation Source }\end{array}$ & $\begin{array}{c}\text { Emission Intensity } \\
{\left[\mathrm{g} \mathrm{CO}_{\mathbf{2}} \mathbf{e} / \mathbf{k W h}\right]}\end{array}$ & Reference \\
\hline Wind-Offshore & 11 & {$[206]$} \\
\hline Wind-Onshore & 11 & {$[206]$} \\
\hline CSP & 21 & {$[207]$} \\
\hline PV-Utility & 45 & {$[208]$} \\
\hline PV-Rooftop & 45 & {$[208]$} \\
\hline Geothermal & 37 & {$[209]$} \\
\hline Biomass & 40 & {$[210]$} \\
\hline Hydropower & 7 & {$[211]$} \\
\hline Nuclear & 12 & {$[212]$} \\
\hline Petroleum & 840 & {$[213]$} \\
\hline Natural Gas-CC & 487 & {$[214]$} \\
\hline Natural Gas-CT & 670 & {$[215]$} \\
\hline Coal & 980 & {$[216]$} \\
\hline
\end{tabular}




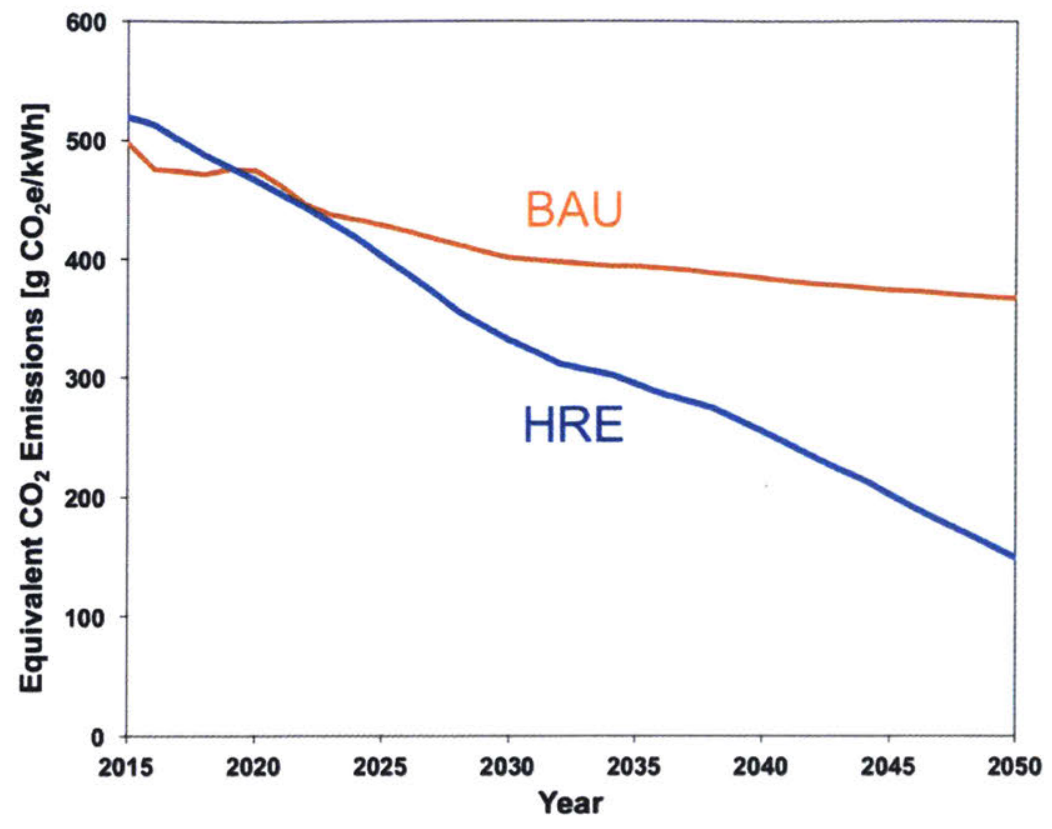

Figure 29. Combined electricity generation equivalent $\mathrm{CO}_{2}$ emissions by scenario.

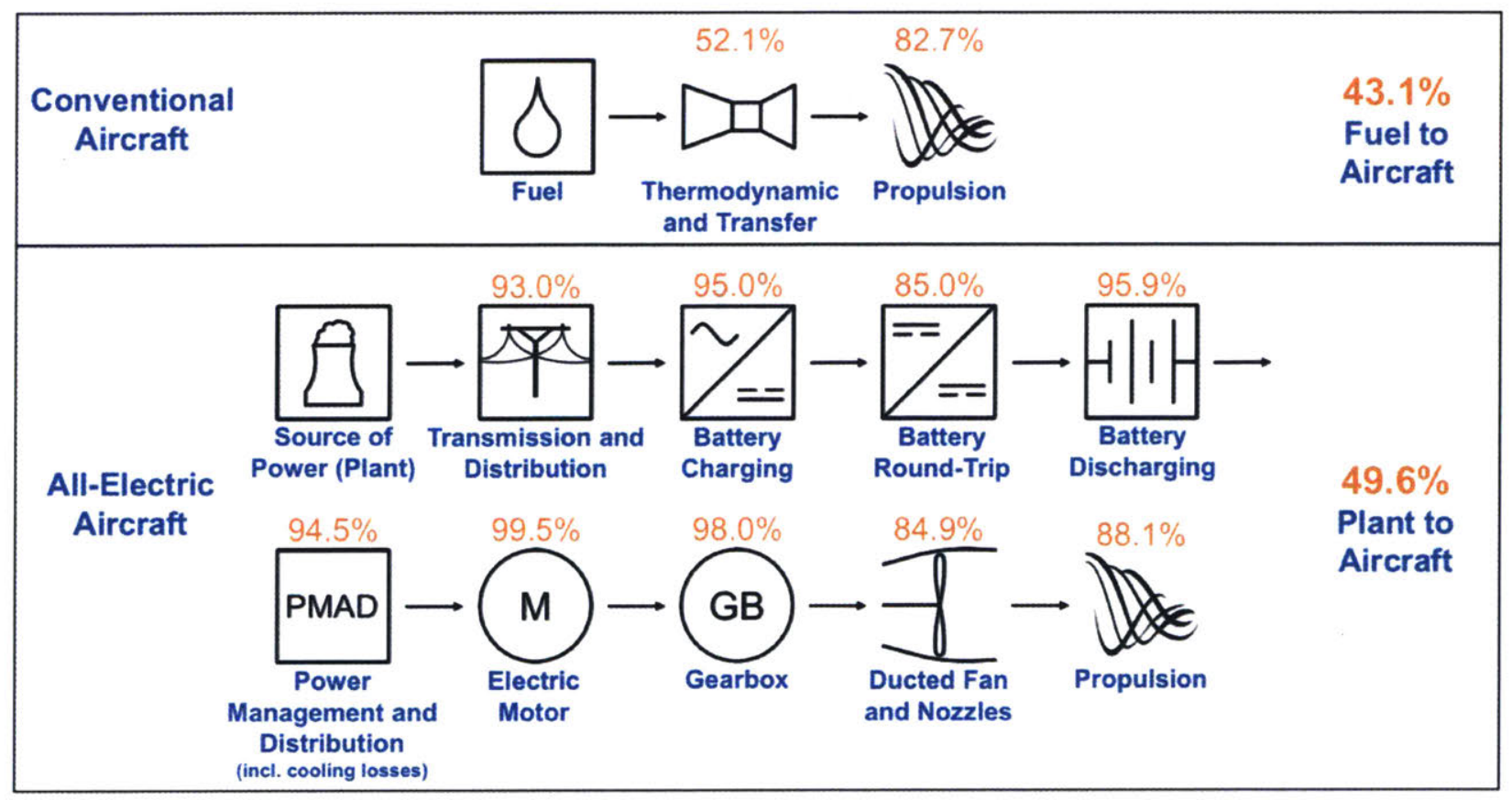

Figure 30. Conventional and AEA energy conversion chain comparison. Efficiencies are calculated during cruise for the A320ref-800 and AEA-800. 


\subsection{Environmental performance results}

An energy conversion chain comparison of the $800 \mathrm{Wh} / \mathrm{kg}$ AEA design (AEA-800) with a conventional aircraft design (A320ref-800) is shown in Figure 30. Both aircraft are optimized for a $500 \mathrm{nmi}$ design range. An onboard efficiency of $43.1 \%$ is observed for the conventional aircraft during cruise. The AEA has a much greater onboard efficiency of $66.1 \%$ during cruise. However, if upstream losses are accounted for, the efficiency is only $49.6 \%$. Additional losses are incurred during power generation, but this varies based on the generation source.

Based on the parameter sweep results in Figures 24-26, a design range was selected for each specific energy assumption for further analysis. The only converged solution with $400 \mathrm{Wh} / \mathrm{kg}$ was at $200 \mathrm{nmi}$. For the other specific energies, the second longest design range was chosen. Using the performance results for these AEA and the corresponding conventional aircraft, the ratio of equivalent $\mathrm{CO}_{2}$ emissions are shown in Figures 31 and 32. In discussing these results, it is important to note that the generating breakdown difference between the BAU and HRE scenarios. Even if the same fraction of energy is from renewable sources, the emissions may be different due to the specific generation choices (e.g. coal vs. natural gas, solar vs. wind).

The non- $\mathrm{CO}_{2}$ direct equivalent emissions are calculated on a $\mathrm{AGWP}_{100}$ and $\mathrm{NPV}_{3 \%}$ basis in Figures 31 and 32, respectively. Under the BAU electrical grid scenario, AEA always result in higher equivalent $\mathrm{CO}_{2}$ emissions than their conventional aircraft counterparts for the missions plotted in Figures 31 and 32. However, under the HRE electrical grid scenario, AEA using 800-2000 Wh/ $\mathrm{kg}$ result in lower equivalent $\mathrm{CO}_{2}$ emissions after approximately 2035 and 2043 using the $\mathrm{AGWP}_{100}$ and $\mathrm{NPV}_{3 \%}$ assumptions, respectively. The electrical grid for these years uses $50 \%$ and $64 \%$ renewable energy. AEA using $400 \mathrm{Wh} / \mathrm{kg}$ batteries have a breakeven point in 2040 and 2046 using the AGWP 100 and $\mathrm{NPV}_{3 \%}$ assumptions, respectively. The electrical grid for these years uses $59 \%$ and $69 \%$ renewable energy. 


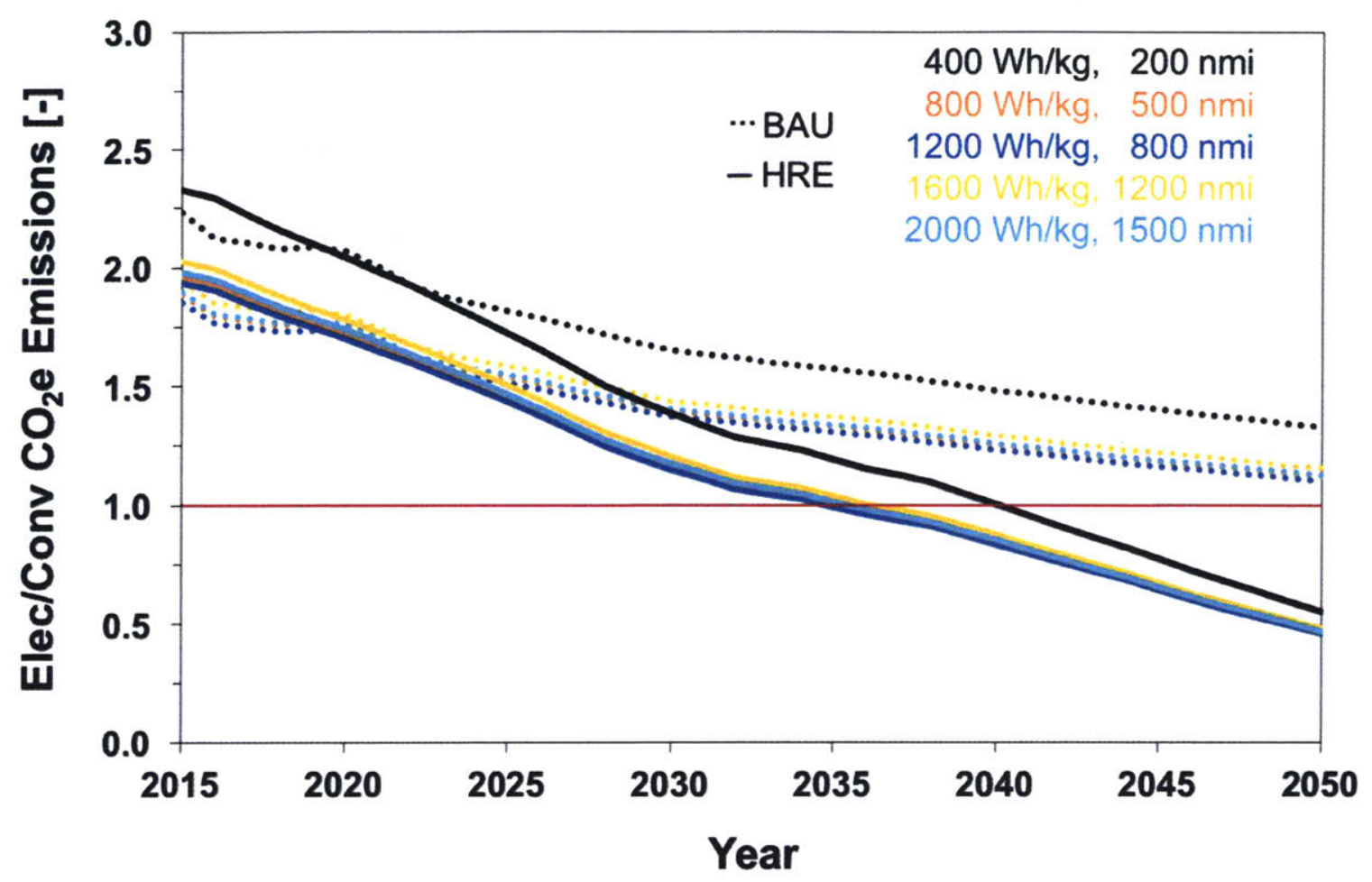

Figure 31. AEA to conventional aircraft equivalent $\mathrm{CO}_{2}$ emissions ratio, $\mathrm{AWP}_{100}$ basis.

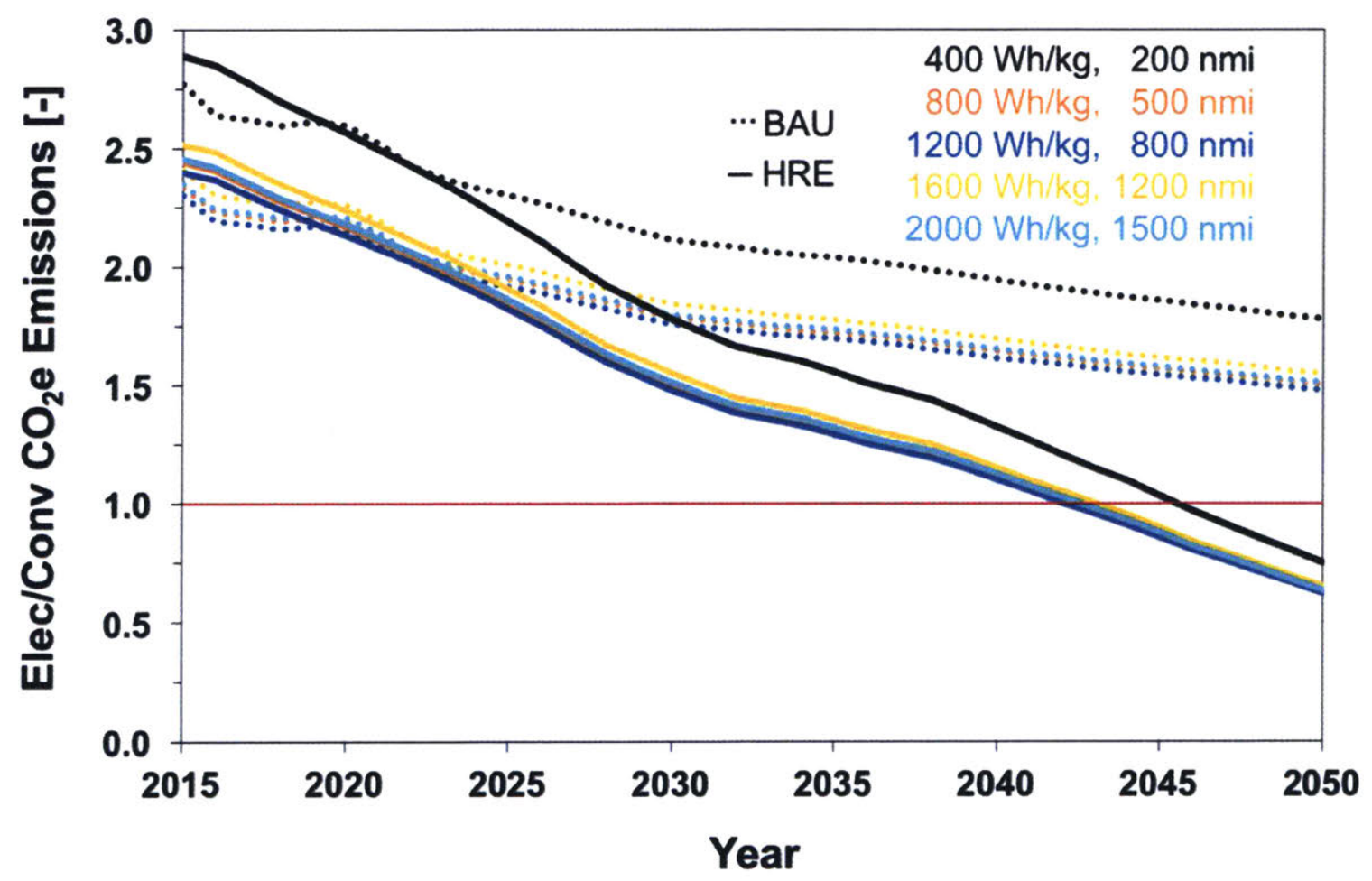

Figure 32. AEA to conventional aircraft equivalent $\mathrm{CO}_{2}$ emissions ratio, $\mathrm{NPV}_{3} \%$ basis. 
The results in Figures 31 and 32 indicate that AEA result in higher equivalent $\mathrm{CO}_{2}$ emissions under the HRE scenario until at least 2035, which requires $50 \%$ renewable energy. It may be desirable to design AEA for shorter ranges than they are capable of achieving in order to realize environmental benefits sooner. For this purpose, the design ranges are decreased for the $800-2000 \mathrm{Wh} / \mathrm{kg}$ cases, and the ratio of equivalent $\mathrm{CO}_{2}$ emissions are plotted in Figures 33 and 34.

Under the BAU electrical grid scenario using a $\mathrm{AWP}_{100}$ basis, $\mathrm{AEA}$ result in lower equivalent $\mathrm{CO}_{2}$ emissions compared to their conventional aircraft counterparts in 2034 for the $800 \mathrm{Wh} / \mathrm{kg}$ design and approximately 2028 for the other designs. This corresponds to $26 \%$ and $24 \%$ renewable energy, respectively. Under the HRE electrical grid scenario, AEA using $800 \mathrm{Wh} / \mathrm{kg}$ have lower equivalent $\mathrm{CO}_{2}$ emissions after about 2027 and 2034 using the $\mathrm{AGWP}_{100}$ and $\mathrm{NPV}_{3 \%}$ assumptions, respectively. The electrical grid for these years uses $36 \%$ and $48 \%$ renewable energy. Aircraft with $1200-2000 \mathrm{Wh} / \mathrm{kg}$ batteries have a breakeven point in 2026 and 2031 using the $\mathrm{AGWP}_{100}$ and $\mathrm{NPV}_{3 \%}$ basis, respectively. The electrical grid for these years uses $34 \%$ and $43 \%$ renewable energy. 


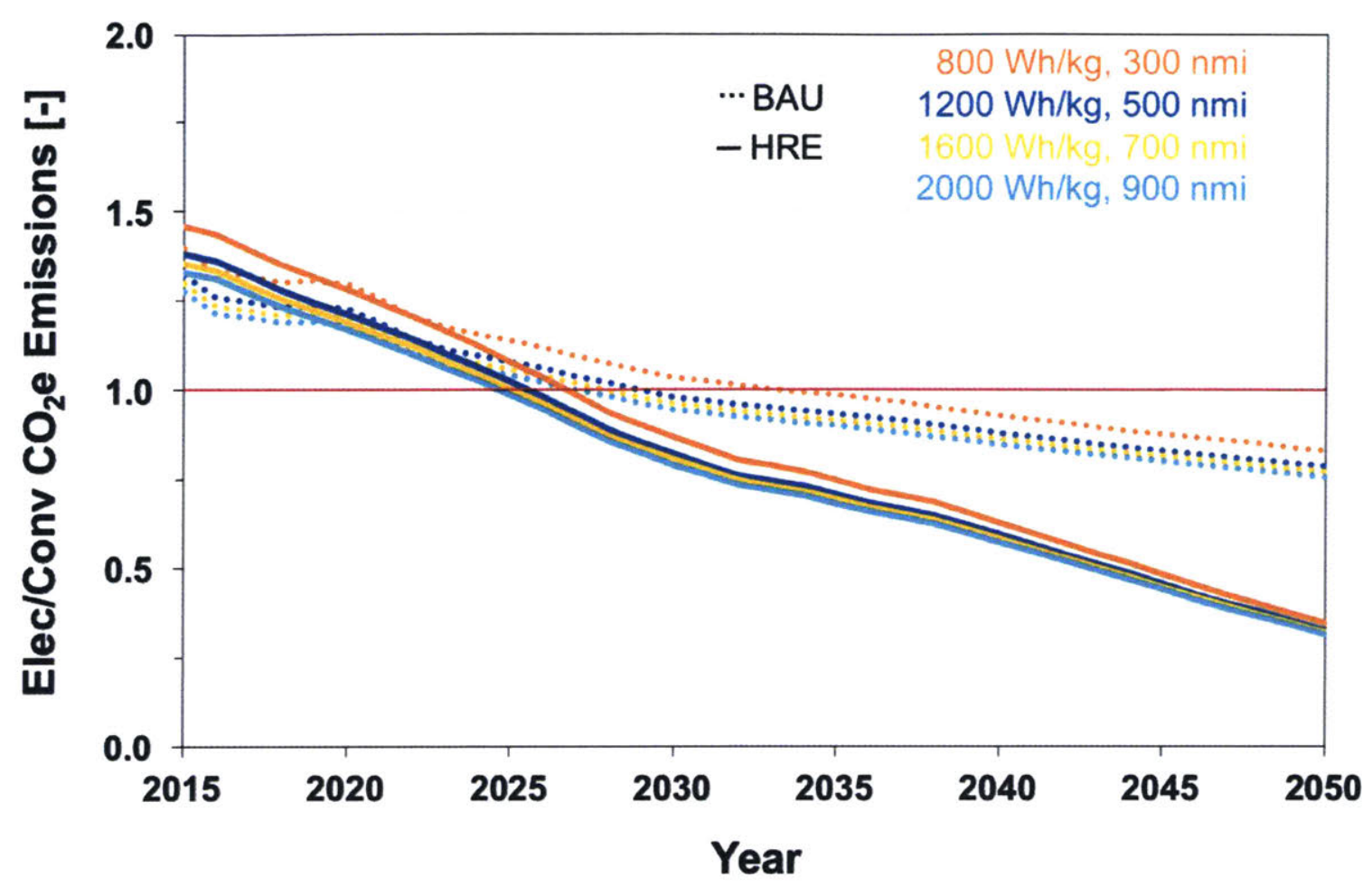

Figure 33. AEA to conventional aircraft equivalent $\mathrm{CO}_{2}$ emissions ratio at reduced design ranges, $\mathrm{AWP}_{100}$ basis.

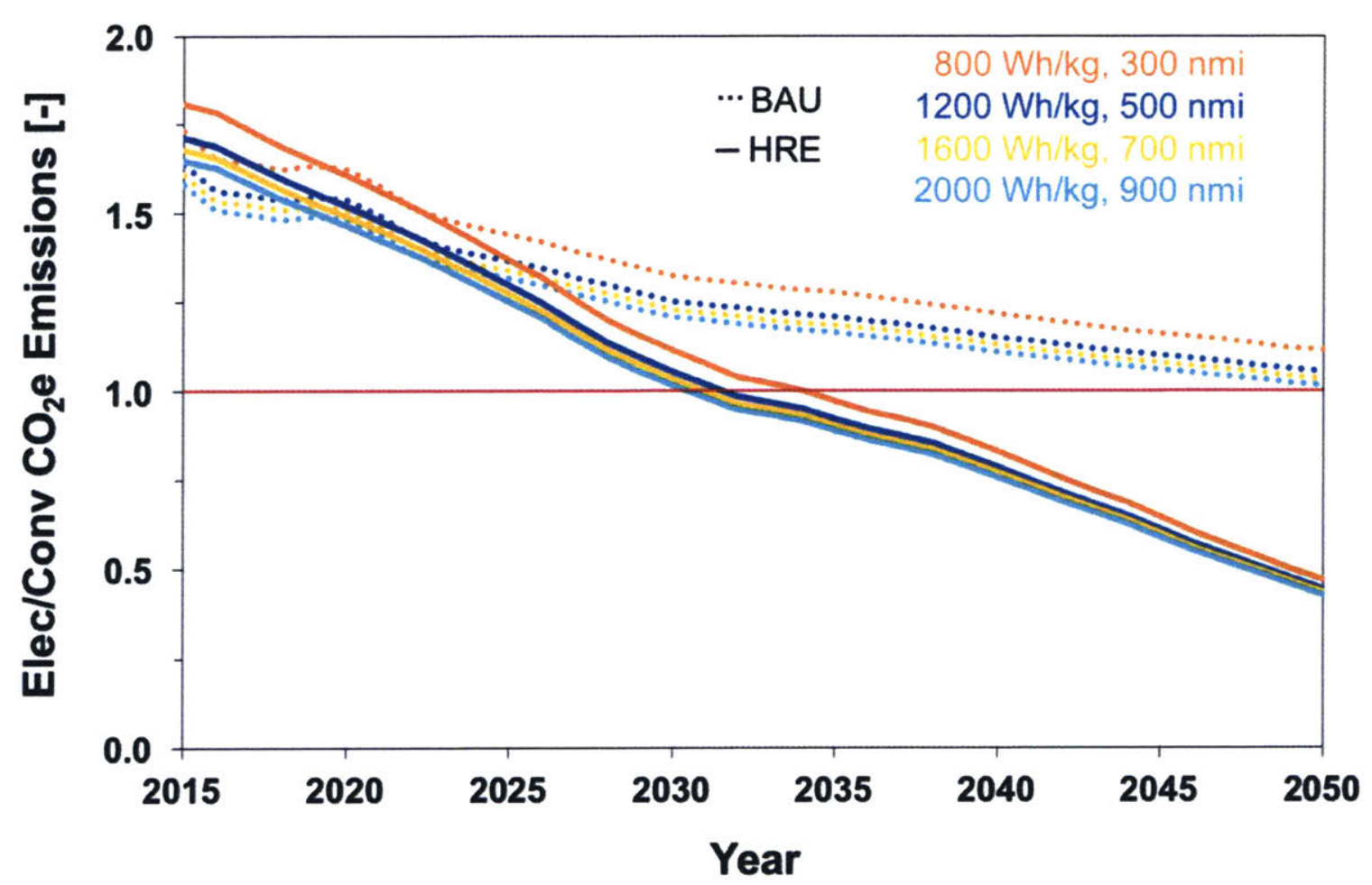

Figure 34. AEA to conventional aircraft equivalent $\mathrm{CO}_{2}$ emissions ratio at reduced design ranges, $\mathrm{NPV}_{3} \%$ basis. 


\section{Chapter 7}

\section{Challenges and areas of future research}

In this work, AEA designs resembling an A320neo have been evaluated. This airframe was selected so the benefits of electric propulsion could be observed for a well-known transport aircraft configuration. However, other configurations may be more suitable for AEA and should be evaluated in future work. A variety of other topics related to AEA warrant further research and are discussed here.

\subsection{Impact analyses}

Presented in this work are equivalent emissions on a flight-by-flight basis. However, this does not include the lifecycle emissions associated with manufacturing. Depending on the battery chemistry, lifecycle emissions for battery manufacture may not be negligible.

Additionally, introduction of AEA is dependent on commercial considerations by aircraft manufacturers, airlines, and airports. There must be a financial incentive to partake in this high-risk venture. Early markets for AEA adoption need to be identified. The cost of AEA components, particularly batteries, is largely unknown, but likely will exceed that of conventional aircraft components. The operating cost change in converting to AEA is largely dependent on the ratio of electricity to jet fuel prices and battery replacement costs, but other financial incentives, such as carbon taxes, may incentive earlier adoption.

The effect on airport capacity and the aviation network, as well as the airport and electrical grid infrastructure should be considered as well. AEA may provide an opportunity for electrical grid load-leveling through night battery charging. Batteries could also be charged during peak solar and wind generation hours, which would limit curtailment of excess power. This would have implications for energy policy in terms of the electricity generating mix that is developed. 


\subsection{Electrical and propulsion system}

Narrow-body AEA require electrical power that is at least an order of magnitude greater than previously seen on aircraft, which poses potential safety challenges. High voltages (e.g. $1 \mathrm{kV}$ ) for this system exceed the air breakdown voltage at high altitudes, so high voltage insulation requirements need further study $[113,149]$. Methods to reduce the risk of power outages and electromagnetic interference should be examined as well.

Advanced propulsion system components are enabling technologies for AEA. These include very low FPR fans, lightweight motors, gearboxes with high gear ratios, variable area nozzles, and an efficient cooling system. HTS components, including motors, generators, converters, inverters, and rectifiers, cryocoolers, and cabling, need further weight and loss reduction before their implementation is reasonable [217]. Analysis of AEA with boundary layer ingestion (BLI) is also recommended for further study.

\subsection{Batteries}

Currently AEA are limited to light aircraft with limited passenger capacity, range, and speed due to rechargeable battery limitations, especially low specific energy. Substantial improvement in battery technology, including specific energy, specific power, and energy density, would be required for narrow-body AEA. Furthermore, the battery packing efficiency (ratio of cell to pack mass) should be improved for aviation purposes from current values of $65-75 \%$ for electric vehicles. To reduce the weight penalty of batteries, NASA is currently studying multifunctional structures with energy storage [218]. This novel design would allow a portion of the aircraft structure to also serve as a battery and is worth further study. Implementation requirements of mass-gaining batteries, such as air intake, pressurization, and maintenance access, are not yet fully understood.

Further analysis of AEA should include consideration of battery state of health. The available capacity of a battery decreases after repeated charge-discharge cycles (capacity fade) $[219,220]$. This impacts the range and replacement requirements. 
The reserve battery requirement in this work was set to $30 \%$ SOC (20\% usable SOC), corresponding to approximately 30 minutes of flight. This should be examined more closely, with consideration of available power at low SOC for aborted landings, as well as deviations and go-around maneuvers.

The battery management system (BMS) for aircraft should be further developed, with consideration of multiple battery packs with various discharge rates. This analysis should include using multiple battery types with varying properties so the energy, power, and economic tradeoff can be observed. Considering the high aviation safety standards and well-publicized battery issues with MOE, such as the Boeing 787 battery fires, an understanding of how to safely manage battery discharge is crucial for AEA to become viable [155].

\subsection{Operations}

Airport infrastructure and operations would be impacted by battery charging requirements. Conventional aircraft typically turnaround in 30-45 minutes, which may be difficult to achieve with AEA battery charging or swapping. State of the art batteries, with respect to specific energy, have recommended charging times of around two hours, which is not reasonable for commercial aviation [119]. Initial study results suggest that the upper end of the current turnaround time interval could potentially be reached via battery swapping [16]. Either option would have implications for airport investments. Charging or swapping infrastructure would be required, and the number of gates needed for an equivalent fleet may increase with turnaround time being limited by charging or swapping rather than passenger movements and servicing.

Runway length currently constrains the AEA aircraft design. Short-haul flights are prevalent at short-runway airports, thus limiting the possible routes for AEA. Longer runways or wings with high lift capabilities would enable AEA implementation. Assisted 
takeoff, such as the ElectroMagnetic Aircraft Launch System (EMALS) is another enabling takeoff technology [221].

AEA have the potential to use DEP for propulsive efficiency benefits. However, DEP may also allow steeper descent. The decent angle of an aircraft is limited by the amount of drag that can be created. Recent research has examined using an engine airbrake to increase drag during descent [222]. Drag could be increased for AEA by allowing some of the propulsors to windmill, which may recover some energy as well. In analyzing this idea, exploitation of the DEP noise reduction potential should be considered. 


\section{Chapter 8}

\section{Conclusion}

The introduction of AEA into commercial aviation would lead to profound impacts on aircraft manufacturers, airlines, airports, and the transportation system as a whole. The concept of all-electric propulsion has expanded the aircraft design space, resulting in over 50 different AEA research projects over the past decade. The majority of these aircraft designs have targeted light aircraft, but numerous narrow-body AEA have also been evaluated. Two of these are commercial narrow-body projects currently in progress.

In this work, AEA were evaluated at design ranges of 200-1600 nmi with 2-10 propulsors and 400-2000 Wh/ $\mathrm{kg}$ batteries. The performance of these AEA was compared to advanced conventionally powered aircraft. All aircraft were based on the A320neo configuration. Optimized AEA were found to use either two or four propulsors depending on the specific energy and design range assumptions. Most cases found the best performance with four propulsors. This result stems primarily from a tradeoff between landing gear weight and electrical and propulsion system weight. Significant aircraft weight and performance penalties limit the design range for each specific energy assumption.

Current battery technology makes AEA with 180 PAX likely infeasible. A factor of four increase in battery pack specific energy to $800 \mathrm{Wh} / \mathrm{kg}$ would enable flights of up to $500 \mathrm{nmi}$. However, a lower design range of $300 \mathrm{nmi}$ would enable improved performance in respect to required energy per mission and equivalent $\mathrm{CO}_{2}$ emissions. Despite the higher total energy use, narrow-body AEA have the potential for lower equivalent $\mathrm{CO}_{2}$ emissions if the electrical grid transitions toward renewable energy. This is largely enabled by the complete elimination of all high-altitude emissions, which would remove associated non$\mathrm{CO}_{2}$ warming. Also, the absence of direct-emissions from ground operations would significantly improve air quality around airports. 
Further benefits would likely be seen using a more advanced configuration, such as the "double bubble" concept seen in the MIT D8, which will be examined in future work. This type of design would also allow for additional battery storage that may be required for longer range AEA. An increased span constraint likely enables improved environmental performance. Finally, the use of DEP may enable further efficiency gains, which may be unique to electric aircraft configurations. 


\section{References}

[1] IPCC, Climate Change 2014: Synthesis Report. Contribution of Working Groups I, II and III to the Fifth Assessment Report of the Intergovernmental Panel on Climate Change [Core Writing Team, R.K. Pachauri and L.A. Meyer (eds.)], Geneva, Switzerland, 2014, pp. 1-151.

[2] International Energy Agency, World Energy Statistics, 2016.

[3] Airbus, Airbus Global Market Forecast - Growing Horizons 2017-2036, 2017.

[4] Boeing, Boeing Current Market Outlook 2010 - 2029, 2010.

[5] Dorbian, C. S., Wolfe, P. J., and Waitz, I. A., 'Estimating the Climate and Air Quality Benefits of Aviation Fuel and Emissions Reductions," Atmospheric Environment, Vol. 45, No. 16, 2011, pp. 2750-2759.

[6] Yim, S. H. L., Lee, G. L., Lee, I. H., Allroggen, F., Ashok, A., Caiazzo, F., Eastham, S. D., Malina, R., and Barrett, S. R. H., "Global, Regional and Local Health Impacts of Civil Aviation Emissions," Environmental Research Letters, Vol. 10, No. 3, 2015, pp. 1-12.

[7] Green, J. E., and Jupp, J. A., "CAEP/9-Agreed Certification Requirement for the Aeroplane $\mathrm{CO}_{2}$ Emissions Standard: A Comment on ICAO Cir 337," Aeronautical Journal, Vol. 120, No. 1226, 2016, pp. 693-723.

[8] Ashcraft, S. W., Padron, A. S., Pascioni, K. A., Stout, G. W., and Huff, D. L., Review of Propulsion Technologies for N+3 Subsonic Vehicle Concepts, Cleveland, OH, 2011.

[9] Darecki, M., Edelstenne, C., Enders, T., Fernandez, E., Hartman, P., Herteman, J.-P., Kerkloh, M., King, I., Ky, P., Mathieu, M., Orsi, G., Schotman, G., Smith, C., and Wörner, J.-D., Flightpath 2050 Europe's Vision for Aviation, 2011.

[10] Hepperle, M., "Electric Flight - Potential and Limitations," AVT-209 Workshop on Energy Efficient Technologies and Concepts Operation, Lisbon, Portugal, 2012, pp. 1-30.

[11] McDonald, R. A., "Electric Propulsion Modeling for Conceptual Aircraft Design," 52nd AIAA Aerospace Sciences Meeting, 2014, pp. 1-19.

[12] Schäfer, A. W., Evans, A. D., Reynolds, T. G., and Dray, L., "Costs of Mitigating $\mathrm{CO}_{2}$ Emissions from Passenger Aircraft," Nature Climate Change, Vol. 6, No. 4, 2015, pp. 412-417.

[13] Staples, M. D., Malina, R., and Barrett, S. R. H., "The Limits of Bioenergy for Mitigating Global Life-Cycle Greenhouse Gas Emissions from Fossil Fuels," Nature Energy, Vol. 2, No. 1, 2017, pp. $1-8$.

[14] Roboam, X., "New Trends and Challenges of Electrical Networks Embedded in 'More Electrical Aircraft,"' 2011 IEEE International Symposium on Industrial Electronics, 2011, pp. 26-31. 
[15] Committee on Propulsion and Energy Systems to Reduce Commercial Aviation Carbon Emissions, Commercial Aircraft Propulsion and Energy Systems Research - Reducing Global Carbon Emissions, 1 ed., National Academies Press, Washington, D.C., 2016.

[16] Bradley, M. K., and Droney, C. K., Subsonic Ultra Green Aircraft Research Phase II: $N+4$ Advanced Concept Development, Huntington Beach, CA, 2012.

[17] Pornet, C., and Isikveren, A. T., "Conceptual Design of Hybrid-Electric Transport Aircraft," Progress in Aerospace Sciences, Vol. 79, No. 1, 2015, pp. 114-135.

[18] Friedrich, C., and Robertson, P. A., "Hybrid-Electric Propulsion for Automotive and Aviation Applications," CEAS Aeronautical Journal, Vol. 6, No. 2, 2015, pp. 279-290.

[19] Jansen, R. H., Bowman, C., Jankovsky, A., Dyson, R. W., and Felder, J. L., "Overview of NASA Electrified Aircraft Propulsion (EAP) Research for Large Subsonic Transports," 53rd AIAA/SAE/ASEE Joint Propulsion Conference, Atlanta, GA, 2017, pp. 1-20.

[20] Rolls-Royce, and Airbus Group, E-Thrust - Electrical Distributed Propulsion System Concept for Lower Fuel Consumption, Fewer Emissions and Less Noise, 2014.

[21] Zunum Aero, 2018, Available: http://zunum.aero/.

[22] Armstrong, M. J., Ross, C. A. H., Blackwelder, M. J., and Rajashekara, K., 'Propulsion System Component Considerations for NASA N3-X Turboelectric Distributed Propulsion System," SAE International Journal of Aerospace, Vol. 5, No. 2, 2012, pp. 344-353.

[23] Vascik, P., and Hansman, R. J., "Systems-Level Analysis of On Demand Mobility for Aviation," MIT, 2017.

[24] A A $^{3}$ "Vahana The Next Technological Breakthrough in Urban Air Mobility.," 2017, Available: https://www.airbus-sv.com/projects/1.

[25] ACS Aviation, "Produtos," 2017, Available: https://www.acs-solutions.com.br/index.php/produtos.

[26] Airbus, Airbus Group E-Fan Brochure, Munich, Germany, 2014.

[27] AirSpaceX, "Clean Electric," 2017, Available: http://airspacex.com/.

[28] APEV, "The Pouchelec, The Electric Pouchel," 2017, Available: http://www.pouchel.com/english/index_eng.php?p=elec_eng.html.

[29] Aurora Flight Sciences, "eVTOL The Future of On-Demand Air Transportation," 2017, Available: http://www.aurora.aero/evtol/.

[30] Autonomous Flight, "The Future is Here.," 2017, Available: http://autonomousflight.com/.

[31] Barnstorff, K., "The Puffin: A Passion for Personal Flight," 2010, Available: https://www.nasa.gov/topics/technology/features/puffin.html. 
[32] Bergqvist, P., "All-Electric Airplane Reaches 153 Knots," Flying Magazine, 2011, Available: https://www.flyingmag.com/news/all-electric-airplane-reaches-153-knots.

[33] Beyond Aviation, "Archive of the Goals of the Beyond Aviation Project," 2017, Available: http://www.beyond-aviation.com/index.html.

[34] Carter Aviation Technologies, 2017, Available: http://www.cartercopters.com/.

[35] Carter, J., "Electric CarterCopter Air Taxi," 2017, Available: http://evtol.news/wpcontent/uploads/2017/06/Carter-Presentation-CAFE-Elec-AC-Symposium-w-video.pdf.

[36] Coppinger, R., 'Prototype Flight Success Could See French All-Electric GA Product," Flight Global, 2008, Available: https://www.flightglobal.com/news/articles/prototype-flight-success-could-seefrench-all-electric-ga-product-220729/.

[37] DeloreanAerospace, 2017, Available: http://www.deloreanaerospace.com/.

[38] Electric Visionary Aircrafts, 2017, Available: http://eva.xyz/.

[39] ElectroVelocity, "The ElectraFlyer X - 100\% Electric Flight," 2011, Available: http://electrovelocity.com/2011/03/04/the-electraflyer-x-100-electric-flight/.

[40] Eviation, "Alice Commuter," 2017, Available: http://www.eviation.co/alice/.

[41] Evektor, "Electric Powered Small Aircraft," 2017, Available: https://www.evektor.cz/en/sportstarepos.

[42] "Extra 330LE Electric Aircraft," Aerospace Technology, 2017, Available: http://www.aerospacetechnology.com/projects/extra-330le-electric-aircraft/.

[43] F. M., "Skylys Aircraft Presents the Air Speeder, an Amphibious eVTOL," Aero Buzz.FR, 2017, Available: https://www.aerobuzz.fr/breves-aviation-generale/skylys-aircraft-presente-lair-speederun-evtol-amphibie/.

[44] Flight of the Century, "Long-ESA," 2017, Available: http://www.flightofthecentury.com/long-esa/.

[45] Grady, M., "E-Flight Takes Center Stage At Aero," 2015, Available: https://www.avweb.com/avwebflash/news/E-Flight-Takes-Center-Stage-At-Aero-223875-1.html.

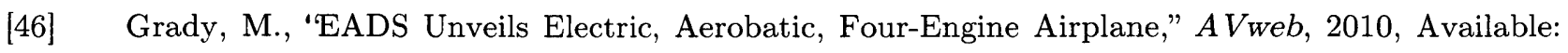
https://www.avweb.com/avwebflash/news/EADSUnveilsElectricAerobaticFourEngineAirplane_2 02805-1.html.

[47] HopFlyt, 2017, Available: https://hopflyt.com/.

[48] Horne, T., "Pipistrel Alpha Electro: The Trainer of the Future?," AOPA, 2015, Available: https://www.aopa.org/news-and-media/all-news/2015/october/pilot/f_pipistrel. 
[49] JAXA, "Demonstration of the Feasibility of Lift Fan Type VTOL Control System," 2017, Available: http://www.aero.jaxa.jp/research/basic/propulsion/liftfan/.

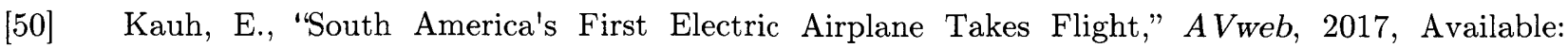
https://www.avweb.com/avwebflash/news/South-Americas-First-Electric-Airplane-Takes-Flight224337-1.html.

[51] Langelaan, J. W., Chakrabarty, A., Deng, A., Miles, K., Plevnik, V., Tomazic, J., Tomazic, T., and Veble, G., "Green Flight Challenge: Aircraft Design and Flight Planning for Extreme Fuel Efficiency," Journal of Aircraft, Vol. 50, No. 3, 2013, pp. 832-846.

[52] LazairInfo.com, "eLazair," 2017, Available: http://lazairinfo.com/electric-lazair/.

[53] Lee, D., 'London-Paris Electric Flight 'In Decade'," $B B C$ News, 2017, Available: http://www.bbc.com/news/technology-39350058.

[54] Lillium GmbH, "Lilium Celebrates Successful Flight Tests of World's First Electric VTOL Jet," 2017, Available: https://lilium.com/press-releases/lilium-celebrates-successful-flights-tests.pdf.

[55] M. R., "The Flight from Demoichelle to Bourget," Aero Buzz.FR, 2010, Available: https://www.aerobuzz.fr/industrie/le-vol-de-la-demoichelle-au/.

[56] Mark, R., "DeLorean's DR-7 Prototype Could Fly in Late 2018," 2017, Available: https://www.flyingmag.com/deloreans-dr-7-prototype-could-fly-in-late-2018\#page-2.

[57] Moore, M., "The Joby S2 VTOL Concept Exploring the New Degrees of Design Freedom of Distributed Electric Propulsion," 2014, Available: http://evtol.news/2014/11/01/the-joby-s2-vtolconcept-nov-1-2014/.

[58] Muoio, D., "NASA has an Ambitious $\$ 43$ Million Plan to Make Electric Planes a Reality," 2017, Available: http://www.businessinsider.com/nasa-is-spending-43-million-on-electric-planes-20175/\#nasa-is-first-building-a-small-entirely-electric-plane-called-the-x-57-it-plans-on-completing-theplane-in-just-under-four-years-2.

[59] Noland, D., 'Who's Killing the Electric Plane?," Popular Mechanics, 2009, Available: http://www.popularmechanics.com/flight/a4465/4330186/.

[60] Panthera, "Technical Data," 2017, Available: http://www.panthera-aircraft.com/technical-data.

[61] Pew, G., "German-Certified Light Electric Plane To Visit Osh," 2013, Available: https://www.avweb.com/avwebflash/news/Germany-Certifies-Light-Electric-Plane-Airventureyuneec-greenwing-espyder-220144-1.html.

[62] Phelps, M., 'Yuneec's E430 Electric Airplane Has Up to 2.5 Hours' Endurance," Flying Magazine, 2009, Available: https://www.flyingmag.com/news/yuneecs-e430-electric-airplane-has-25-hoursendurance.

[63] Pipistrel, "Alpha Electro (prototype name WATTsUP)," 2017, Available: http://wattsup.pipistrel.si/aircraft/\#techdata. 
[64] Reynolds, R., "Electric MC30E Firefly Flies With New Motor," EAA, 2011, Available: https://web.archive.org/web/20111217064903/http:/eaa.org/news/2011/2011-08-10_firefly.asp.

[65] Ruixiang General Aircraft Manufacturing Corporation, Ltd., "Ruixiang Extended Range TwoSeater All-Electric Light-Sport Aircraft," 2017, Available: http://rgac.biz/Ruixiang/Productshow/ERX1EA.php.

[66] Ruixiang General Aircraft Manufacturing Corporation, Ltd., "Ruixiang Two-Seater All-Electric Light-Sport Aircraft," 2017, Available: http://rgac.biz/Ruixiang/Productshow/ERX1E.php.

[67] S2, 2017, Available: http://www.jobyaviation.com/S2/.

[68] Seaplane International, "The First Electric-Powered Amphibia in the World," 2011, Available: http://www.seaplaneinternational.com/2011/08/12/the-first-electric-powered-amphibia-in-theworld/.

[69] Siemens, "Aerobatic Airplane Extra 330LE," 2016, Available: https://www.siemens.com/press/ pool/de/events/2016/corporate/2016-12-innovation/inno2016-aerobatic-airplane-e.pdf.

[70] Sonex Aircraft, "e-Flight esa," 2017, Available: http://www.sonexaircraft.com/research/eflight.html.

[71] Steiner, H.-J., Vratny, P. C., Gologan, C., Wieczorek, K., Isikveren, A. T., and Hornung, M., "Optimum Number of Engines for Transport Aircraft Employing Electrically Powered Distributed Propulsion," CEAS Aeronautical Journal, Vol. 5, No. 2, 2014, pp. 157-170.

[72] Stoll, A., "Faster, Quieter, Safer, and Cheaper Distributed Electric Propulsion and the Coming VTOL Revolution," 2017, Available: https://sites.nationalacademies.org/cs/groups/depssite/documents/webpage/deps_169312.pdf.

[73] Stückl, S., van Toor, J., and Lobentanzer, H., "VoltAir - The All Electric Propulsion Concept Platform - A Vision For Atmospheric Friendly Flight," 28th Congress of the International Council of the Aeronautical Sciences, Brisbane, Australia, 2012, pp. 1-11.

[74] Swartz, K., "Charging Forward: New eVTOL Concepts Advance," The Electric VTOL News, 2017, Available: http://evtol.news/2017/06/22/charging-forward-new-evtol-concepts-advance/.

[75] The Lilium Jet, 2017, Available: https://lilium.com/.

[76] Vahana, 2017, Available: https://vahana.aero/.

[77] Vegh, J. M., Alonso, J. J., Orra, T. H., and Ilario da Silva, C. R., "Flight Path and Wing Optimization of Lithium-Air Battery Powered Passenger Aircraft," 53rd AIAA Aerospace Sciences Meeting, Kissimmee, FL, 2015, pp. 1-13.

[78] Vegh, J. M., and Alonso, J. J., 'Design and Optimization of Short-Range Aluminum-Air Powered Aircraft," 54th AIAA Aerospace Sciences Meeting, San Diego, CA, 2016, pp. 1-15. 
[79] Vratny, P. C., A Battery Powered Transport Aircraft, AV Akademikverlag GmbH \& Co. KG, Saarbrucken, Germany, 2012.

[80] Yuneec-Flightstar e-Spyder, 2009, Available: https://web.archive.org/web/20091107050125/http:/www.flyespyder.com/.

[81] Zee, 2017, Available: http://www.zee.aero/.

[82] "Zee Z-P1 Spotted Again," The Electric VTOL News, 2017, Available: http://evtol.news/2017/05/02/zee-z-p1-spotted-again/.

[83] Uber Elevate, "Fast-Forwarding to the Future of On-Demand, Urban Air Transportation," 2017, Available: https://www.uber.com/info/elevate/.

[84] Uber Elevate, Fast-Forwarding to a Future of On-Demand Urban Air Transportation, 2016.

[85] Borer, N. K., Patterson, M. D., Viken, J. K., Moore, M. D., Clarke, S. C., Redifer, M. E., Christie, R. J., Stoll, A. M., Dubois, A., Bevirt, J., Gibson, A. R., Foster, T. J., and Osterkamp, P. G., 'Design and Performance of the NASA SCEPTOR Distributed Electric Propulsion Flight Demonstrator," 16th AIAA Aviation Technology, Integration, and Operations Conference, Washington, D.C., 2016, pp. 1-20.

[86] Papathakis, K. V., Burkhardt, P. A., Ehmann, D. W., and Sessions, A. M., "Safety Considerations for Electric, Hybrid-Electric, and Turbo-Electric Distributed Propulsion Aircraft Testbeds," 53rd AIAA/SAE/ASEE Joint Propulsion Conference, American Institute of Aeronautics and Astronautics, Atlanta, GA, 2017, pp. 1-12.

[87] Hornung, M., Isikveren, A. T., Cole, M., and Sizmann, A., "Ce-Liner - Case Study for eMobility in Air Transportation," 13th AIAA Aviation Technology, Integration, and Operations Conference, Los Angeles, CA, 2013, pp. 1-11.

[88] U.S. Department of Energy, "DOE Awards \$6 Million to First Crop of Battery500 Seedlings," 2017, Available: https://chargedevs.com/newswire/doe-awards-6-million-to-first-crop-of-battery500seedlings/.

[89] BMW, "BMW Group Technology Workshops E-Mobility," 2016, pp. 1-23.

[90] USABC, Advanced Battery Development, 2013.

[91] Chan, C. K., Peng, H., Liu, G., Mcllwrath, K., Zhang, X. F., Huggins, R. A., and Cui, Y., 'HighPerformance Lithium Battery Anodes Using Silicon Nanowires," Nature Nanotechnology, Vol. 3, No. 1, 2008, pp. 31-35.

[92] Anderman, M., Assessing the Future of Hybrid and Electric Vehicles: The xEV Industry Insider Report, 2013.

[93] Pillot, C., "The Rechargeable Battery Market and Main Trends 2014-2025," 2016, pp. 1-98. 
[94] Romare, M., and Dahllöf, L., The Life Cycle Energy Consumption and Greenhouse Gas Emissions from Lithium-Ion Batteries, 2017.

[95] Blomgren, G. E., "The Development and Future of Lithium Ion Batteries," Journal of The Electrochemical Society, Vol. 164, No. 1, 2017, pp. A5019-A5025.

[96] Idaho National Laboratory Advanced Vehicles, "Library - Alphabetical," https://avt.inl.gov/content/pubs-az [retrieved 31 January 2018].

[97] Kukkonen, S., "Current Trends in Battery Technology," 2014, pp. 1-26.

[98] Nitta, N., Wu, F., Lee, J. T., and Yushin, G., "Li-ion Battery Materials: Present and Future," Materials Today, Vol. 18, No. 5, 2015, pp. 252-264.

[99] Ji-hye, S., "Solid-State Battery for Samsung Galaxy Likely in Years," The Korea Herald, 2017, Available: http://www.koreaherald.com/view.php?ud=20170630000615.

[100] Materials Research Laboratory, "Jennifer Rupp Wins International Electrochemistry Prize," MIT News, 2017, Available: http://news.mit.edu/2017/mit-jennifer-rupp-wins-internationalelectrochemistry-prize-1222.

[101] Reisch, M., "Solid-State Batteries Inch Their Way Toward Commercialization," Chemical \& Engineering News, Vol. 95, No. 46, 2017, pp. 19-21, Available: https://cen.acs.org/articles/95/i46/Solid-state-batteries-inch-way.html.

[102] Fetcenko, M., "BASF - ANL Collaboration on NCM Cathode Materials BASF," 2014, pp. 1-13.

[103] Schipper, F., Erickson, E. M., Erk, C., Shin, J.-Y., Chesneau, F. F., and Aurbach, D., "ReviewRecent Advances and Remaining Challenges for Lithium Ion Battery Cathodes," Journal of The Electrochemical Society, Vol. 164, No. 1, 2017, pp. A6220-A6228.

[104] Jayaprakash, N., Shen, J., Moganty, S. S., Corona, A., and Archer, L. A., "Porous Hollow Carbon@Sulfur Composites for High-Power Lithium-Sulfur Batteries," Angewandte Chemie International Edition, Vol. 50, No. 26, 2011, pp. 5904-5908.

[105] Yin, Y.-X., Xin, S., Guo, Y.-G., and Wan, L.-J., "Lithium-Sulfur Batteries: Electrochemistry, Materials, and Prospects," Angewandte Chemie International Edition, Vol. 52, No. 50, 2013, pp. 13186-13200.

[106] Balaish, M., Kraytsberg, A., and Ein-Eli, Y., "A Critical Review on Lithium-Air Battery Electrolytes," Physical Chemistry Chemical Physics, Vol. 16, No. 7, 2014, p. 2801.

[107] Grande, L., Paillard, E., Hassoun, J., Park, J.-B., Lee, Y.-J., Sun, Y.-K., Passerini, S., and Scrosati, B., "The Lithium/Air Battery: Still an Emerging System or a Practical Reality?," Advanced Materials, Vol. 27, No. 5, 2015, pp. 784-800.

[108] Kuhn, H., and Sizmann, A., "Fundamental Prerequisites for Electric Flying," Deutscher Luft- und Raumfahrtkongress 2012, Berlin, Germany, 2012, pp. 1-8. 
[109] SolidEnergy, Hermes ${ }^{T M}$ High Energy Rechargeable Metal Cells for Space, 2017.

[110] Bruce, P. G., Freunberger, S. A., Hardwick, L. J., and Tarascon, J.-M., 'Li- $\mathrm{O}_{2}$ and Li-S Batteries with High Energy Storage," Nature Materials, Vol. 11, No. 2, 2011, pp. 19-29.

[111] Yang, C.-P., Yin, Y.-X., and Guo, Y.-G., "Elemental Selenium for Electrochemical Energy Storage," Journal of Physical Chemistry Letters, Vol. 6, No. 2, 2015, pp. 256-266.

[112] Christensen, J., Albertus, P., Sanchez-Carrera, R. S., Lohmann, T., Kozinsky, B., Liedtke, R., Ahmed, J., and Kojic, A., "A Critical Review of Li/Air Batteries," Journal of The Electrochemical Society, Vol. 159, No. 2, 2012, pp. R1-R30.

[113] Dever, T. P., Duffy, K. P., Provenza, A. J., Loyselle, P. L., Choi, B. B., Morrison, C. R., and Lowe, A. M., Assessment of Technologies for Noncryogenic Hybrid Electric Propulsion, Cleveland, OH, 2015.

[114] Kushnir, D., 'Lithium Ion Battery Recycling Technology 2015: Current State and Future Prospects. ESA REPORT \# 2015:18," 2015, pp. 1-56.

[115] Woodford, W. H., Ransil, R. A., and Chiang, Y.-M., Advanced Batteries: “Beyond Li-ion,” 2012.

[116] Xu, J., Design Perspectives on Delivery Drones, Santa Monica, CA, 2017.

[117] Pornet, C., Gologan, C., Vratny, P. C., Seitz, A., Schmitz, O., Isikveren, A. T., and Hornung, M., "Methodology for Sizing and Performance Assessment of Hybrid Energy Aircraft," Journal of Aircraft, Vol. 52, No. 1, 2015, pp. 1-12.

[118] Stückl, S., "Methods for the Design and Evaluation of Future Aircraft Concepts Utilizing Electric Propulsion Systems," Technische Universität München, Bauhaus Luftfahrt, 2015.

[119] Panasonic, Panasonic Lithium Ion NCR18650B, 2012.

[120] OXlS Energy Limited, Ultra Light Lithium Sulfur Pouch Cell, 2017.

[121] Drela, M., TASOPT 2.16 Transport Aircraft System OPTimization Technical Description, Cambridge, MA, 2016.

[122] Drela, M., "Design Drivers of Energy-Efficient Transport Aircraft," SAE International Journal of Aerospace, Vol. 4, No. 2, 2011, pp. 602-608.

[123] Drela, M., Simultaneous Optimization of the Airframe, Powerplant, and Operation of Transport Aircraft, London, UK, 2010.

[124] Greitzer, E. M., Bonnefoy, P. A., de la Rosa Blanco, E., Dorbian, C. S., Drela, M., Hall, D. K., Hansman, R. J., Hileman, J. I., Liebeck, R. H., Lovegren, J., Mody, P., Pertuze, J. A., Sato, S., Spakovszky, Z. S., Tan, C. S., Hollman, J. S., Duda, J. E., Fitzgerald, N., Houghton, J., Kerrebrock, J. L., Kiwada, G. F., Kordonowy, D., Parrish, J. C., Tylko, J., Wen, E. A., and Lord, W. K., N+3 Aircraft Concept Designs and Trade Studies, Volume 2: Appendices - Design Methodologies for Aerodynamics, Structures, Weight, and Thermodynamic Cycles, Cambridge, MA, 2010. 
[125] Dyson, R. W., NASA Electric Aircraft Test Bed (NEAT) Development Plan - Design, Fabrication, Installation, Cleveland, OH, 2016.

[126] Berg, F., Palmer, J., Miller, P., Husband, M., and Dodds, G., 'HTS Electrical System for a Distributed Propulsion Aircraft," IEEE Transactions on Applied Superconductivity, Vol. 25, No. 3, 2015, pp. 1-5.

[127] Isikveren, A. T., Seitz, A., Vratny, P. C., Pornet, C., Plötner, K. O., and Hornung, M., "Conceptual Studies of Universally-Electric Systems Architectures Suitable for Transport Aircraft," Deutscher Luft- und Raumfahrtkongress 2012, Berlin, Germany, 2012, pp. 1-16.

[128] Jones, C. E., Norman, P. J., Galloway, S. J., Burt, G. M., Armstrong, M. J., and Bollman, A. M., "A Pre-Design Sensitivity Analysis Tool for Consideration of Full- Electric Aircraft Propulsion Electrical Power System Architectures," 2015 International Conference on Electrical Systems for Aircraft, Railway, Ship Propulsion and Road Vehicle, Aachen, Germany, 2015, pp. 1-6.

[129] Pornet, C., "Electric Drives for Propulsion System of Transport Aircraft," New Applications of Electric Drives, edited by Chomat, M., 2015, pp. 115-142.

[130] Cao, W., Mecrow, B. C., Atkinson, G. J., Bennett, J. W., and Atkinson, D. J., "Overview of Electric Motor Technologies Used for More Electric Aircraft (MEA)," IEEE Transactions on Industrial Electronics, Vol. 59, No. 9, 2012, pp. 3523-3531.

[131] Datta, A., and Johnson, W., "Requirements for a Hydrogen Powered All-Electric Manned Helicopter," 12th AIAA Aviation Technology, Integration, and Operations Conference, Indianapolis, IN, 2012, pp. 1-28.

[132] Larminie, J., and Lowry, J., Electric Vehicle Technology Explained, John Wiley \& Sons, Ltd, Chichester, UK, 2003.

[133] Schiferl, R., Flory, A., Livoti, W. C., and Umans, S. D., "High-Temperature Superconducting Synchronous Motors: Economic Issues for Industrial Applications," IEEE Transactions on Industry Applications, Vol. 44, No. 5, 2008, pp. 1376-1384.

[134] Sinsay, J. D., Tracey, B., Alonso, J. J., Kontinos, D. A., Melton, J. E., and Grabbe, S., "Air Vehicle Design and Technology Considerations for an Electric VTOL Metro-Regional Public Transportation System," 12th AIAA Aviation Technology, Integration, and Operations Conference, Indianapolis, IN, 2012, pp. 1-16.

[135] Snyder, C. A., Berton, J. J., Brown, G. V., Dolce, J. L., Dravid, N. V., Eichenberg, D. J., Freeh, J. E., Gallo, C. A., Jones, S. M., Kundu, K. P., Marek, C. J., Millis, M. G., Murthy, P. L., Roach, T. M., Smith, T. D., Stefko, G. L., Sullivan, R. M., Tornabene, R. T., Geiselhart, K. A., and Kascak, A. F., Propulsion Investigation for Zero and Near-Zero Emissions Aircraft, Cleveland, OH, 2009.

[136] Petermaier, K., "Electric Propulsion Components with High Power Densities for Aviation," 2015, pp. 1-16.

[137] Clarke, S. C., "Aircraft Electric Propulsion Systems: Applied Research at NASA," 2015, pp. 1-37. 
[138] Xia, X., 'Dynamic Power Distribution Management for All Electric Aircraft," Cranfield, 2011.

[139] Shehab, E., and Palmer, J., "Modelling of Cryogenic Cooling System Design Concepts for Superconducting Aircraft Propulsion," IET Electrical Systems in Transportation, Vol. 6, No. 3, 2016, pp. 170-178.

[140] Armstrong, M. J., "Identification of Emergent Off-Nominal Operational Requirements During Conceptual Architecting of the More Electric Aircraft," Georgia Tech, 2011.

[141] McLoughlin, A., "More Electric - Ready for Take Off?," 13th European Conference on Power Electronics and Applications, Barcelona, Spain, 2009, pp. 1-7.

[142] Fite, E. B., Fan Performance From Duct Rake Instrumentation on a 1.294 Pressure Ratio, 725 $\mathrm{ft} / \mathrm{sec}$ Tip Speed Turbofan Simulator Using Vaned Passage Casing Treatment, 2006.

[143] Beltramo, M. N., Trapp, D. L., Kimoto, B. W., and Marsh, D. P., Parametric Study of Transport Aircraft Systems, Cost and Weight, 1977.

[144] Camilleri, W., "An Assessment of High Overall Pressure Ratio Intercooled Engines for Civil Aviation," Cranfield, 2014.

[145] Calkins, F. T., and Mabe, J. H., "Shape Memory Alloy Based Morphing Aerostructures," Journal of Mechanical Design, Vol. 132, No. 11, 2010, p. 111012.

[146] Mabe, J., "Variable Area Jet Nozzle for Noise Reduction Using Shape Memory Alloy Actuators," The Journal of the Acoustical Society of America, Vol. 123, No. 5, 2008, pp. 5487-5492.

[147] Giakoumakis, E., "Techno-Economic and Environmental Risk Assessment of a Turbo-Electric Distributed Propulsion System on a Blended Wing Body Aircraft," Cranfield, 2014.

[148] Sagerser, D. A., Lieblein, S., and Krebs, R. P., Empirical Expressions for Estimating Length and Weight of Axial-Flow Components of VTOL Powerplants, 1971.

[149] Bowman, C., Jansen, R., Brown, G. V., Duffy, K. P., and Trudell, J., "Key Performance Parameter Driven Technology Goals for Electric Machines and Power Systems," 2015, pp. 1-34.

[150] Schiltgen, B. T., Gibson, A. R., Green, M. W., and Freeman, J., 'More Electric Aircraft: 'Tube and Wing' Hybrid Electric Distributed Propulsion with Superconducting and Conventional Electric Machines," SAE 2013 AeroTech Congress \& Exhibition, Montréal, Canada, 2013, pp. 1-13.

[151] Vratny, P. C., Forsbach, P., Seitz, A., and Hornung, M., 'Investigation of Universally Electric Propulsion Systems for Transport Aircraft," 29th Congress of the International Council of the Aeronautical Sciences, St. Petersburg, Russia, 2014, pp. 1-13.

[152] Brown, G. V., Kascak, A. F., Ebihara, B., Johnson, D., Choi, B. B., Siebert, M., and Buccieri, C., NASA Glenn Research Center Program in High Power Density Motors for Aeropropulsion, 2005.

[153] Miyairi, Y., Perullo, C. A., and Mavris, D. N., "A Parametric Environment for Weight and Sizing Prediction of Motor/Generator for Hybrid Electric Propulsion," 51st AIAA/SAE/ASEE Joint Propulsion Conference, Orlando, FL, 2015, pp. 1-19. 
[154] Antcliff, K. R., Guynn, M. D., Marien, T., Wells, D. P., Schneider, S. J., and Tong, M. T., 'Mission Analysis and Aircraft Sizing of a Hybrid-Electric Regional Aircraft," 54th AIAA Aerospace Sciences Meeting, San Diego, CA, 2016, pp. 1-18.

[155] Olson, M. D., "A Conceptual Approach to Flight-Training Mission and Cost Analysis of an AllElectric Aircraft Equipped with Regenerative Energy Devices," 15th AIAA Aviation Technology, Integration, and Operations Conference, Dallas, TX, 2015, pp. 1-31.

[156] Patterson, M. D., German, B. J., and Moore, M. D., "Performance Analysis and Design of OnDemand Electric Aircraft Concepts," 12th AIAA Aviation Technology, Integration, and Operations Conference, Indianapolis, IN, 2012, pp. 1-28.

[157] Chen, M., and Rincón-Mora, G. A., "Accurate Electrical Battery Model Capable of Predicting Runtime and I-V Performance," IEEE Transactions on Energy Conversion, Vol. 21, No. 2, 2006, pp. 504-511.

[158] Propp, K., Marinescu, M., Auger, D. J., O'Neill, L., Fotouhi, A., Somasundaram, K., Offer, G. J., Minton, G., Longo, S., Wild, M., and Knap, V., "Multi-Temperature State-Dependent Equivalent Circuit Discharge Model for Lithium-Sulfur Batteries," Journal of Power Sources, Vol. 328, No. 1, 2016, pp. 289-299.

[159] Tremblay, O., "Experimental Validation of a Battery Dynamic Model for EV Applications," 24th International Battery, Hybrid and Fuel Cell Electric Vehicle Symposium and Exhibition 2009, EVS 24, 2009, pp. 930-939.

[160] Zhang, T., Marinescu, M., O'Neill, L., Wild, M., and Offer, G., 'Modeling the Voltage Loss Mechanisms in Lithium-Sulfur Cells: The Importance of Electrolyte Resistance and Precipitation Kinetics," Physical Chemistry Chemical Physics, Vol. 17, No. 35, 2015, pp. 22581-22586.

[161] Doerffel, D., and Sharkh, S. A., "A Critical Review of Using the Peukert Equation for Determining the Remaining Capacity of Lead-Acid and Lithium-Ion Batteries," Journal of Power Sources, Vol. 155, No. 2, 2006, pp. 395-400.

[162] USABC, Appendix I Derivation of USABC Battery Peak Power Calculations, 2017.

[163] Bradley, M. K., Allen, T. J., and Droney, C. K., Subsonic Ultra Green Aircraft Research: Phase II - Volume I - Truss Braced Wing Design Exploration, Huntington Beach, CA, 2014.

[164] Vratny, P. C., Gologan, C., Pornet, C., Isikveren, A. T., and Hornung, M., "Battery Pack Modeling Methods for Universally-Electric Aircraft," 4th CEAS Air \& Space Conference, Linköping, Sweden, 2013, pp. 525-535.

[165] Bruner, S., "N+3 Phase I Final Review," 2010, pp. 1-172.

[166] Chakraborty, I., Mavris, D. N., Emeneth, M., and Schneegans, A., "An Integrated Approach to Vehicle and Subsystem Sizing and Analysis for Novel Subsystem Architectures," Proceedings of the Institution of Mechanical Engineers, Part G: Journal of Aerospace Engineering, Vol. 0, No. 0, 2015, pp. $1-19$. 
[167] Lukaczyk, T., Wendorff, A. D., Botero, E., MacDonald, T., Momose, T., Variyar, A., Vegh, J. M., Colonno, M. R., Economon, T. D., Alonso, J. J., Orra, T. H., and Ilario da Silva, C. R., "SUAVE: An Open-Source Environment for Multi-Fidelity Conceptual Vehicle Design," 16th AIAA/ISSMO Multidisciplinary Analysis and Optimization Conference, Dallas, TX, 2015, pp. 1-56.

[168] Isikveren, A. T., "Quasi-Analytical Modelling and Optimisation Techniques for Transport Aircraft Design," KTH, Bauhaus Luftfahrt, 2002.

[169] Liebeck, R. H., Page, M. A., Rawdon, B. K., Scott, P. W., and Wright, R. A., Concepts for Advanced Subsonic Transports, NASA CR 4624, 1994.

[170] Linnell, R., Weight Estimation Methods, FKHV-1-RL790724:01, 1979.

[171] Torenbeek, E., Advanced Aircraft Design: Conceptual Design, Analysis and Optimization of Subsonic Civil Airplanes, John Wiley \& Sons, 2013.

[172] Torenbeek, E., Synthesis of Subsonic Airplane Design, Delft University Press, 1982.

[173] Raymer, D. P., Aircraft Design: A Conceptual Approach, 4th ed., AIAA Education Series, Reston, Virginia, 2006.

[174] Seitz, A., "Advanced Methods for Propulsion System Integration in Aircraft Conceptual Design," Universität München, 2012.

[175] Daggett, D. L., Brown, S. T., and Kawai, R. T., Ultra-Efficient Engine Diameter Study, 2003.

[176] Guynn, M. D., Berton, J. J., Fisher, K. L., Haller, W. J., Tong, M. T., and Thurman, D. R., Engine Concept Study for an Advanced Single-Aisle Transport, 2009.

[177] Airbus, A320 Aircraft Characteristics Airport and Maintenance Planning, 2017.

[178] Drela, M., "Development of the D8 Transport Configuration," 29th AIAA Applied Aerodynamics Conference, Honolulu, HI, 2011, pp. 1-14.

[179] Boeing, Boeing Commercial Aircraft - Design Groups/Codes (FAA \& ICAO), 2014.

[180] Brown, G. V., 'Weights and Efficiencies of Electric Components of a Turboelectric Aircraft Propulsion System," 49th AIAA Aerospace Sciences Meeting, Orlando, FL, 2011, pp. 1-18.

[181] Pagonis, M., "Electrical Power Aspects of Distributed Propulsion Systems in Turbo-Electric Powered Aircraft," Cranfield, 2015.

[182] Felder, J. L., Brown, G. V., and Dae Kim, H., "Turboelectric Distributed Propulsion in a Hybrid Wing Body Aircraft," ISABE 2011, Gothenburg, Sweden, 2015, pp. 1-20.

[183] Isikveren, A. T., Pornet, C., Vratny, P. C., and Schmidt, M., "Optimization of Commercial Aircraft Using Battery-Based Voltaic-Joule/Brayton Propulsion," Journal of Aircraft, 2016, pp. 1-16. 
[184] Xi, H. X., Gong, W. Z., Zhang, Y., Bi, Y. F., Ding, H. K., Wen, H., Hou, B., and Xin, Y., "China's $33.5 \mathrm{~m}, 35 \mathrm{kV} / 2 \mathrm{kA}$ HTS AC Power Cable's Operation in Power Grid," Physica C: Superconductivity, Vol. 445-448, No. 1, 2006, pp. 1054-1057.

[185] Bombardier, C Series, 2015, Available: http://commercialaircraft.bombardier.com/content/dam/ Websites/bca/literature/cseries/Bombardier-Commercial-Aircraft-CSeries-Brochure-en.pdf.pdf.

[186] Fehrm, B., 'United Aircraft's and COMAC's Eventful Year," Leeham News and Comment, 2018, Available: https://leehamnews.com/2018/01/03/united-aircraft-comac-goes-flying/\#more-25897.

[187] Kirner, R., Raffaelli, L., Rolt, A., Laskaridis, P., Doulgeris, G., and Singh, R., "An Assessment of Distributed Propulsion: Advanced Propulsion System Architectures for Conventional Aircraft Configuration," Aerospace Science and Technology, Vol. 50, No. 1, 2016, pp. 212-219.

[188] Kling, U., Empl, D., Boegler, O., and Isikveren, A. T., "Future Aircraft Wing Structures Using Renewable Materials," Deutscher Luft- und Raumfahrtkongress 2015, 2015, pp. 1-8.

[189] Abbas, A., de Vicente, J., and Valero, E., "Aerodynamic Technologies to Improve Aircraft Performance," Aerospace Science and Technology, Vol. 28, No. 1, 2013, pp. 100-132.

[190] Duvelleroy, M. and Fendt, M., "Airbus" "BLADE" Laminar Flow Wing Demonstrator Makes First Flight," 2017, Available: http://www.airbus.com/newsroom/press-releases/en/2017/09/airbus__blade_-laminar-flow-wing-demonstrator-makes-first-fligh.html.

[191] Hall, D. K., "Analysis of Civil Aircraft Propulsors with Boundary Layer Ingestion," MIT, 2015.

[192] Stratton, R. W., Min Wong, H., and Hileman, J. I., Life Cycle Greenhouse Gas Emissions from Alternative Jet Fuels, Cambridge, MA, 2010.

[193] Lu, J., Jung Lee, Y., Luo, X., Chun Lau, K., Asadi, M., Wang, H.-H., Brombosz, S., Wen, J., Zhai, D., Chen, Z., Miller, D. J., Sub Jeong, Y., Park, J.-B., Zak Fang, Z., Kumar, B., Salehi-Khojin, A., Sun, Y.-K., Curtiss, L. A., and Amine, K., "A Lithium-Oxygen Battery Based on Lithium Superoxide," Nature, Vol. 529, No. 7586, 2016, pp. 377-382.

[194] OAG, 2015, https://www.oag.com/.

[195] Bradley, M. K., and Droney, C. K., Subsonic Ultra Green Aircraft Research: Phase I Final Report, Huntington Beach, CA, 2011.

[196] Hileman, J. I., Donohoo, P. E., and Stratton, R. W., "Energy Content and Alternative Jet Fuel Viability," Journal of Propulsion and Power, Vol. 26, No. 6, 2010, pp. 1184-1196.

[197] Rosen, C. V., '2017_Scenario Based Lifecycle Analysis of Greenhouse Gas Emissions from Petroleum-Derived Transportation Fuels in 2050," MIT, 2017.

[198] Grobler, C., Allroggen, F., and Barrett, S. R. H., Derived Climate Metrics Prepared as Part of ASCENT Project 21, 2017.

[199] U.S. Energy Information Administration, November 2017 Monthly Energy Review, 2017. 
[200] . Capasso, C., and Veneri, O., "Experimental Analysis on the Performance of Lithium Based Batteries for Road Full Electric and Hybrid Vehicles," Applied Energy, Vol. 136, No. 1, 2014, pp. 921-930.

[201] USABC, Appendix F Glossary of Battery and Battery Testing Terminology for the USABC Battery Test Procedures, 2017.

[202] Gohardani, A. S., Millecam, N., and Dunn, R., "Green Aerospace Engineering: A Focus on the Technical and Economical Hurdles of Next Generation Lithium-Ion Batteries," 54th AIAA Aerospace Sciences Meeting, San Diego, CA, 2016, pp. 1-19.

[203] Manthiram, A., Chung, S.-H., and Zu, C., 'Lithium-Sulfur Batteries: Progress and Prospects," Advanced Materials, Vol. 27, No. 12, 2015, pp. 1980-2006.

[204] U.S. Energy Information Administration, Annual Energy Outlook 2017 with Projections to 2050, 2017.

[205] Mai, T., Wiser, R., Sandor, D., Brinkman, G., Heath, G., Denholm, P., Hostick, D. J., Darghouth, N., Schlosser, A., and Strzepek, K., Exploration of High-Penetration Renewable Electricity Futures. Vol. 1 of Renewable Electricity Futures Study, Golden, CO, 2012.

[206] Dolan, S. L., and Heath, G. A., "Life Cycle Greenhouse Gas Emissions of Utility-Scale Wind Power," Journal of Industrial Ecology, Vol. 16, No. S1, 2012, pp. S136-S154.

[207] Burkhardt, J. J., Heath, G., and Cohen, E., 'Life Cycle Greenhouse Gas Emissions of Trough and Tower Concentrating Solar Power Electricity Generation," Journal of Industrial Ecology, Vol. 16, No. S1, 2012, pp. S93-S109.

[208] Hsu, D. D., O'Donoughue, P., Fthenakis, V., Heath, G. A., Kim, H. C., Sawyer, P., Choi, J.-K., and Turney, D. E., 'Life Cycle Greenhouse Gas Emissions of Crystalline Silicon Photovoltaic Electricity Generation," Journal of Industrial Ecology, Vol. 16, No. S1, 2012, pp. S122-S135.

[209] Eberle, A., Heath, G. A., Nicholson, S., and Carpenter, A., Systematic Review of Life Cycle Greenhouse Gas Emissions from Geothermal Electricity, Golden, CO, 2017.

[210] O'Connor, D., Literature Review and Sensitivity Analysis of Biopower Life-Cycle Assessments and Greenhouse Gas Emission, Palo Alto, CA, 2013.

[211] Kumar, A., Schei, T., Ahenkorah, A., Caceres Rodriguez, R., Devernay, J.-M., Freitas, M., Hall, D., Killingtveit, A., and Liu, Z., Hydropower. In IPCC Special Report on Renewable Energy Sources and Climate Change Mitigation [O. Edenhofer, R. Pichs-Madruga, Y. Sokona, K. Seyboth, P. Matschoss, S. Kadner, T. Zwickel, P. Eickemeier, G. Hansen, S. Schlömer, C. von Stechow (eds)], Cambridge University Press, Cambridge, United Kingdom and New York, NY, USA, 2011.

[212] Warner, E. S., and Heath, G. A., 'Life Cycle Greenhouse Gas Emissions of Nuclear Electricity Generation," Journal of Industrial Ecology, Vol. 16, No. S1, 2012, pp. S73-S92. 
[213] Moomaw, W., Burgherr, P., Heath, G., Lenzen, M., Nyboer, J., and Verbruggen, A., Annex II: Methodology. In IPCC Special Report on Renewable Energy Sources and Climate Change Mitigation [O. Edenhofer, R. Pichs-Madruga, Y. Sokona, K. Seyboth, P. Matschoss, S. Kadner, T. Zwickel, P. Eickemeier, G. Hansen, S. Schlömer, C. von Stechow (eds)], Cambridge University Press, Cambridge, Cambridge, United Kingdom and New York, NY, USA, 2011.

[214] O'Donoughue, P. R., Heath, G. A., Dolan, S. L., and Vorum, M., "Life Cycle Greenhouse Gas Emissions of Electricity Generated from Conventionally Produced Natural Gas," Journal of Industrial Ecology, Vol. 18, No. 1, 2014, pp. 125-144.

[215] Heath, G. A., O'Donoughue, P., Arent, D. J., and Bazilian, M., "Harmonization of Initial Estimates of Shale Gas Life Cycle Greenhouse Gas Emissions for Electric Power Generation," Proceedings of the National Academy of Sciences, Vol. 111, No. 31, 2014, pp. E3167-E3176.

[216] Whitaker, M., Heath, G. A., O'Donoughue, P., and Vorum, M., "Life Cycle Greenhouse Gas Emissions of Coal-Fired Electricity Generation," Journal of Industrial Ecology, Vol. 16, No. S1, 2012, pp. S53-S72.

[217] Brown, G. V., Felder, J., Kim, H. D., Chu, J., Tong, M., Trudell, J., Dever, T. P., Choi, B., and Morrison, C., 'Efficient Flight-Weight Electric Systems," 2012, pp. 1-28.

[218] Misra, A., "Summary of 2017 NASA Workshop on Assessment of Advanced Battery Technologies for Aerospace Applications," 2018, pp. 1-18.

[219] Gogoana, R., "Internal Resistance Variances in Lithium-Ion Batteries and Implications in Manufacturing," MIT, 2012.

[220] Wiaux, J. P., and Chanson, C., "The Lithium-Ion Battery Service Life Parameters," 2013, pp. 113.

[221] Patterson, D., Monti, A., Brice, C., Dougal, R., Pettus, R., Srinivas, D., Dilipchandra, K., and Bertoncelli, T., 'Design and Simulation of an Electromagnetic Aircraft Launch System," Industry Applications Conference, 2002, Pittsburgh, PA, 2002, pp. 1950-1957.

[222] Shah, P. N., Pfeiffer, G., Davis, R., Hartley, T., and Spakovszky, Z. S., "Full-Scale Turbofan Demonstration of a Deployable Engine Air-Brake for Drag Management Applications," Journal of Engineering for Gas Turbines and Power, Vol. 139, No. 11, 2017, pp. 1-13. 